\title{
C-H Bond Functionalization of (Hetero)aryl Bromide Enabled Synthesis of Brominated Biaryl Compounds
}

\author{
Kai-Hui Liu, Guang-Qi Hu, Cai-Xia Wang, Fei-Fei Sheng, Jing-Wen Bai, Jian-Guo Gu, Hong-Hai Zhang* \\ Key Laborabory of Flexible Electronics (KLOFE) \& Institute of Advanced Materials (IAM), Jiangsu National Synergistic \\ Innovation Center for Advanced Materials (SICAM), Nanjing Tech University (Nanjing Tech), 30 Puzhu Road, Nanjing \\ 211816, P.R. China \\ iamhhzhang@njtech.edu.cn
}

\section{Supporting Information}

General: General: NMR spectra were recorded at $23{ }^{\circ} \mathrm{C}$ on a Varian VNMRS $400 \mathrm{MHz}$ NMR spectrometer in $\mathrm{CDCl}_{3}$ unless otherwise noted. Chemical shifts were determined relative to residual $\mathrm{CHCl}_{3}(7.26 \mathrm{ppm})$ for proton, and to the $\mathrm{CDCl}_{3}$ "triplet" at $77.23 \mathrm{ppm}$ for carbon. GCMS experiments were carried out using an Agilent GC/MS instrument consisting of a $6890 \mathrm{~N}$ series GC and a 5973 Mass Selective Detector System. All yields reported refer to isolated yields unless otherwise indicated. All the reagents and solvents were purchased from commercial sources and used as received. The HRMS data was obtained from ThermoFisher LCQTM Deca XP plus ion trap LC/MS. 


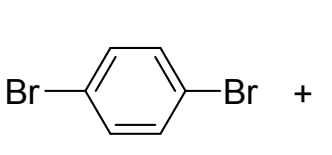

$1 \mathrm{a}$<smiles>Ic1ccccc1I</smiles>

2

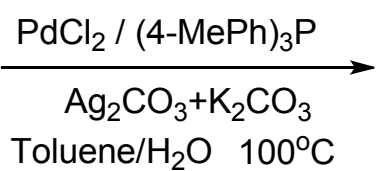

Toluene/ $\mathrm{H}_{2} \mathrm{O} \quad 100^{\circ} \mathrm{C}$

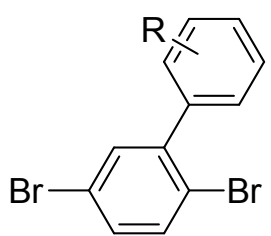

3

General Procedure for $\mathrm{PdCl}_{2}$ Catalyzed Coupling reaction with 1,4-dibromobenzene and substituted iodobenzene as example: 1,4-dibromobenzene (944 $\mathrm{mg}, 4 \mathrm{mmol})$ and compound 2 (1 mmol) were added to a vigorously stirred solution of silver carbonate $(540 \mathrm{mg}, 2 \mathrm{mmol}$ ), palladium chloride (17.7 mg, $0.1 \mathrm{mmol})$, tri ( $p$-tolyl)phosphine $(60 \mathrm{mg}, 0.2 \mathrm{mmol})$, potassium carbonate $(138 \mathrm{mg}, 1 \mathrm{mmol})$ in $\mathrm{H}_{2} \mathrm{O}(0.5 \mathrm{~mL})$ and toluene $(0.5 \mathrm{~mL})$ under $\mathrm{N}_{2}$. The reaction mixture was stirred at $100^{\circ} \mathrm{C}$ in oil bath for 12 hours. Then the reaction was quenched with saturated $\mathrm{NH}_{4} \mathrm{Cl}$ solution. The product was extracted with dichloromethane $(3 \times 20 \mathrm{~mL})$. The combined organic layer was washed with brine and dried over $\mathrm{Na}_{2} \mathrm{SO}_{4}$. After removal of solvents under vacuum, the crude product was purified via column chromatography.

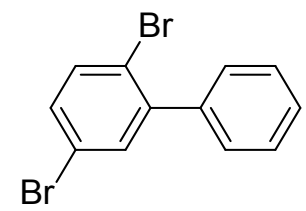

3a: Isolated yield: $237 \mathrm{mg}(77 \%)$, White solid. m.p. : $41-45^{\circ} \mathrm{C}$

Purified via column chromatography (petroleum ether 100\%).

${ }^{1} \mathrm{H}$ NMR $\left(400 \mathrm{MHz}, \mathrm{CDCl}_{3}\right): \delta 7.53(\mathrm{~d}, J=8.4 \mathrm{~Hz}, 1 \mathrm{H}), 7.48(\mathrm{~d}, J=2.4 \mathrm{~Hz}, 1 \mathrm{H}), 7.47-7.37(\mathrm{~m}, 5 \mathrm{H})$, $7.33(\mathrm{dd}, J=8.4,2.4 \mathrm{~Hz}, 1 \mathrm{H})$.

${ }^{13} \mathrm{C}$ NMR (100 MHz, $\left.\mathrm{CDCl}_{3}\right): 144.5,139.9,134.5,134.1,131.8,129.3,128.2,128.2,121.4,121.0$.

HRMS (EI) $m / z$ : calcd for $\mathrm{C}_{12} \mathrm{H}_{8} \mathrm{Br}_{2}^{+}\left([\mathrm{M}]^{+}\right)$309.8993; Found 309.8992.

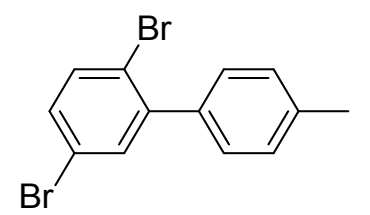

3b: Isolated yield: $233 \mathrm{mg}(72 \%)$, White solid. m.p. : $68-70^{\circ} \mathrm{C}$

Purified via column chromatography (petroleum ether $100 \%$ ).

${ }^{1} \mathrm{H}$ NMR $\left(400 \mathrm{MHz}, \mathrm{CDCl}_{3}\right): \delta 7.51(\mathrm{~d}, J=8.4 \mathrm{~Hz}, 1 \mathrm{H}), 7.46(\mathrm{~d}, J=2.4 \mathrm{~Hz}, 1 \mathrm{H}), 7.37-7.31(\mathrm{~m}, 1 \mathrm{H})$, $7.30(\mathrm{~d}, J=2.4 \mathrm{~Hz}, 1 \mathrm{H}), 7.27(\mathrm{~s}, 1 \mathrm{H}), 7.25-7.23(\mathrm{~m}, 2 \mathrm{H}), 2.42(\mathrm{~s}, 3 \mathrm{H})$.

${ }^{13} \mathrm{C}$ NMR $\left(100 \mathrm{MHz}, \mathrm{CDCl}_{3}\right): \delta 144.4,138.0,137.0,134.5,134.1,133.2,131.5,129.1,128.9,121.5$, 121.2, 21.4.

HRMS (EI) $m / z$ : calcd for $\mathrm{C}_{13} \mathrm{H}_{10} \mathrm{Br}_{2}{ }^{+}\left([\mathrm{M}]^{+}\right)$323.9149; Found 323.9147. 


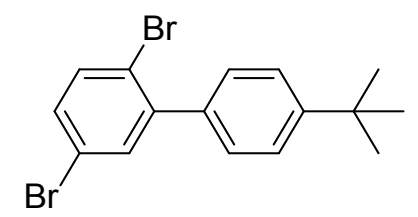

3c: Isolated yield: $295 \mathrm{mg}$ (84\%), White solid. m.p. : 100-102 ${ }^{\circ} \mathrm{C}$

Purified via column chromatography (petroleum ether $100 \%$ ).

${ }^{1} \mathrm{H}$ NMR $\left(400 \mathrm{MHz}, \mathrm{CDCl}_{3}\right): \delta 7.52(\mathrm{~d}, J=8.4 \mathrm{~Hz}, 1 \mathrm{H}), 7.48(\mathrm{~d}, J=2.4 \mathrm{~Hz}, 1 \mathrm{H}), 7.45(\mathrm{~d}, J=8.4 \mathrm{~Hz}, 2$ $\mathrm{H}), 7.37-7.29(\mathrm{~m}, 3 \mathrm{H}), 1.37(\mathrm{~s}, 9 \mathrm{H})$.

${ }^{13} \mathrm{C}$ NMR $\left(100 \mathrm{MHz}, \mathrm{CDCl}_{3}\right): \delta 151.1,144.4,136.9,134.5,134.2,133.2,131.4,128.9,125.1,121.4$, 121.2, 34.7, 31.4 .

HRMS (EI) $m / z$ : calcd for $\mathrm{C}_{16} \mathrm{H}_{16} \mathrm{Br}_{2}^{+}\left([\mathrm{M}]^{+}\right)$365.9619; Found 365.9618.

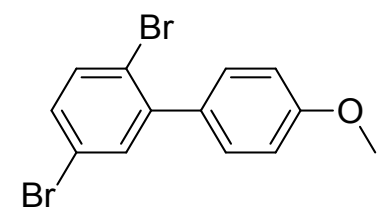

3d: Isolated yield: $237 \mathrm{mg}(70 \%)$, White solid. m.p. : 87-890

Purified via column chromatography (petroleum ether/dichloromethane $=8: 1$ ).

${ }^{1} \mathrm{H}$ NMR $\left(400 \mathrm{MHz}, \mathrm{CDCl}_{3}\right): \delta 7.51(\mathrm{~d}, J=8.4 \mathrm{~Hz}, 1 \mathrm{H}), 7.46(\mathrm{~d}, J=2.4 \mathrm{~Hz}, 1 \mathrm{H}), 7.34-7.28(\mathrm{~m}, 3 \mathrm{H})$, $6.97-6.95(\mathrm{~m}, 2 \mathrm{H}), 3.86(\mathrm{~s}, 3 \mathrm{H})$.

${ }^{13} \mathrm{C}$ NMR (100 MHz, $\left.\mathrm{CDCl}_{3}\right): \delta 159.5,144.1,134.5,134.1,132.3,131.4,130.5,121.6,121.2,113.6,55.4$.

HRMS (EI) $m / z$ : calcd for $\mathrm{C}_{13} \mathrm{H}_{10} \mathrm{Br}_{2} \mathrm{O}^{+}\left([\mathrm{M}]^{+}\right) 339.9098$; Found 339.9102.<smiles>Clc1ccc(-c2cc(Br)ccc2Br)cc1</smiles>

3e: Isolated yield: $137 \mathrm{mg}(46 \%)$, White solid. m.p. : $84-86^{\circ} \mathrm{C}$

Purified via column chromatography (petroleum ether 100\%).

${ }^{1} \mathrm{H}$ NMR $\left(400 \mathrm{MHz}, \mathrm{CDCl}_{3}\right): \delta 7.52(\mathrm{~d}, J=8.4 \mathrm{~Hz}, 1 \mathrm{H}), 7.44(\mathrm{~d}, J=2.4 \mathrm{~Hz}, 1 \mathrm{H}), 7.42-7.40(\mathrm{~m}, 2 \mathrm{H})$, $7.35-7.31(\mathrm{~m}, 3 \mathrm{H})$.

${ }^{13} \mathrm{C}$ NMR (100 MHz, $\left.\mathrm{CDCl}_{3}\right): \delta 143.2,138.2,134.6,133.9,132.1,130.6,129.1,128.5,128.3,121.3$.

HRMS (EI) $m / z$ : calcd for $\mathrm{C}_{12} \mathrm{H}_{7} \mathrm{Br}_{2} \mathrm{Cl}^{+}\left([\mathrm{M}]^{+}\right)$343.8603; Found 343.8618 .

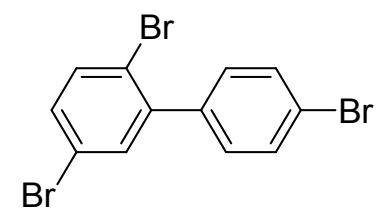

3f: Isolated yield: $193 \mathrm{mg}(50 \%)$, White solid. m.p. : 87-89 $\mathrm{C}$

Purified via column chromatography (petroleum ether 100\%).

${ }^{1} \mathrm{H}$ NMR (400 MHz, DMSO- $\left.d_{6}\right): \delta 7.70-7.64(\mathrm{~m}, 3 \mathrm{H}), 7.57-7.51(\mathrm{~m}, 2 \mathrm{H}), 7.35(\mathrm{~d}, J=8.4 \mathrm{~Hz}, 2 \mathrm{H})$. 
${ }^{13} \mathrm{C}$ NMR (100 MHz, DMSO- $\left.d_{6}\right): \delta 143.2,138.8,135.4,133.9,132.9,131.8,131.7,122.3,121.5,121.3$. HRMS (EI) $m / z$ : calcd for $\mathrm{C}_{12} \mathrm{H}_{7} \mathrm{Br}_{3}^{+}\left([\mathrm{M}]^{+}\right) 387.8098$; Found 387.8100 .<smiles>FC(F)(F)c1ccc(-c2cc(Br)ccc2Br)cc1</smiles>

3g: Isolated yield: $324 \mathrm{mg}(86 \%)$, White solid. m.p. : 70-72 ${ }^{\circ} \mathrm{C}$ Purified via column chromatography (petroleum ether $100 \%$ ).

${ }^{1} \mathrm{H}$ NMR $\left(400 \mathrm{MHz}, \mathrm{CDCl}_{3}\right): \delta 7.70(\mathrm{~d}, J=8.4 \mathrm{~Hz}, 1 \mathrm{H}), 7.56-7.46(\mathrm{~m}, 2 \mathrm{H}), 7.36(\mathrm{~s}, 4 \mathrm{H})$.

${ }^{19} \mathrm{~F} \mathrm{NMR}\left(376 \mathrm{MHz}, \mathrm{CDCl}_{3}\right): \delta-62.4(\mathrm{~s}, 3 \mathrm{~F})$.

${ }^{13} \mathrm{C} \mathrm{NMR}\left(100 \mathrm{MHz}, \mathrm{CDCl}_{3}\right): \delta 143.4,143.0,134.7,133.8,132.5,130.5\left(\mathrm{q}, J_{\mathrm{F}}=32.6 \mathrm{~Hz}\right), 129.8,125.3(\mathrm{q}$, $\left.J_{\mathrm{F}}=3.8 \mathrm{~Hz}\right), 124.1\left(\mathrm{q}, J_{\mathrm{F}}=270.7 \mathrm{~Hz}\right), 121.5,121.1$.

HRMS (EI) $m / z$ : calcd for $\mathrm{C}_{13} \mathrm{H}_{7} \mathrm{Br}_{2} \mathrm{~F}_{3}{ }^{+}\left([\mathrm{M}]^{+}\right) 377.8867$; Found 377.8876.

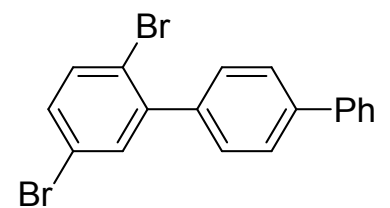

3h: Isolated yield: $328 \mathrm{mg}(93 \%)$, White solid. m.p. : 102-104 $\mathrm{C}$

Purified via column chromatography (petroleum ether $100 \%$ ).

${ }^{1} \mathrm{H}$ NMR (400 MHz, DMSO-d 6 ): $\delta 7.78-7.70(\mathrm{~m}, 5 \mathrm{H}), 7.63-7.61(\mathrm{~m}, 1 \mathrm{H}), 7.55-7.48$ (m, $\left.5 \mathrm{H}\right), 7.40$ $(\mathrm{t}, J=6.4 \mathrm{~Hz}, 1 \mathrm{H})$.

${ }^{13} \mathrm{C}$ NMR $\left(100 \mathrm{MHz}, \mathrm{CDCl}_{3}\right): \delta 144.1,141.0,140.5,138.7,134.6,134.1,131.8,129.7,128.9,127.6$, 127.2, 126.9, 121.4, 121.3.

HRMS (EI) $m / z$ : calcd for $\mathrm{C}_{18} \mathrm{H}_{12} \mathrm{Br}_{2}^{+}\left([\mathrm{M}]^{+}\right) 385.9306$; Found 385.9320.

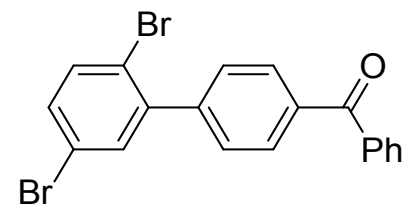

3i: Isolated yield: $268 \mathrm{mg}(65 \%)$, White solid. m.p. : $97-99^{\circ} \mathrm{C}$

Purified via column chromatography (petroleum ether/dichloromethane $=4: 1$ ).

${ }^{1} \mathrm{H} \mathrm{NMR}\left(400 \mathrm{MHz}, \mathrm{CDCl}_{3}\right): \delta 7.88(\mathrm{~d}, J=8.4 \mathrm{~Hz}, 2 \mathrm{H}), 7.87-7.84(\mathrm{~m}, 2 \mathrm{H}), 7.62(\mathrm{t}, J=6.0 \mathrm{~Hz}, 1 \mathrm{H})$, $7.56(\mathrm{~d}, J=8.4 \mathrm{~Hz}, 1 \mathrm{H}), 7.53-7.50(\mathrm{~m}, 5 \mathrm{H}), 7.38(\mathrm{dd}, J=8.4,2.4 \mathrm{~Hz}, 1 \mathrm{H})$.

${ }^{13} \mathrm{C}$ NMR $\left(100 \mathrm{MHz}, \mathrm{CDCl}_{3}\right): \delta 192.3,143.8,143.4,137.5,137.1,134.7,133.8,132.7,132.3,130.1$, 130.0, 129.5, 129.3, 128.4, 121.4, 121.1 .

HRMS (EI) $m / z$ : calcd for $\mathrm{C}_{19} \mathrm{H}_{12} \mathrm{Br}_{2} \mathrm{O}^{+}\left([\mathrm{M}]^{+}\right)$413.9255; Found 413.9268. 


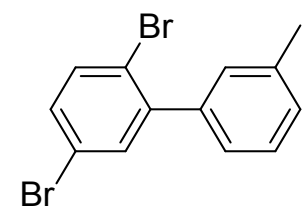

3j: Isolated yield: $313 \mathrm{mg}(97 \%)$, White solid. m.p. : $68-70^{\circ} \mathrm{C}$

Purified via column chromatography (petroleum ether $100 \%$ ).

${ }^{1} \mathrm{H}$ NMR $\left(400 \mathrm{MHz}, \mathrm{CDCl}_{3}\right): \delta 7.52(\mathrm{~d}, J=8.4 \mathrm{~Hz}, 1 \mathrm{H}), 7.47(\mathrm{~d}, J=2.4 \mathrm{~Hz}, 1 \mathrm{H}), 7.37-7.30(\mathrm{~m}, 2 \mathrm{H})$, $7.24-7.17(\mathrm{~m}, 3 \mathrm{H}), 2.42(\mathrm{~s}, 3 \mathrm{H})$.

${ }^{13} \mathrm{C}$ NMR $\left(100 \mathrm{MHz}, \mathrm{CDCl}_{3}\right): \delta 144.6,139.8,137.9,134.4,134.0,131.6,129.9,128.9,128.0,126.4$, 121.4, 121.2, 21.5.

HRMS (EI) $m / z$ : calcd for $\mathrm{C}_{13} \mathrm{H}_{10} \mathrm{Br}_{2}^{+}\left([\mathrm{M}]^{+}\right)$323.9149; Found 323.9154.

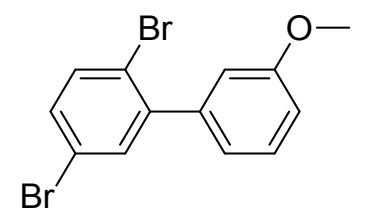

3k: Isolated yield: $265 \mathrm{mg}$ (78\%), White solid. m.p. : 87-890

Purified via column chromatography (petroleum ether/dichloromethane $=8: 1$ ).

${ }^{1} \mathrm{H}$ NMR $\left(400 \mathrm{MHz}, \mathrm{CDCl}_{3}\right): \delta 7.52(\mathrm{~d}, J=8.4 \mathrm{~Hz}, 1 \mathrm{H}), 7.48(\mathrm{~d}, J=2.4 \mathrm{~Hz}, 1 \mathrm{H}), 7.37-7.31(\mathrm{~m}, 2 \mathrm{H})$, $6.97-6.91(\mathrm{~m}, 3 \mathrm{H}), 3.85(\mathrm{~s}, 3 \mathrm{H})$.

${ }^{13} \mathrm{C}$ NMR $\left(100 \mathrm{MHz}, \mathrm{CDCl}_{3}\right): \delta 159.2,144.3,141.1,134.5,134.0,131.8,129.3,121.7,121.3,121.2$, $114.9,113.8,55.4$.

HRMS (EI) $m / z$ : calcd for $\mathrm{C}_{13} \mathrm{H}_{10} \mathrm{Br}_{2} \mathrm{O}^{+}\left([\mathrm{M}]^{+}\right)$339.9098; Found 339.9101.

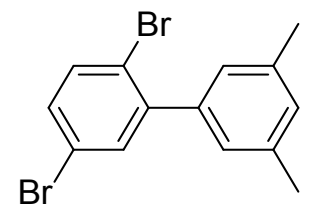

31: Isolated yield: $185 \mathrm{mg}(55 \%)$, White solid. m.p. : $89-91^{\circ} \mathrm{C}$

Purified via column chromatography (petroleum ether 100\%).

${ }^{1} \mathrm{H}$ NMR $\left(400 \mathrm{MHz}, \mathrm{DMSO}-d_{6}\right): \delta 7.66(\mathrm{~d}, J=8.0,1 \mathrm{H}), 7.53-7.47(\mathrm{~m}, 2 \mathrm{H}), 7.05(\mathrm{~s}, 1 \mathrm{H}), 6.98(\mathrm{~s}, 2 \mathrm{H})$, $2.34-2.28(\mathrm{~s}, 6 \mathrm{H})$.

${ }^{13} \mathrm{C}$ NMR (100 MHz, DMSO- $\left.d_{6}\right): \delta 144.7,139.6,137.8,135.2,134.0,132.4,130.0,127.2,121.4,121.3$, 21.4.

HRMS (EI) $m / z$ : calcd for $\mathrm{C}_{14} \mathrm{H}_{12} \mathrm{Br}_{2}{ }^{+}\left([\mathrm{M}]^{+}\right)$337.9306; Found 337.9292.

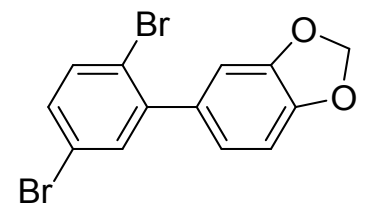

3m: Isolated yield: $229 \mathrm{mg}(65 \%)$, White solid. m.p. : $110-112^{\circ} \mathrm{C}$ 
Purified via column chromatography (petroleum ether 100\%).

${ }^{1} \mathrm{H} \mathrm{NMR}\left(400 \mathrm{MHz}, \mathrm{CDCl}_{3}\right): \delta 7.50(\mathrm{~d}, J=8.4 \mathrm{~Hz}, 1 \mathrm{H}), 7.45(\mathrm{~d}, J=2.4 \mathrm{~Hz}, 1 \mathrm{H}), 7.30(\mathrm{dd}, J=8.4,2.4$ $\mathrm{Hz}, 1 \mathrm{H}), 6.89-6.80$ (m, $3 \mathrm{H}), 6.02$ (s, $2 \mathrm{H})$.

${ }^{13} \mathrm{C}$ NMR $\left(100 \mathrm{MHz}, \mathrm{CDCl}_{3}\right): \delta 147.5,147.3,144.0,134.5,134.1,133.7,131.6,123.0,121.6,121.1$, 109.9, 108.1, 101.3.

HRMS (EI) $m / z$ : calcd for $\mathrm{C}_{13} \mathrm{H}_{8} \mathrm{Br}_{2} \mathrm{O}_{2}^{+}\left([\mathrm{M}]^{+}\right) 353.8891$; Found 353.8899.

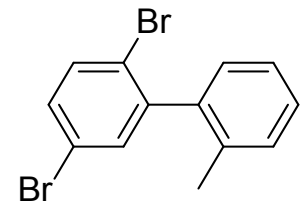

3n: Isolated yield: $148 \mathrm{mg}(46 \%)$, White solid. m.p. : $69-71^{\circ} \mathrm{C}$ Purified via column chromatography (petroleum ether $100 \%$ ).

${ }^{1} \mathrm{H}$ NMR $\left(400 \mathrm{MHz}, \mathrm{DMSO}-d_{6}\right): \delta 7.68(\mathrm{~d}, J=8.4 \mathrm{~Hz}, 1 \mathrm{H}), 7.53(\mathrm{dd}, J=8.4,2.4 \mathrm{~Hz}, 1 \mathrm{H}), 7.47(\mathrm{~d}, J=$ $2.4 \mathrm{~Hz}, 1 \mathrm{H}), 7.31(\mathrm{~m}, 3 \mathrm{H}), 7.09(\mathrm{~d}, J=6.8 \mathrm{~Hz}, 1 \mathrm{H}), 2.03(\mathrm{~s}, 3 \mathrm{H})$.

${ }^{13} \mathrm{C}$ NMR $\left(100 \mathrm{MHz}, \mathrm{DMSO}-d_{6}\right): \delta 144.6,139.9,135.6,134.8,133.8,132.7,130.4,129.4,128.9,126.3$, 122.6, 121.2, 19.9.

HRMS (EI) $m / z$ : calcd for $\mathrm{C}_{13} \mathrm{H}_{10} \mathrm{Br}_{2}^{+}\left([\mathrm{M}]^{+}\right)$323.9149; Found 323.9157.

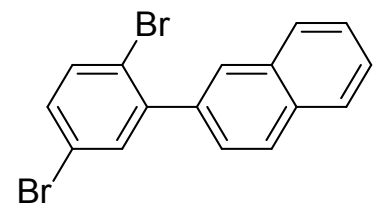

3o: Isolated yield: $252 \mathrm{mg}$ (70\%), White solid. m.p. : $105-107^{\circ} \mathrm{C}$

Purified via column chromatography (petroleum ether 100\%).

${ }^{1} \mathrm{H}$ NMR $\left(400 \mathrm{MHz}, \mathrm{CDCl}_{3}\right): \delta 7.91-7.84(\mathrm{~m}, 4 \mathrm{H}), 7.58-7.51(\mathrm{~m}, 5 \mathrm{H}), 7.37(\mathrm{dd}, J=8.4,2.4 \mathrm{~Hz}, 1 \mathrm{H})$. ${ }^{13} \mathrm{C}$ NMR $\left(100 \mathrm{MHz}, \mathrm{CDCl}_{3}\right): \delta 144.4,137.4,134.5,134.3,133.0,132.8,131.8,128.3,128.3,127.8$, 127.7, 127.2, 126.6, 126.5, 121.6, 121.3.

HRMS (EI) $m / z$ : calcd for $\mathrm{C}_{16} \mathrm{H}_{10} \mathrm{Br}_{2}^{+}\left([\mathrm{M}]^{+}\right) 359.9149$; Found 359.9146.

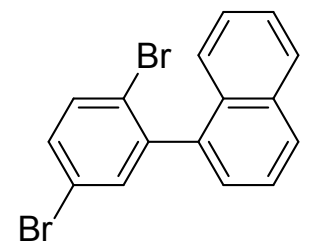

3p: Isolated yield: $197 \mathrm{mg}(55 \%)$, White solid. m.p. : 105-107

Purified via column chromatography (petroleum ether 100\%).

${ }^{1} \mathrm{H}$ NMR $\left(400 \mathrm{MHz}, \mathrm{CDCl}_{3}\right): \delta 7.93(\mathrm{~d}, J=8.4 \mathrm{~Hz}, 2 \mathrm{H}), 7.60(\mathrm{~d}, J=8.4 \mathrm{~Hz}, 1 \mathrm{H}), 7.57-7.49(\mathrm{~m}, 3 \mathrm{H})$, $7.47-7.42(\mathrm{~m}, 3 \mathrm{H}), 7.35(\mathrm{~d}, J=6.8 \mathrm{~Hz}, 1 \mathrm{H})$.

${ }^{13} \mathrm{C}$ NMR $\left(100 \mathrm{MHz}, \mathrm{CDCl}_{3}\right): \delta 143.3,137.8,134.7,134.1,133.5,132.2,131.2,128.7,128.4,127.0$, $126.5,126.1,125.7,125.2,123.2,121.1$.

HRMS (EI) $m / z$ : calcd for $\mathrm{C}_{16} \mathrm{H}_{10} \mathrm{Br}_{2}^{+}\left([\mathrm{M}]^{+}\right)$359.9149; Found 359.9137. 


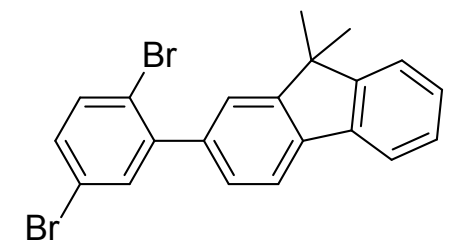

3q: Isolated yield: $318 \mathrm{mg}(75 \%)$, White solid. m.p. : $135-138^{\circ} \mathrm{C}$

Purified via column chromatography (petroleum ether $100 \%$ ).

${ }^{1} \mathrm{H} \mathrm{NMR}\left(400 \mathrm{MHz}, \mathrm{CDCl}_{3}\right): \delta 7.77(\mathrm{t}, J=7.6 \mathrm{~Hz}, 2 \mathrm{H}), 7.65(\mathrm{~s}, 1 \mathrm{H}), 7.55(\mathrm{~d}, J=5.6 \mathrm{~Hz}, 1 \mathrm{H}), 7.47-$ 7.45 (m, $2 \mathrm{H}), 7.38-7.32(\mathrm{~m}, 4 \mathrm{H}), 1.53$ (s, $6 \mathrm{H})$.

${ }^{13} \mathrm{C}$ NMR $\left(100 \mathrm{MHz}, \mathrm{CDCl}_{3}\right): \delta 154.0,153.5,144.8,139.2,138.7,138.6,134.6,134.1,131.6,128.2$, 127.6, 127.1, 123.9, 122.7, 121.5, 121.2, 120.3, 119.7, 47.0, 27.1.

HRMS (EI) $m / z$ : calcd for $\mathrm{C}_{21} \mathrm{H}_{16} \mathrm{Br}_{2}{ }^{+}\left([\mathrm{M}]^{+}\right)$425.9619; Found 425.9617.

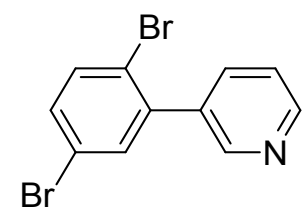

3r: Isolated yield: $176 \mathrm{mg}(57 \%)$, White solid. m.p. : $92-94^{\circ} \mathrm{C}$

Purified via column chromatography (petroleum ether $/$ ethyl acetate $=5: 1$ ).

${ }^{1} \mathrm{H}$ NMR $\left(400 \mathrm{MHz}, \mathrm{CDCl}_{3}\right): \delta 8.65(\mathrm{~s}, 2 \mathrm{H}), 7.74(\mathrm{~d}, J=7.6 \mathrm{~Hz}, 1 \mathrm{H}), 7.56(\mathrm{~d}, J=8.4 \mathrm{~Hz}, 1 \mathrm{H}), 7.47(\mathrm{~d}$, $J=2.4 \mathrm{~Hz}, 1 \mathrm{H}), 7.39$ (dd, $J=8.4,2.4 \mathrm{~Hz}, 2 \mathrm{H})$.

${ }^{13} \mathrm{C}$ NMR (100 MHz, $\left.\mathrm{CDCl}_{3}\right): \delta 149.7,149.2,140.8,136.8,135.6,134.7,133.9,132.6,123.0,121.5$.

HRMS (EI) $m / z$ : calcd for $\mathrm{C}_{11} \mathrm{H}_{7} \mathrm{Br}_{2} \mathrm{~N}^{+}\left([\mathrm{M}]^{+}\right) 310.8945$; Found 310.8954 .

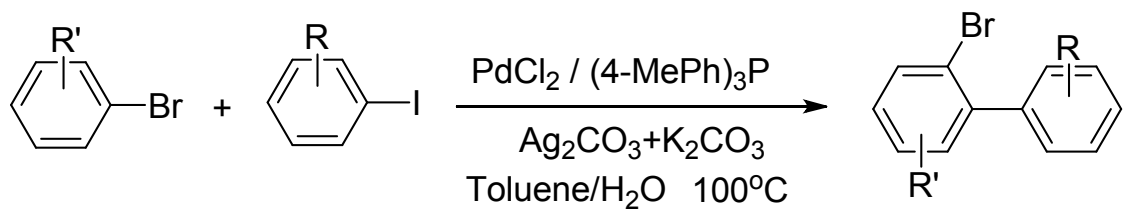

General Procedure for $\mathbf{P d C l}_{2}$ Catalyzed Coupling reation with substituted aryl bromide and aryl iodide as example: 1,4-dibromonaphthalene (1.12 g, $4 \mathrm{mmol})$ and 1-(tert-butyl)-4-iodobenzene (260 $\mathrm{mg}$, $1 \mathrm{mmol}$ ) were added to a vigorously stirred solution of silver carbonate (540 $\mathrm{mg}, 2 \mathrm{mmol}$ ), palladium chloride $(17.7 \mathrm{mg}, 0.1 \mathrm{mmol})$, tri $(p$-tolyl)phosphine $(60 \mathrm{mg}, 0.2 \mathrm{mmol})$, potassium carbonate $(138 \mathrm{mg}, 1$ mmol) in $\mathrm{H}_{2} \mathrm{O}(0.5 \mathrm{~mL})$ and toluene $(0.5 \mathrm{~mL})$ under $\mathrm{N}_{2}$. The reaction mixture was stirred at $100^{\circ} \mathrm{C}$ in oil bath for 12 hours. The reaction was then quenched with saturated $\mathrm{NH}_{4} \mathrm{Cl}$ solution. The product was extracted with dichloromethane $(3 \times 20 \mathrm{~mL})$. The combined organic layer was washed with brine and dried over $\mathrm{Na}_{2} \mathrm{SO}_{4}$. After removal of solvents under vacuum, the crude product was purified via column chromatography. 
<smiles>CC(C)(C)c1ccc(-c2cc(Br)c3ccccc3c2Br)cc1</smiles>

4a: Isolated yield: $249 \mathrm{mg}$ (60\%), White solid. m.p. : $130-132^{\circ} \mathrm{C}$

Purified via column chromatography (petroleum ether 100\%).

${ }^{1} \mathrm{H}$ NMR (400 MHz, $\left.\mathrm{CDCl}_{3}\right): \delta 8.47-8.45(\mathrm{~m}, 1 \mathrm{H}), 8.29-8.27(\mathrm{~m}, 1 \mathrm{H}), 7.80(\mathrm{~s}, 1 \mathrm{H}), 7.70-7.64(\mathrm{~m}, 2$ $\mathrm{H}), 7.45$ (dd, $J=32.0,6.4 \mathrm{~Hz}, 4 \mathrm{H}), 1.40(\mathrm{~s}, 9 \mathrm{H})$.

${ }^{13} \mathrm{C}$ NMR $\left(100 \mathrm{MHz}, \mathrm{CDCl}_{3}\right): \delta 150.9,141.2,138.0,133.4,132.3,131.8,130.0,129.2,128.5,128.4$, 128.1, 127.8, 127.8, 127.5, 125.0, 122.3, 122.2, 34.7, 31.3.

HRMS (EI) $m / z$ : calcd for $\mathrm{C}_{20} \mathrm{H}_{18} \mathrm{Br}_{2}^{+}\left([\mathrm{M}]^{+}\right)$415.9775; Found 415.9789.

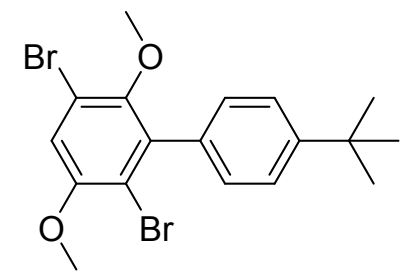

4b: Isolated yield: $297 \mathrm{mg}$ (70\%), White solid. m.p. : 125-127\% C

Purified via column chromatography (petroleum ether / ethyl acetate $=20: 1$ ).

${ }^{1} \mathrm{H}$ NMR (400 MHz, $\left.\mathrm{CDCl}_{3}\right): \delta 7.44(\mathrm{~d}, J=8.4 \mathrm{~Hz}, 2 \mathrm{H}), 7.20(\mathrm{~d}, J=8.4 \mathrm{~Hz}, 2 \mathrm{H}), 7.10(\mathrm{~s}, 1 \mathrm{H}), 3.91$ (s, $3 \mathrm{H}), 3.36(\mathrm{~s}, 3 \mathrm{H}), 1.37$ (s, $9 \mathrm{H})$.

${ }^{13} \mathrm{C}$ NMR (100 MHz, $\left.\mathrm{CDCl}_{3}\right): \delta 150.8,129.3,124.8,114.8,60.8,56.8,31.3,29.7$.

HRMS (EI) $m / z$ : calcd for $\mathrm{C}_{18} \mathrm{H}_{20} \mathrm{Br}_{2} \mathrm{O}_{2}^{+}\left([\mathrm{M}]^{+}\right)$425.9830; Found 425.9847 .

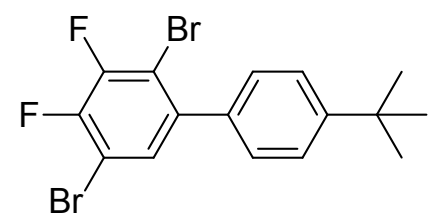

4c: Isolated yield: $392 \mathrm{mg}(98 \%)$, White solid. m.p. : 95-97 C

Purified via column chromatography (petroleum ether 100\%).

${ }^{1} \mathrm{H} \mathrm{NMR}\left(400 \mathrm{MHz}, \mathrm{CDCl}_{3}\right): \delta 7.46(\mathrm{~d}, J=8.4 \mathrm{~Hz}, 2 \mathrm{H}), 7.36(\mathrm{dd}, J=5.2,1.6 \mathrm{~Hz}, 1 \mathrm{H}), 7.29(\mathrm{~d}, J=8.4$ $\mathrm{Hz}, 2 \mathrm{H}), 1.37$ (s, $9 \mathrm{H})$.

${ }^{19} \mathrm{~F}$ NMR $\left(376 \mathrm{MHz}, \mathrm{CDCl}_{3}\right): \delta-122.2(\mathrm{~d}, J=29.8 \mathrm{~Hz}, 1 \mathrm{~F}),-123.4(\mathrm{~d}, J=23.8 \mathrm{~Hz}, 1 \mathrm{~F})$.

${ }^{13} \mathrm{C}$ NMR $\left(100 \mathrm{MHz}, \mathrm{CDCl}_{3}\right): \delta 151.7,148.6\left(\mathrm{~d}, J_{\mathrm{F}}=264.4 \mathrm{~Hz}\right), 147.5\left(\mathrm{~d}, J_{\mathrm{F}}=250.5 \mathrm{~Hz}\right), 140.2,135.3$, $129.1\left(\mathrm{~d}, J_{\mathrm{F}}=3.4 \mathrm{~Hz}\right), 129.0,125.3,110.6\left(\mathrm{~d}, J_{\mathrm{F}}=17.7 \mathrm{~Hz}\right), 108.8\left(\mathrm{~d}, J_{\mathrm{F}}=15.3 \mathrm{~Hz}\right), 35.2,32.1$.

HRMS (EI) $m / z$ : calcd for $\mathrm{C}_{16} \mathrm{H}_{14} \mathrm{Br}_{2} \mathrm{~F}_{2}^{+}\left([\mathrm{M}]^{+}\right)$401.9430; Found 401.9444. 
<smiles>CC(C)(C)c1ccc(-c2c(Br)cc(Br)cc2Br)cc1</smiles>

4d: Isolated yield: $318 \mathrm{mg}(72 \%)$, White solid. m.p. : $110-112^{\circ} \mathrm{C}$ Purified via column chromatography (petroleum ether $100 \%$ ).

${ }^{1} \mathrm{H}$ NMR (400 MHz, $\left.\mathrm{CDCl}_{3}\right): \delta 7.79(\mathrm{~s}, 2 \mathrm{H}), 7.45(\mathrm{~d}, J=8.4 \mathrm{~Hz}, 2 \mathrm{H}), 7.10(\mathrm{~d}, J=8.4 \mathrm{~Hz}, 2 \mathrm{H}), 1.37$ (s, $9 \mathrm{H})$.

${ }^{13} \mathrm{C}$ NMR $\left(100 \mathrm{MHz}, \mathrm{CDCl}_{3}\right): \delta 151.5,129.1,129.0,128.9,125.2,34.7,31.3$.

HRMS (EI) $m / z$ : calcd for $\mathrm{C}_{16} \mathrm{H}_{15} \mathrm{Br}_{3}{ }^{+}\left([\mathrm{M}]^{+}\right)$443.8724; Found 443.8727.<smiles>CC(C)(C)c1ccc(-c2cc(C(F)(F)F)ccc2Br)cc1</smiles>

4e: Isolated yield: $195 \mathrm{mg}(55 \%)$, White solid. m.p. : 66-68 ${ }^{\circ} \mathrm{C}$ Purified via column chromatography (petroleum ether 100\%).

${ }^{1} \mathrm{H}$ NMR $\left(400 \mathrm{MHz}, \mathrm{CDCl}_{3}\right): \delta 7.79(\mathrm{~d}, J=8.0 \mathrm{~Hz}, 1 \mathrm{H}), 7.58(\mathrm{~d}, J=2.4 \mathrm{~Hz}, 1 \mathrm{H}), 7.47(\mathrm{~d}, J=8.0 \mathrm{~Hz}, 2$ $\mathrm{H}), 7.44-7.41(\mathrm{~m}, 1 \mathrm{H}), 7.35(\mathrm{~d}, J=8.4 \mathrm{~Hz}, 2 \mathrm{H}), 1.38(\mathrm{~s}, 9 \mathrm{H})$.

${ }^{19} \mathrm{~F}$ NMR $\left(376 \mathrm{MHz}, \mathrm{CDCl}_{3}\right): \delta-56.8(\mathrm{~s}, 0.05 \mathrm{~F}$, isomer), $-62.5(\mathrm{~s}, 1 \mathrm{~F})$.

${ }^{13} \mathrm{C}$ NMR $\left(100 \mathrm{MHz}, \mathrm{CDCl}_{3}\right): \delta 151.4,143.4,136.9,133.8,130.1,129.8,129.0,128.2\left(\mathrm{q}, J_{\mathrm{F}}=3.8 \mathrm{~Hz}\right)$, $126.7,125.3,125.2\left(\mathrm{q}, J_{\mathrm{F}}=3.8 \mathrm{~Hz}\right), 123.8\left(\mathrm{q}, J_{\mathrm{F}}=235.3 \mathrm{~Hz}\right), 34.8,31.4$.

HRMS (EI) $m / z$ : calcd for $\mathrm{C}_{17} \mathrm{H}_{16} \mathrm{BrF}_{3}^{+}\left([\mathrm{M}]^{+}\right) 356.0387$; Found 356.0393.

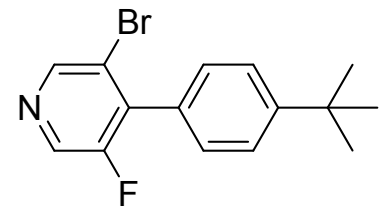

4f: Isolated yield: $304 \mathrm{mg}(98 \%)$, White solid. m.p. : 96-98 $\mathrm{C}$

Purified via column chromatography (petroleum ether / ethyl acetate $=8: 1$ ).

${ }^{1} \mathrm{H} \mathrm{NMR}\left(400 \mathrm{MHz}, \mathrm{CDCl}_{3}\right): \delta 8.71(\mathrm{~s}, 2 \mathrm{H}), 7.49(\mathrm{~d}, J=8.4 \mathrm{~Hz}, 2 \mathrm{H}), 7.15(\mathrm{~d}, J=8.4 \mathrm{~Hz}, 2 \mathrm{H}), 1.38(\mathrm{~s}$, $9 \mathrm{H})$.

${ }^{19} \mathrm{~F}$ NMR $\left(376 \mathrm{MHz}, \mathrm{CDCl}_{3}\right): \delta-125.8(\mathrm{~s}, 1 \mathrm{~F})$.

${ }^{13} \mathrm{C} \mathrm{NMR}\left(100 \mathrm{MHz}, \mathrm{CDCl}_{3}\right): \delta 156.8\left(\mathrm{~d}, J_{\mathrm{F}}=259.2 \mathrm{~Hz}\right), 152.5,148.2\left(\mathrm{~d}, J_{\mathrm{F}}=4.8 \mathrm{~Hz}\right), 138.2\left(\mathrm{~d}, J_{\mathrm{F}}=15.3\right.$ $\mathrm{Hz}), 137.6\left(\mathrm{~d}, J_{\mathrm{F}}=25.8 \mathrm{~Hz}\right), 129.2,128.5,125.5,121.9,34.9,32.3$.

HRMS (EI) $m / z$ : calcd for $\mathrm{C}_{15} \mathrm{H}_{15} \mathrm{BrFN}^{+}\left([\mathrm{M}]^{+}\right)$307.0372; Found 307.0378.

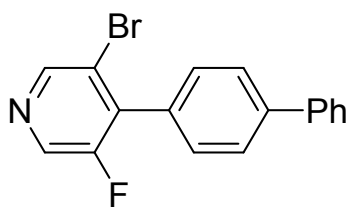


4g: Isolated yield: $320 \mathrm{mg}$ (98\%), White solid. m.p. : 98-100

Purified via column chromatography (petroleum ether / ethyl acetate $=3: 1$ ).

${ }^{1} \mathrm{H}$ NMR $\left(400 \mathrm{MHz}, \mathrm{CDCl}_{3}\right): \delta 8.69(\mathrm{~s}, 1 \mathrm{H}), 8.50(\mathrm{~s}, 1 \mathrm{H}), 7.78-7.64(\mathrm{~m}, 4 \mathrm{H}), 7.50-7.45(\mathrm{~m}, 4 \mathrm{H})$, $7.42-7.36(\mathrm{~m}, 1 \mathrm{H})$.

${ }^{19} \mathrm{~F}$ NMR $\left(376 \mathrm{MHz}, \mathrm{CDCl}_{3}\right): \delta-125.6(\mathrm{~s}, 1 \mathrm{~F})$.

${ }^{13} \mathrm{C} \mathrm{NMR}\left(100 \mathrm{MHz}, \mathrm{CDCl}_{3}\right): \delta 156.6\left(\mathrm{~d}, J_{\mathrm{F}}=259.2 \mathrm{~Hz}\right), 148.2\left(\mathrm{~d}, J_{\mathrm{F}}=4.8 \mathrm{~Hz}\right), 142.2,140.3,137.7\left(\mathrm{~d}, J_{\mathrm{F}}\right.$ $=15.2 \mathrm{~Hz}), 137.3\left(\mathrm{~d}, J_{\mathrm{F}}=24.9 \mathrm{~Hz}\right), 130.3,130.0,129.0,127.9,127.3,127.2,121.7$.

HRMS (EI) $m / z$ : calcd for $\mathrm{C}_{17} \mathrm{H}_{11} \mathrm{BrFN}^{+}\left([\mathrm{M}]^{+}\right) 327.0059$; Found 327.0074.<smiles>Clc1cncc(Br)c1-c1ccc(-c2ccccc2)cc1</smiles>

4h: Isolated yield: $338 \mathrm{mg}(98 \%)$, White solid. m.p. : 108-110 $\mathrm{C}$

Purified via column chromatography (petroleum ether / ethyl acetate $=3: 1$ ).

${ }^{1} \mathrm{H}$ NMR $\left(400 \mathrm{MHz}, \mathrm{CDCl}_{3}\right): \delta 8.74(\mathrm{~s}, 1 \mathrm{H}), 8.62(\mathrm{~s}, 1 \mathrm{H}), 7.73(\mathrm{~d}, J=8.4 \mathrm{~Hz}, 2 \mathrm{H}), 7.67(\mathrm{~d}, J=8.4 \mathrm{~Hz}$, $2 \mathrm{H}), 7.48(\mathrm{t}, J=7.6 \mathrm{~Hz}, 2 \mathrm{H}), 7.41-7.33(\mathrm{~m}, 3 \mathrm{H})$.

${ }^{13} \mathrm{C}$ NMR $\left(100 \mathrm{MHz}, \mathrm{CDCl}_{3}\right): \delta 150.2,148.3,141.9,140.3,134.8,132.1,129.2,128.9,127.8,127.3$, 127.2, 122.6.

HRMS (EI) $m / z$ : calcd for $\mathrm{C}_{17} \mathrm{H}_{11} \mathrm{BrClN}^{+}\left([\mathrm{M}]^{+}\right)$342.9763; Found 342.9761.<smiles>FC(F)(F)c1ccc(-c2c(Cl)cncc2Br)cc1</smiles>

4i: Isolated yield: $328 \mathrm{mg}(98 \%)$, White solid. m.p. : $88-90^{\circ} \mathrm{C}$

Purified via column chromatography (petroleum ether / ethyl acetate $=5: 1$ ).

${ }^{1} \mathrm{H} \mathrm{NMR}\left(400 \mathrm{MHz}, \mathrm{CDCl}_{3}\right): \delta 8.74(\mathrm{~s}, 1 \mathrm{H}), 8.64(\mathrm{~s}, 1 \mathrm{H}), 7.78(\mathrm{~d}, J=8.0 \mathrm{~Hz}, 2 \mathrm{H}), 7.39(\mathrm{~d}, J=8.0 \mathrm{~Hz}$, $2 \mathrm{H})$.

${ }^{19} \mathrm{~F}$ NMR $\left(376 \mathrm{MHz}, \mathrm{CDCl}_{3}\right): \delta-62.6(\mathrm{~s}, 3 \mathrm{~F})$.

${ }^{13} \mathrm{C}$ NMR $\left(100 \mathrm{MHz}, \mathrm{CDCl}_{3}\right): \delta 150.3,148.4,147.2,139.4,131.7,131.4,131.1,129.3,125.7\left(\mathrm{q}, J_{\mathrm{F}}=3.8\right.$

$\mathrm{Hz}), 123.9\left(\mathrm{q}, J_{\mathrm{F}}=270.7 \mathrm{~Hz}\right), 122.0$.

HRMS (EI) $m / z$ : calcd for $\mathrm{C}_{12} \mathrm{H}_{6} \mathrm{BrClF}_{3} \mathrm{~N}^{+}\left([\mathrm{M}]^{+}\right)$334.9324; Found 334.9328.

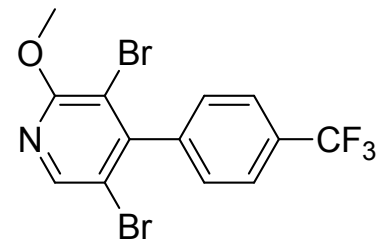

4j: Isolated yield: $367 \mathrm{mg}(90 \%)$, White solid. m.p. : 105-107 $\mathrm{C}$

Purified via column chromatography (petroleum ether / ethyl acetate $=5: 1$ ).

${ }^{1} \mathrm{H} \mathrm{NMR}\left(400 \mathrm{MHz}, \mathrm{CDCl}_{3}\right): \delta 8.30(\mathrm{~s}, 1 \mathrm{H}), 7.75(\mathrm{~d}, J=8.0 \mathrm{~Hz}, 2 \mathrm{H}), 7.32(\mathrm{~d}, J=8.0 \mathrm{~Hz}, 2 \mathrm{H}), 4.04(\mathrm{~s}$, $3 \mathrm{H})$. 
${ }^{19} \mathrm{~F}$ NMR $\left(376 \mathrm{MHz}, \mathrm{CDCl}_{3}\right): \delta-62.5(\mathrm{~s}, 3 \mathrm{~F})$

${ }^{13} \mathrm{C}$ NMR $\left(100 \mathrm{MHz}, \mathrm{CDCl}_{3}\right): \delta 160.0,151.2,146.7,142.3,131.1,129.1,125.6\left(\mathrm{q}, J_{\mathrm{F}}=3.8 \mathrm{~Hz}\right), 124.0(\mathrm{q}$, $\left.J_{\mathrm{F}}=270.7 \mathrm{~Hz}\right), 112.7,108.8,55.2$.

HRMS (EI) $m / z$ : calcd for $\mathrm{C}_{13} \mathrm{H}_{8} \mathrm{Br}_{2} \mathrm{~F}_{3} \mathrm{NO}^{+}\left([\mathrm{M}]^{+}\right) 408.8925$; Found 408.8913 .
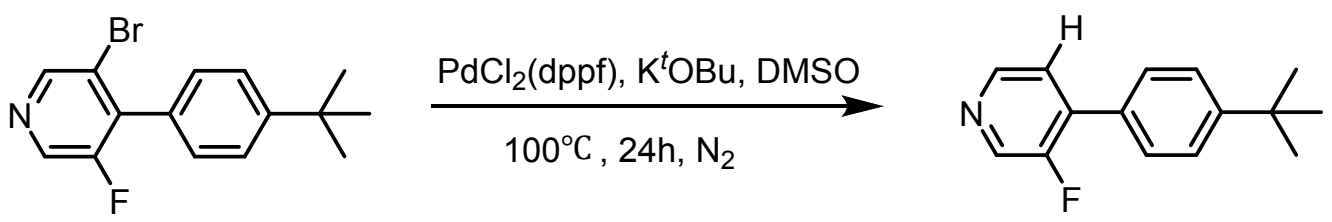

Procedure for Palladium Catalyzed hydrodebromination reaction: A $25 \mathrm{ml}$ oven-dried Schlenk-tube was charged with $\mathrm{PdCl}_{2}$ (4 mg, $2 \mathrm{~mol} \%$ ), dppf (12 mg, $3 \mathrm{~mol} \%$ ), and potassium $t$-butoxide (280 $\mathrm{mg}, 2.5$ mmol). The tube was evacuated and backfilled with argon (this procedure was repeated three times). Compound $\mathbf{4 f}$ (155 mg, $0.5 \mathrm{mmol})$, DMSO $(4.0 \mathrm{ml})$ were added by syringe under a counter flow of argon at room temperature. The tube was then sealed and the mixture was allowed to stir at the appointed temperature $\left(100^{\circ} \mathrm{C}\right)$ for 24 hours. Upon completion of the reaction, the mixture was cooled to room temperature and the product was extracted with dichloromethane $(3 \times 20 \mathrm{~mL})$. The combined organic layer was washed with brine and dried over $\mathrm{Na}_{2} \mathrm{SO}_{4}$. After removal of solvents under vacuum, the crude product was purified via column chromatography. A white solid was isolated in $75 \%$ yield.

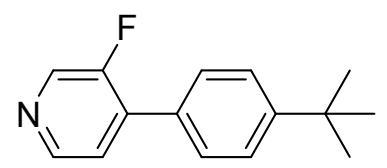

5a: Isolated yield: $86 \mathrm{mg}(75 \%)$, White solid. m.p. : 66-68 ${ }^{\circ} \mathrm{C}$

Purified via column chromatography (petroleum ether / ethyl acetate $=8: 1$ ).

${ }^{1} \mathrm{H} \mathrm{NMR}\left(400 \mathrm{MHz}, \mathrm{CDCl}_{3}\right): \delta 8.52(\mathrm{~d}, J=2.8 \mathrm{~Hz}, 1 \mathrm{H}), 8.45(\mathrm{~d}, J=5.0 \mathrm{~Hz}, 1 \mathrm{H}), 7.59-7.51(\mathrm{~m}, 4 \mathrm{H})$, $7.41(\mathrm{dd}, J=6.8,5.0 \mathrm{~Hz}, 1 \mathrm{H}), 1.37(\mathrm{~s}, 9 \mathrm{H})$.

${ }^{19} \mathrm{~F}$ NMR $\left(376 \mathrm{MHz}, \mathrm{CDCl}_{3}\right): \delta-132.8(\mathrm{~s}, 1 \mathrm{~F})$.

${ }^{13} \mathrm{C} \mathrm{NMR}\left(100 \mathrm{MHz}, \mathrm{CDCl}_{3}\right): \delta 155.9\left(\mathrm{~d}, J_{\mathrm{F}}=257.3 \mathrm{~Hz}\right), 152.6,146.0\left(\mathrm{~d}, J_{\mathrm{F}}=5.3 \mathrm{~Hz}\right), 139.2\left(\mathrm{~d}, J_{\mathrm{F}}=25.8\right.$ $\mathrm{Hz}), 138.9,136.0\left(\mathrm{~d}, J_{\mathrm{F}}=10.7 \mathrm{~Hz}\right), 130.0,128.6,125.9,124.2,34.8,31.3$.

HRMS (EI) $m / z$ : calcd for $\mathrm{C}_{15} \mathrm{H}_{16} \mathrm{FN}^{+}\left([\mathrm{M}]^{+}\right)$229.1267; Found 229.1277.
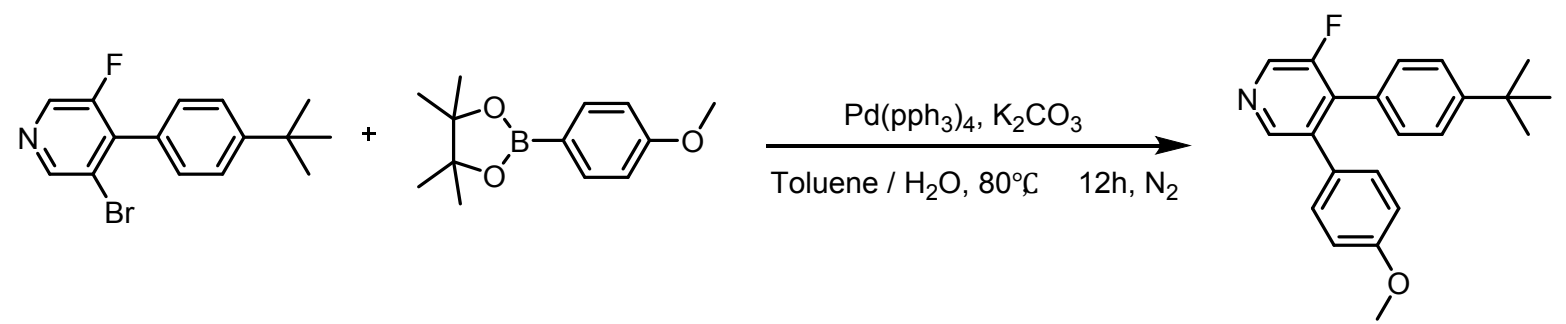

Procedure for Palladium Catalyzed Cross-Coupling Reaction: Compound 4f (309 mg, $1 \mathrm{mmol}$ ), 
boronic ester (351 mg, $1.5 \mathrm{mmol}), \mathrm{Pd}\left(\mathrm{PPh}_{3}\right)_{4}(58 \mathrm{mg}, 5 \%)$ and potassium carbonate $(552 \mathrm{mg}, 4 \mathrm{mmol})$ was added to the solution of toluene $/ \mathrm{H}_{2} \mathrm{O}(\mathrm{v}: \mathrm{v}=4: 2)$ under $\mathrm{N}_{2}$. The reaction mixture was stirred at $80{ }^{\circ} \mathrm{C}$ for 12 hours. The product was extracted with dichloromethane $(3 \times 20 \mathrm{~mL})$. The combined organic layer was washed with brine and dried over $\mathrm{Na}_{2} \mathrm{SO}_{4}$. After removal of solvents under vacuum, the crude product was obtained via column chromatography purification in $65 \%$ yield.

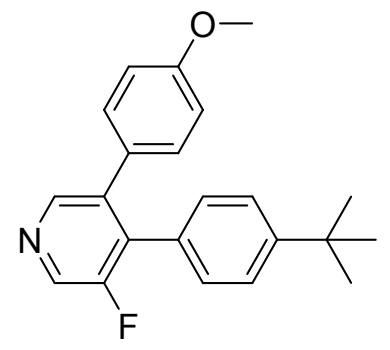

5b: Isolated yield: $217 \mathrm{mg}(65 \%)$, White solid. m.p. : 115-117 $\mathrm{C}$

Purified via column chromatography (petroleum ether / ethyl acetate $=4: 1$ ).

${ }^{1} \mathrm{H}$ NMR $\left(400 \mathrm{MHz}, \mathrm{CDCl}_{3}\right): \delta 8.47(\mathrm{~d}, J=9.6 \mathrm{~Hz}, 2 \mathrm{H}), 7.31(\mathrm{~d}, J=8.4 \mathrm{~Hz}, 2 \mathrm{H}), 7.09-7.02(\mathrm{~m}, 4 \mathrm{H})$, $6.78(\mathrm{~d}, J=8.4 \mathrm{~Hz}, 2 \mathrm{H}), 3.79$ (s, $3 \mathrm{H}), 1.30(\mathrm{~s}, 9 \mathrm{H})$.

${ }^{19} \mathrm{~F}$ NMR $\left(376 \mathrm{MHz}, \mathrm{CDCl}_{3}\right): \delta-131.7(\mathrm{~s}, 1 \mathrm{~F})$.

${ }^{13} \mathrm{C}$ NMR $\left(100 \mathrm{MHz}, \mathrm{CDCl}_{3}\right): \delta 159.1,157.0\left(\mathrm{~d}, J_{\mathrm{F}}=253.3 \mathrm{~Hz}\right), 151.4,146.6\left(\mathrm{~d}, J_{\mathrm{F}}=4.7 \mathrm{~Hz}\right), 137.5$, $136.8\left(\mathrm{~d}, J_{\mathrm{F}}=27.3 \mathrm{~Hz}\right), 131.1,129.9,128.7,128.4,125.2,116.1,114.8,113.8,55.3,34.7,31.3$.

HRMS (EI) $m / z$ : calcd for $\mathrm{C}_{22} \mathrm{H}_{22} \mathrm{FNO}^{+}\left([\mathrm{M}]^{+}\right)$335.1685; Found 335.1695.
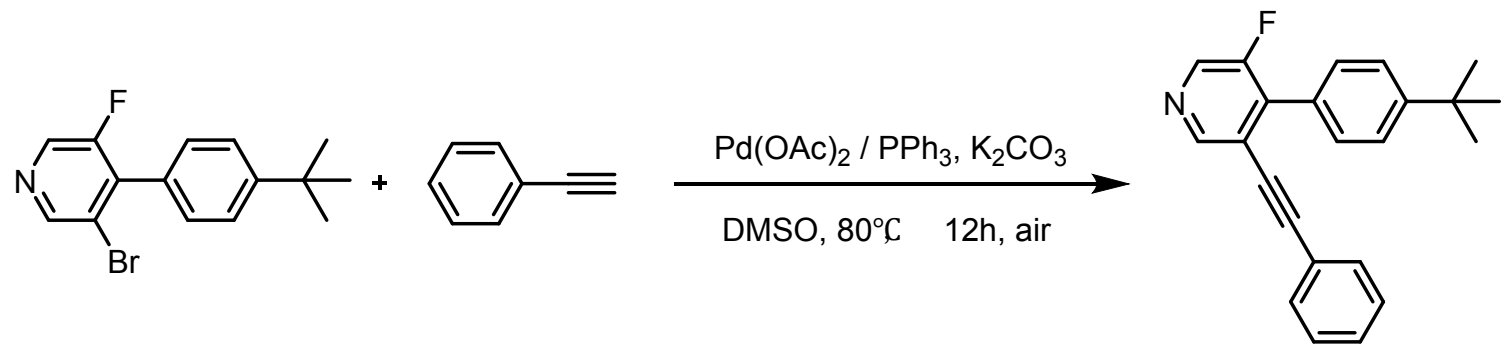

Procedure for Palladium Catalyzed Sonogashira Reaction: In a $25 \mathrm{~mL}$ flask, a mixture of phenylacetylene (174 mg, $1.5 \mathrm{mmol})$, compound $4 \mathrm{f}$ (309 $\mathrm{mg}, 1 \mathrm{mmol}), \mathrm{PPh}_{3}$ (53 mg, $0.2 \mathrm{mmol}$ ), $\mathrm{Pd}(\mathrm{OAc})_{2}(12 \mathrm{mg}, 2 \mathrm{~mol} \%)$, and $\mathrm{K}_{2} \mathrm{CO}_{3}(207 \mathrm{mg}, 1.5 \mathrm{mmol})$ in DMSO $(5 \mathrm{~mL})$ was heated at $80{ }^{\circ} \mathrm{C}$. The resulting mixture was poured into $\mathrm{H}_{2} \mathrm{O}$ and extracted with EtOAc three times. Combined organic layers were dried over $\mathrm{Na}_{2} \mathrm{SO}_{4}$ and concentrated in vacuo. The product was isolated by flash chromatography on a silica gel column in $70 \%$ yield.

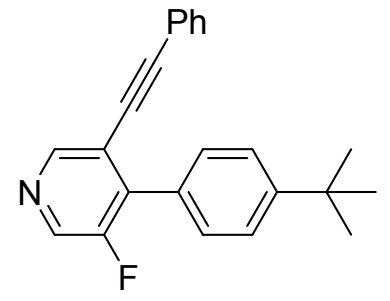


5c: Isolated yield: $230 \mathrm{mg}(70 \%)$, White solid. m.p. : $110-112^{\circ} \mathrm{C}$

Purified via column chromatography (petroleum ether / ethyl acetate $=8: 1$ ).

${ }^{1} \mathrm{H}$ NMR (400 MHz, $\left.\mathrm{CDCl}_{3}\right): \delta 8.61(\mathrm{~s}, 1 \mathrm{H}), 8.42(\mathrm{~s}, 1 \mathrm{H}), 7.54-7.48(\mathrm{~m}, 4 \mathrm{H}), 7.28-7.25(\mathrm{~m}, 5 \mathrm{H})$, $1.35(\mathrm{~s}, 9 \mathrm{H})$.

${ }^{19} \mathrm{~F}$ NMR $\left(376 \mathrm{MHz}, \mathrm{CDCl}_{3}\right): \delta-132.6(\mathrm{~s}, 1 \mathrm{~F})$.

${ }^{13} \mathrm{C} \mathrm{NMR}\left(100 \mathrm{MHz}, \mathrm{CDCl}_{3}\right): \delta 156.5\left(\mathrm{~d}, J_{\mathrm{F}}=254.4 \mathrm{~Hz}\right), 152.5,149.1\left(\mathrm{~d}, J_{\mathrm{F}}=4.8 \mathrm{~Hz}\right), 138.1\left(\mathrm{~d}, J_{\mathrm{F}}=13.4\right.$ $\mathrm{Hz}), 137.8\left(\mathrm{~d}, J_{\mathrm{F}}=26.3 \mathrm{~Hz}\right), 131.6,129.8,129.0,128.4,128.1,125.1,122.5,120.8,95.8,85.1,34.9,31.3$. HRMS (EI) $m / z$ : calcd for $\mathrm{C}_{23} \mathrm{H}_{20} \mathrm{FN}^{+}\left([\mathrm{M}]^{+}\right) 329.1580$; Found 329.1589.

\section{Experiments for mechanistic study}

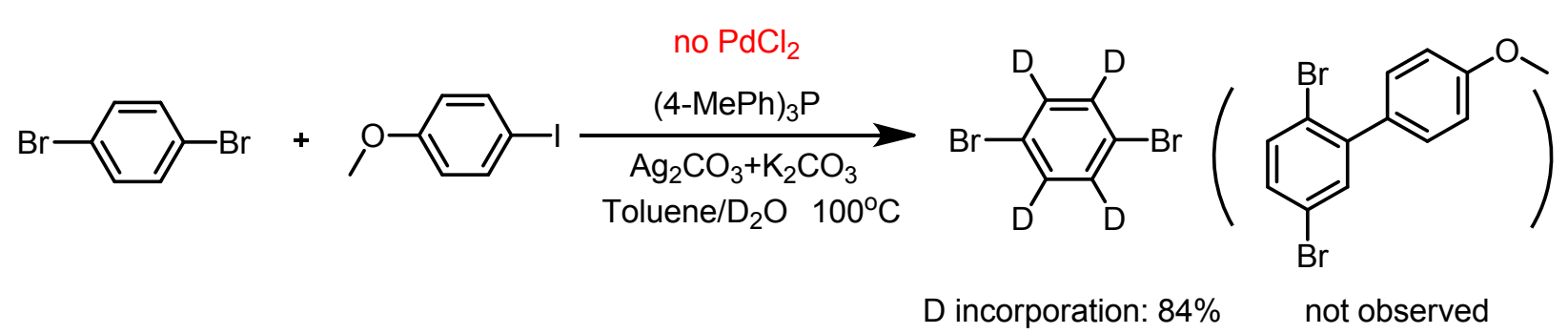

Reaction in $\mathbf{D}_{2} \mathbf{O}$ without $\mathbf{P d C l}_{2}$ as catalyst: A $10 \mathrm{ml}$ oven-dried Schlenk-tube was charged with 1,4dibromobenzene (472 mg, $2 \mathrm{mmol}$ ), 4-iodophenyl ether (117 mg, $0.5 \mathrm{mmol})$, Silver carbonate (276 mg, 1 $\mathrm{mmol})$, tri-p-tolylphosphine $(30 \mathrm{mg}, 0.10 \mathrm{mmol})$ and potassium carbonate $(69 \mathrm{mg}, 0.5 \mathrm{mmol})$. The tube was evacuated and backfilled with argon (this procedure was repeated three times). $\mathrm{D}_{2} \mathrm{O}(0.25 \mathrm{ml})$ and toluene $(0.25 \mathrm{ml})$ were added by syringe under a counter flow of argon at room temperature. The tube was then sealed and the mixture was allowed to stir at the appointed temperature $\left(100^{\circ} \mathrm{C}\right)$ for 12 hours. Upon completion of the reaction, the mixture was cooled to room temperature and diluted with ethyl acetate. The solution was directly analyzed by GC-MS, which showed no cross coupling product formed. On the contrary, the starting material, 1,4-dibromobenzene, is obviously deuterated, providing deuterated 1,4dibromobenzene with deuterium incorporation of $84 \%$.

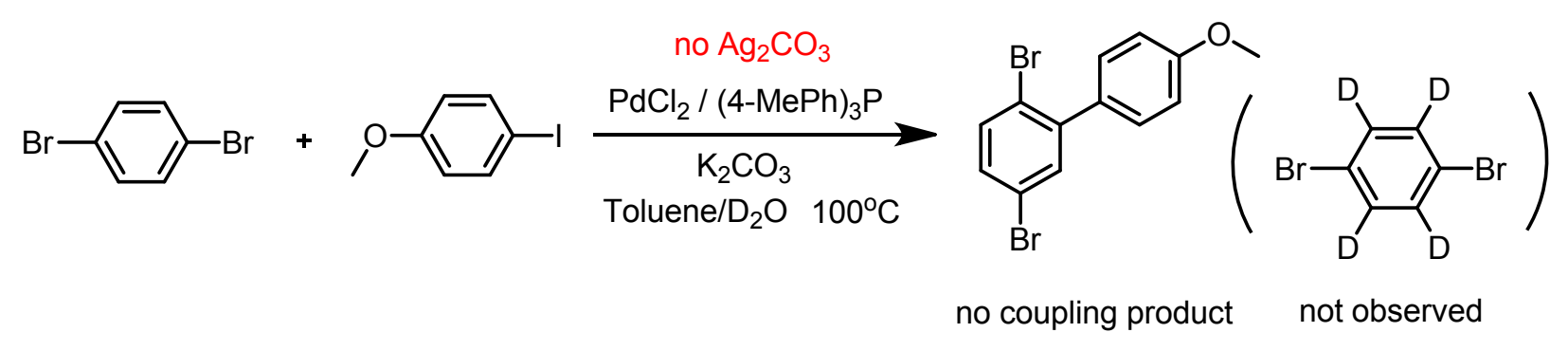

Reaction in $\mathbf{D}_{2} \mathbf{O}$ without $\mathbf{A g}_{2} \mathbf{C O}_{3}$ : A $10 \mathrm{ml}$ oven-dried Schlenk-tube was charged with 1,4dibromobenzene (472 mg, $2 \mathrm{mmol}$ ), 4-iodophenyl ether (117 mg, $0.5 \mathrm{mmol}), \mathrm{PdCl}_{2}$ (9 mg, $0.05 \mathrm{mmol}$ ), tri-p-tolylphosphine $(30 \mathrm{mg}, 0.10 \mathrm{mmol})$ and potassium carbonate $(69 \mathrm{mg}, 0.5 \mathrm{mmol})$. The tube was evacuated and backfilled with argon (this procedure was repeated three times). $\mathrm{D}_{2} \mathrm{O}(0.25 \mathrm{ml})$ and toluene $(0.25 \mathrm{ml})$ were added by syringe under a counter flow of argon at room temperature. The tube was then sealed and the mixture was allowed to stir at the appointed temperature $\left(100^{\circ} \mathrm{C}\right)$ for 12 hours. Upon completion of the reaction, the mixture was cooled to room temperature and diluted with ethyl acetate. The solution was directly analyzed by GC-MS, which showed no cross coupling product and deuterated 1,4-dibromobenzene formed. 

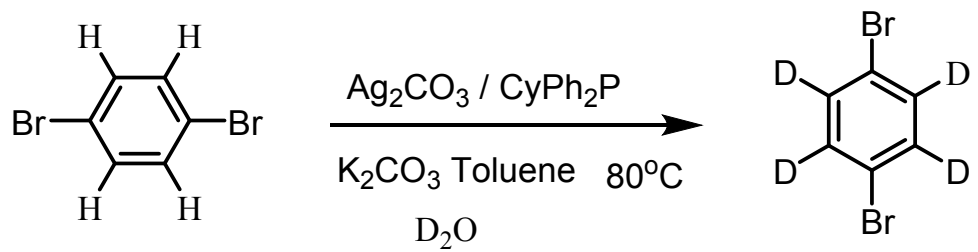

Procedure for preparation of deuterated 1,4-dibromobenzene : 1,4-dibromobenzene (2.36 g, 10 mmol) was added to a vigorously stirred solution of silver carbonate (552 $\mathrm{mg}, 2 \mathrm{mmol})$, cyclohexyldiphenylphosphine $(1.34 \mathrm{~g}, 5 \mathrm{mmol})$, potassium carbonate $(1.38 \mathrm{~g}, 10 \mathrm{mmol})$ and $\mathrm{D}_{2} \mathrm{O}(4 \mathrm{~g}$, $200 \mathrm{mmol})$ in toluene $(2 \mathrm{ml})$ in the air. The reaction mixture was stirred at $100{ }^{\circ} \mathrm{C}$ in oil bath for $12 \mathrm{~h}$. Then the reaction was quenched with saturated $\mathrm{NH}_{4} \mathrm{Cl}$ solution. The product was extracted with dichloromethane $(3 \times 20 \mathrm{ml})$. The combined organic layer was washed with brine and dried over $\mathrm{Na}_{2} \mathrm{SO}_{4}$. After removal of solvents under vacuum, the crude product was purified via column chromatography. The product was isolated as yellow oil with $85 \%$ yield $(2.0 \mathrm{~g})$. The level of deuterium incorporation was estimated from ${ }^{1} \mathrm{H}$ NMR as $97 \%$ (total: $0.97 * 4=3.88 \mathrm{D}$ ).

Parallel experiment for KIE study with non-deuterated compound as starting material: In a $25 \mathrm{ml}$ round bottom flask was charged with 1,4-dibromobenzene $(1.8 \mathrm{~g}, 8 \mathrm{mmol})$, 4-iodophenyl ether (428 $\mathrm{mg}$, $2 \mathrm{mmol}$ ), $\mathrm{PdCl}_{2}$ (35.4 mg, $0.2 \mathrm{~mol}$ ), Silver carbonate $(1.1 \mathrm{~g}, 4 \mathrm{mmol})$, tri-p-tolylphosphine (122 mg, 0.4 $\mathrm{mol}$ ) and potassium carbonate $(276 \mathrm{mg}, 2 \mathrm{mmol})$. The round bottom flask was evacuated and backfilled with argon (this procedure was repeated three times). Water $(1 \mathrm{ml})$ and toluene $(1 \mathrm{ml})$ were added by syringe under a counter flow of argon at room temperature. The round bottom flask was then sealed and the mixture was allowed to stir at the appointed temperature $\left(100^{\circ} \mathrm{C}\right)$. The aliquot was taken in 1 hour, 2 hours and 3 hours for analysis. GC-Ms analysis showed the yield of the cross coupling product is $16 \%$ (1 h), $27 \%(2 \mathrm{~h})$ and $44 \%(3 \mathrm{~h})$.

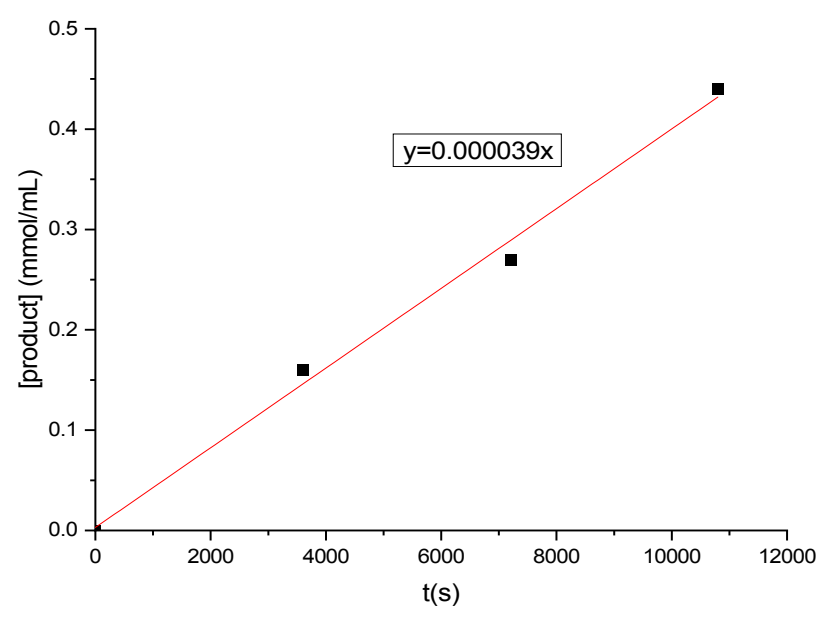

Parallel experiment for KIE study with deuterated compound as starting material: In a $25 \mathrm{ml}$ round bottom flask was charged with 1,4-dibromobenzene- $d 4$ (1.8 g, $8 \mathrm{mmol})$, 4-iodophenyl ether (428 $\mathrm{mg}, 2$ $\mathrm{mmol}), \mathrm{PdCl}_{2}$ (35.4 mg, $\left.0.2 \mathrm{~mol}\right)$, Silver carbonate (1.1 g, $\left.4 \mathrm{mmol}\right)$, tri-p-tolylphosphine (122 mg, $\left.0.4 \mathrm{~mol}\right)$ and potassium carbonate $(276 \mathrm{mg}, 2 \mathrm{mmol})$. The round bottom flask was evacuated and backfilled with argon (this procedure was repeated three times). Water $(1 \mathrm{ml})$ and toluene $(1 \mathrm{ml})$ were added by syringe under a counter flow of argon at room temperature. The round bottom flask was then sealed and the mixture was allowed to stir at the appointed temperature $\left(100^{\circ} \mathrm{C}\right)$. The aliquot was taken in 1 hour, 2 hours and 3 hours for analysis. GC-Ms analysis showed the yield of the cross coupling product is $3 \%$ ( 1 
h), $8 \%(2 \mathrm{~h})$ and $13 \%(3 \mathrm{~h})$.

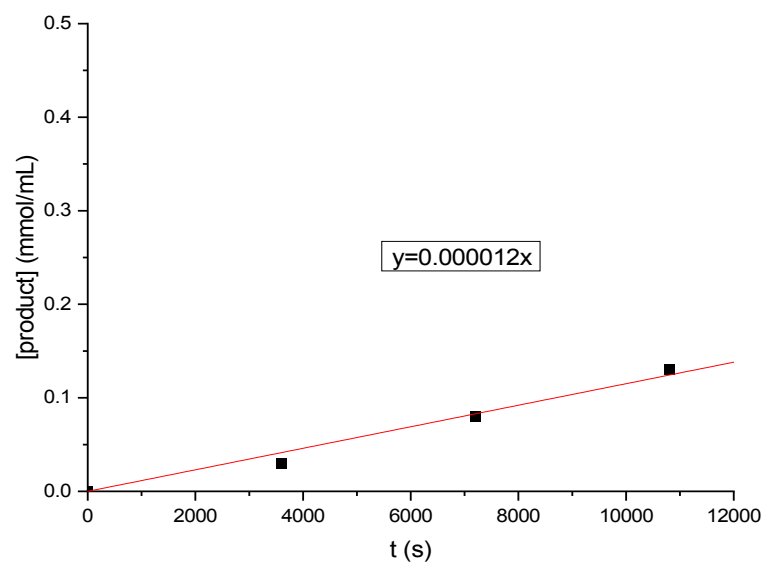

Based on these experiments, we calculated

$k_{\mathrm{H}}=0.000039 \mathrm{mmol} \cdot \mathrm{ml}^{-1} \cdot \mathrm{s}^{-1} ; k_{\mathrm{D}}=0.000012 \mathrm{mmol} \cdot \mathrm{ml}^{-1} \cdot \mathrm{s}^{-1}$

$k_{\mathrm{H}} / k_{\mathrm{D}}=3.3$

Proton and Carbon NMR Spectra: 

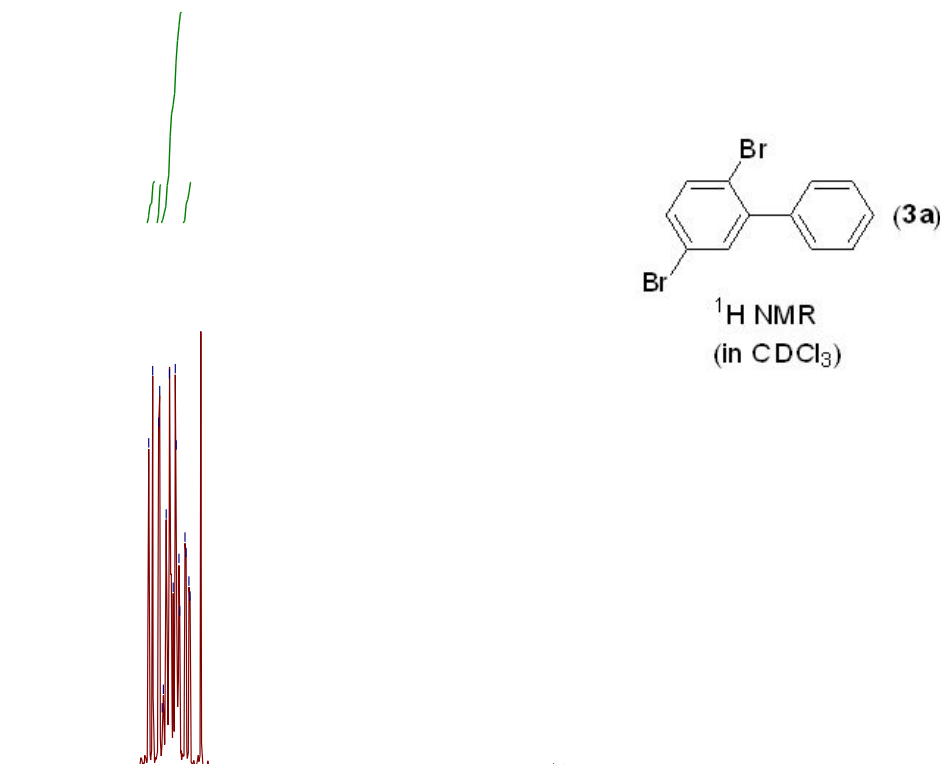

(in $\mathrm{CDCl}_{3}$ )

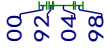

- 0 เ
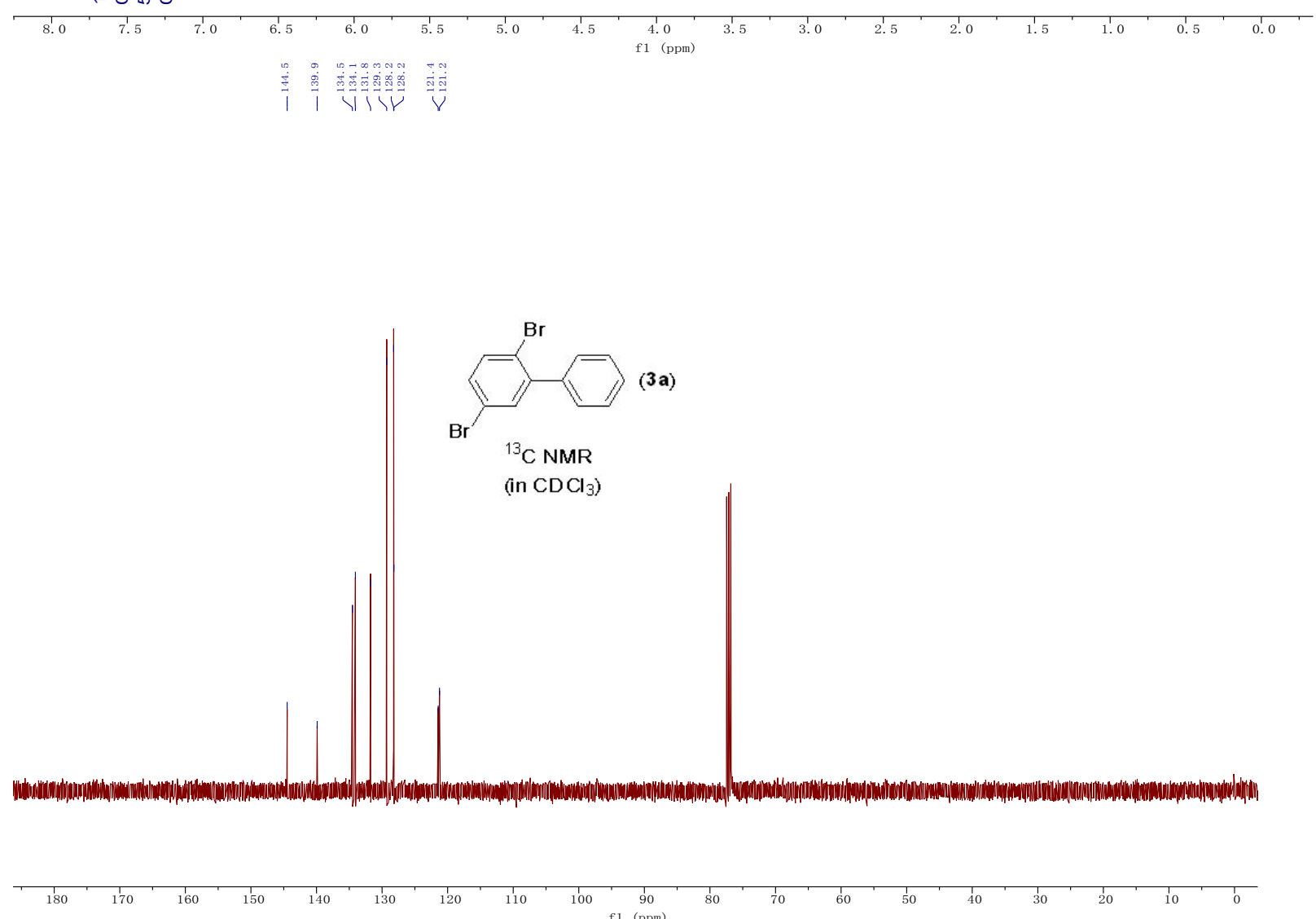

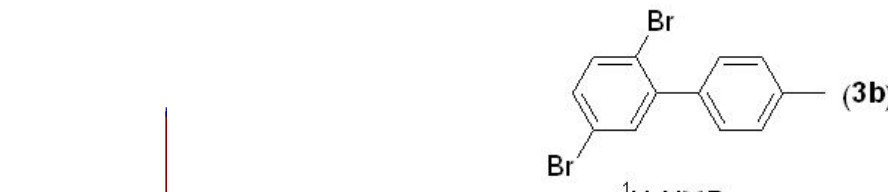

${ }^{1} \mathrm{H}$ NMR

(in $\mathrm{CDCl}_{3}$ )
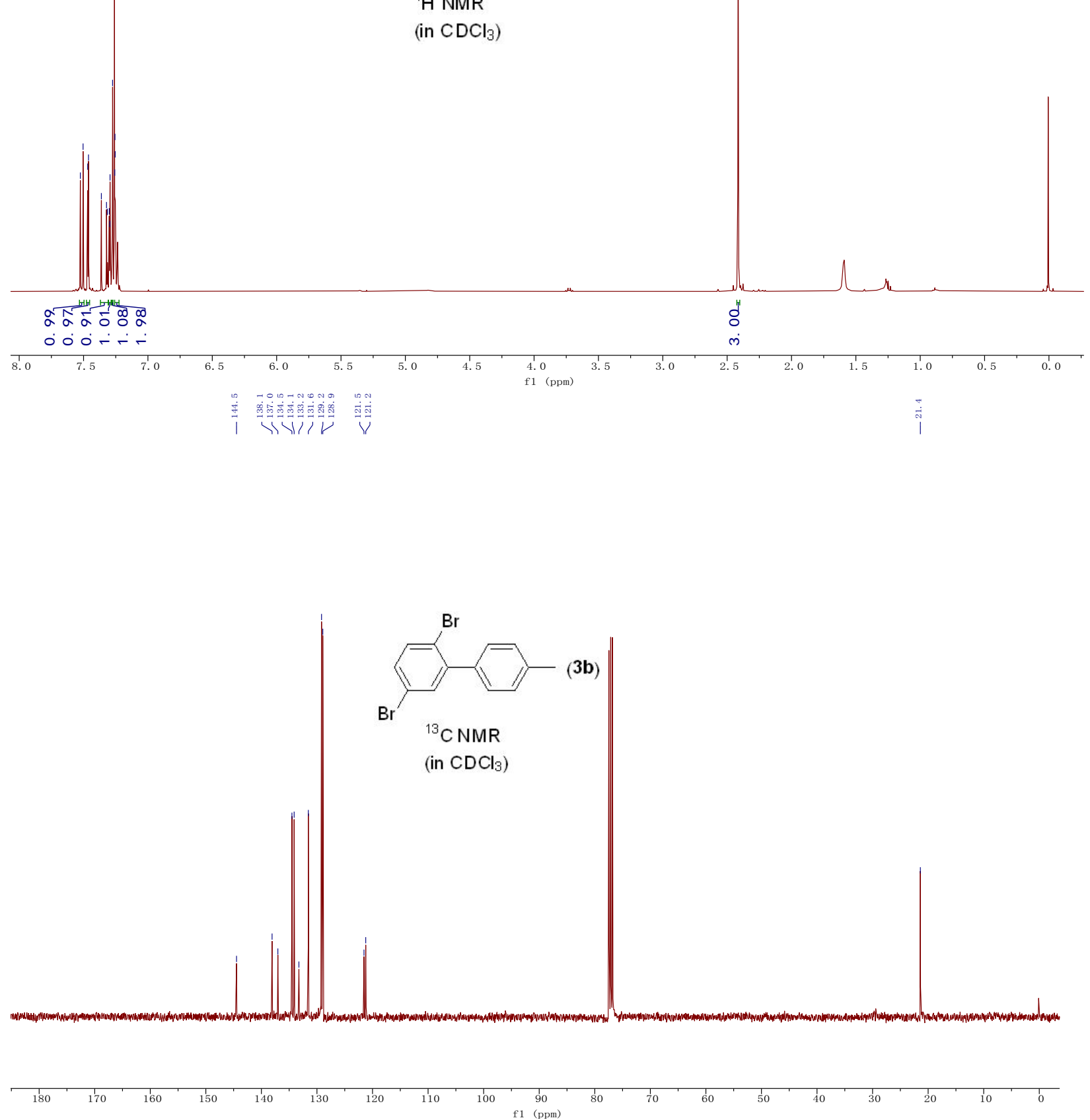

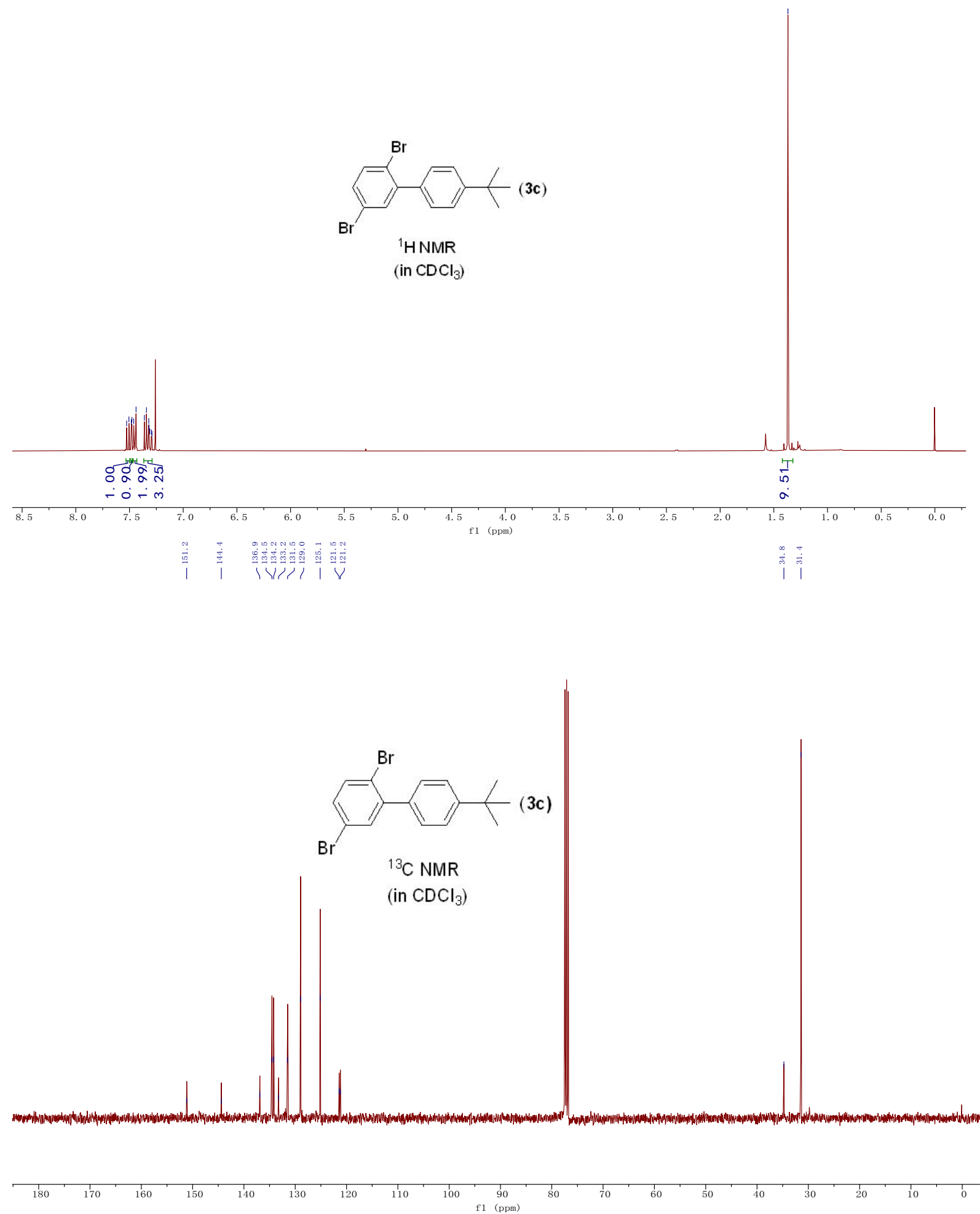

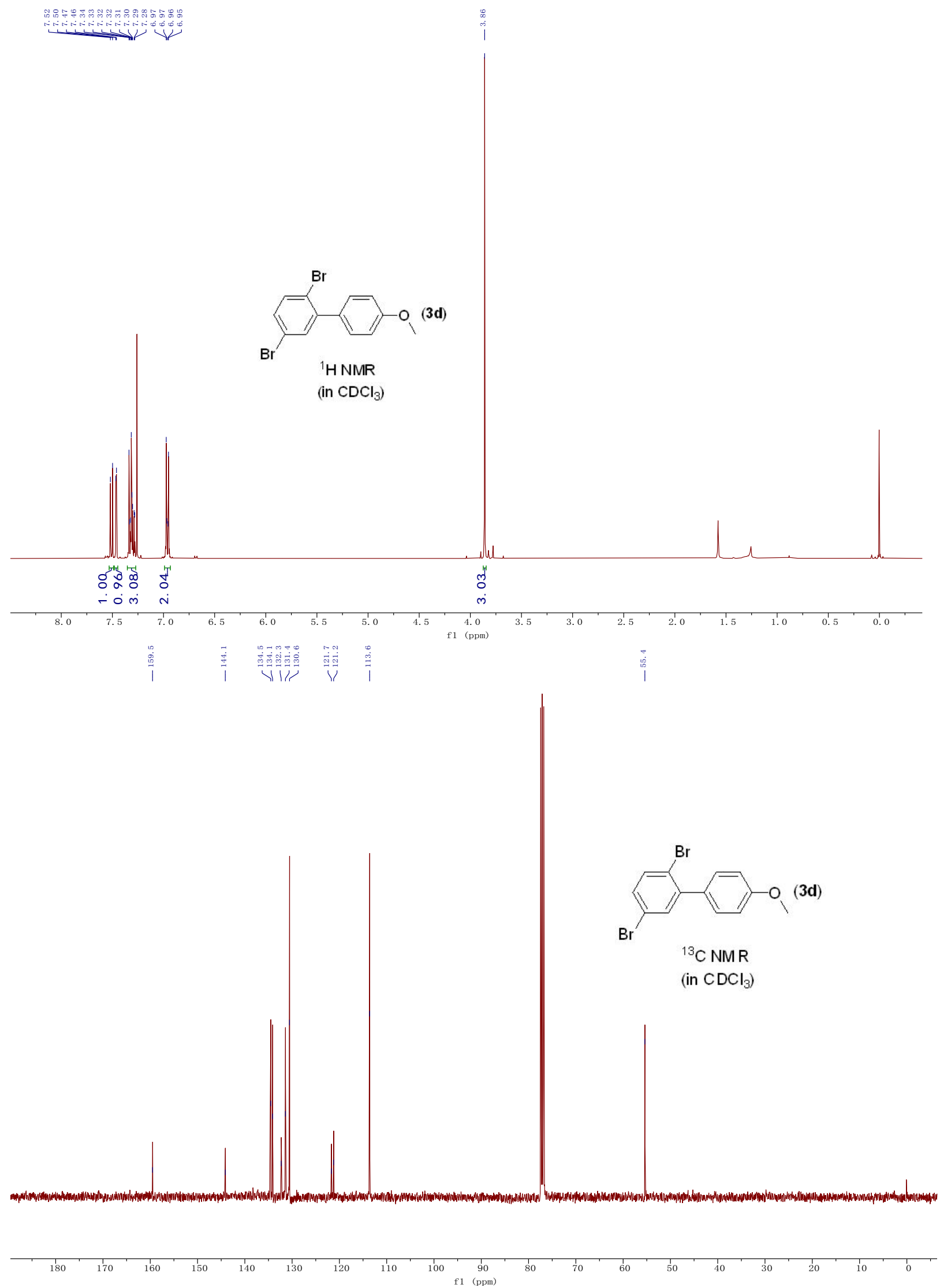


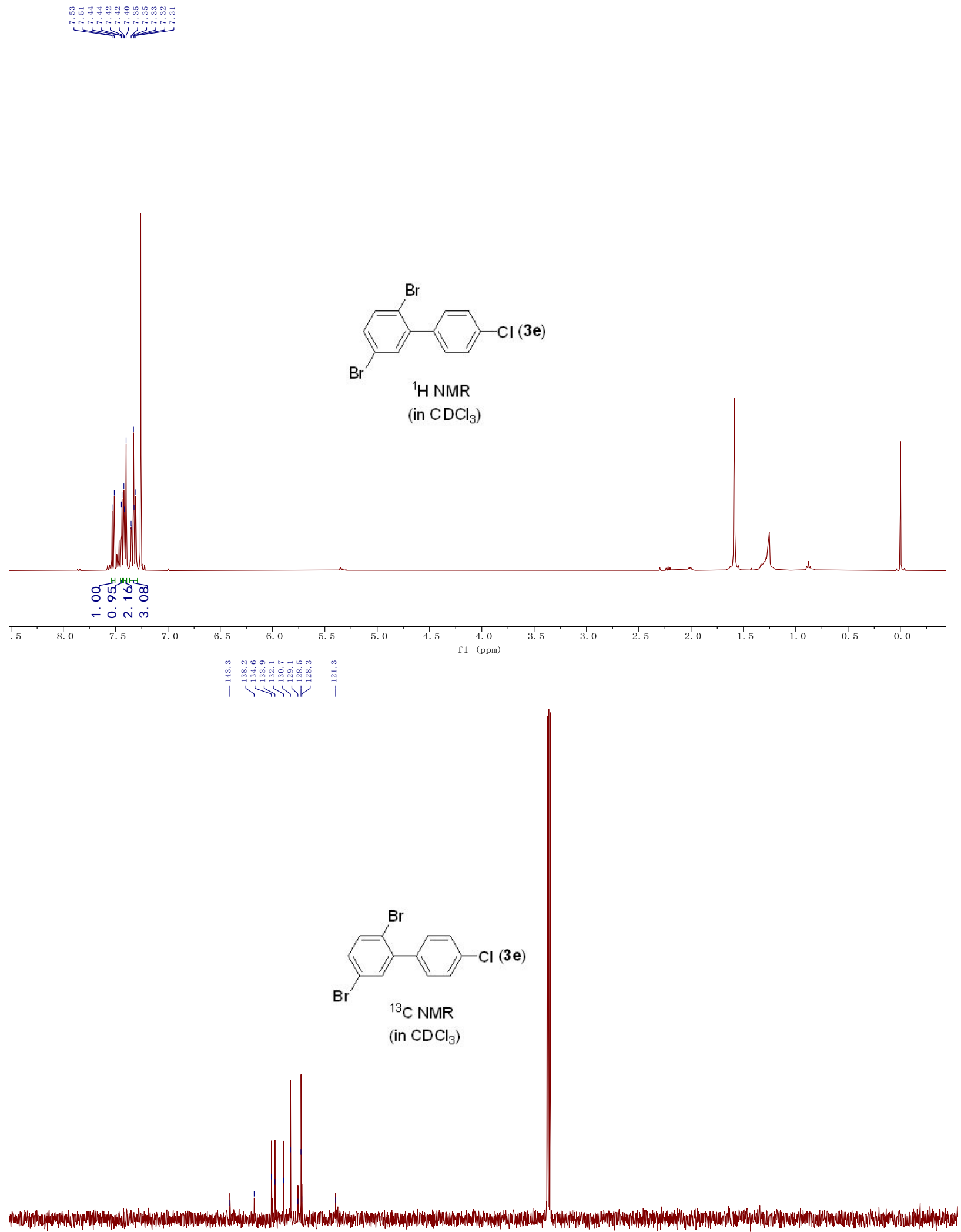

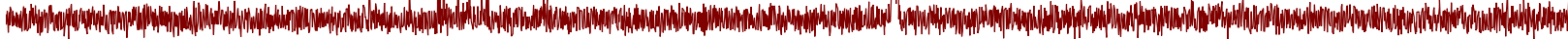

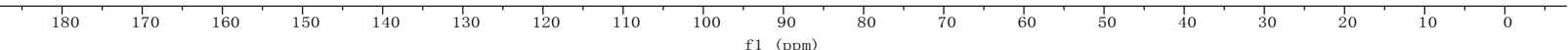



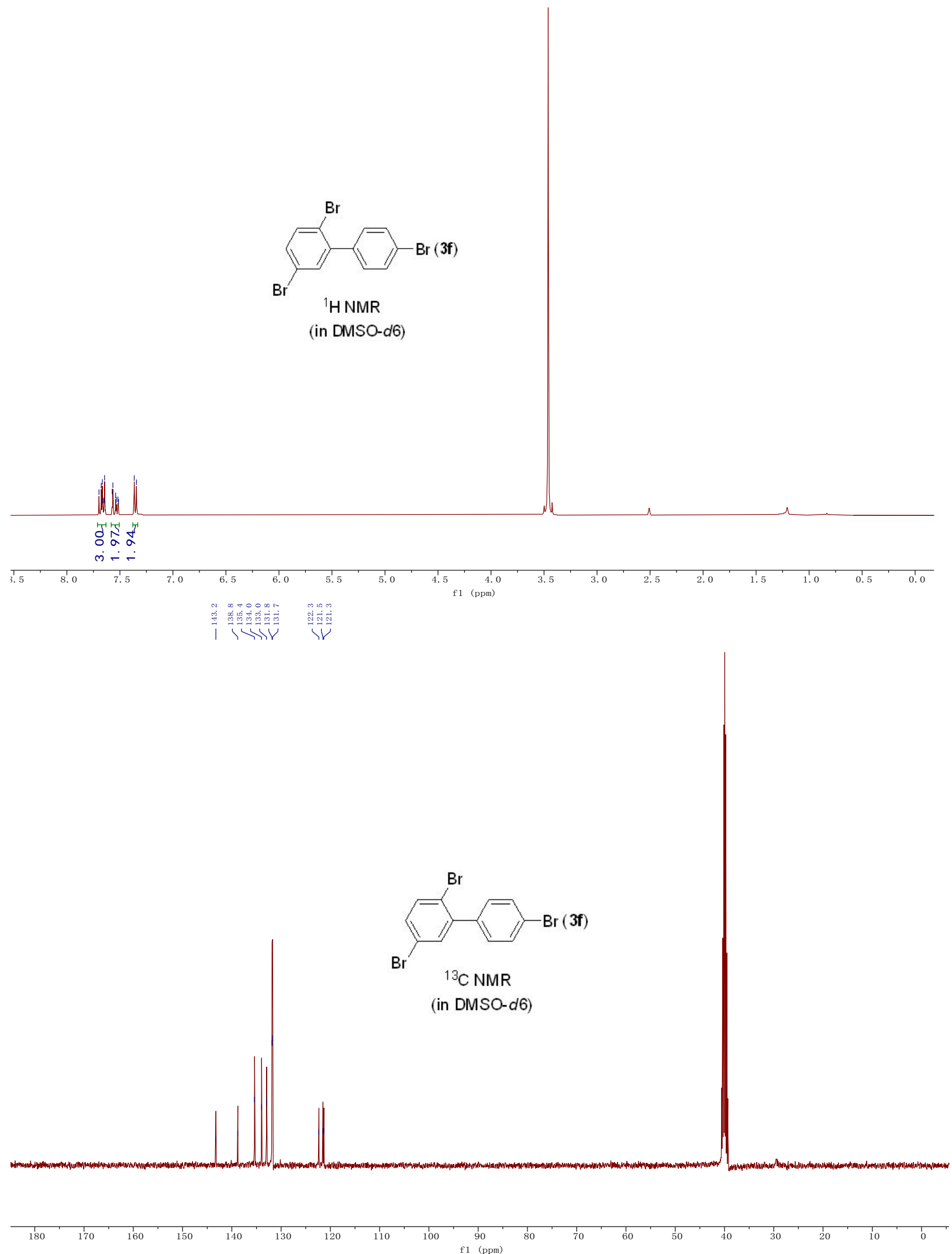

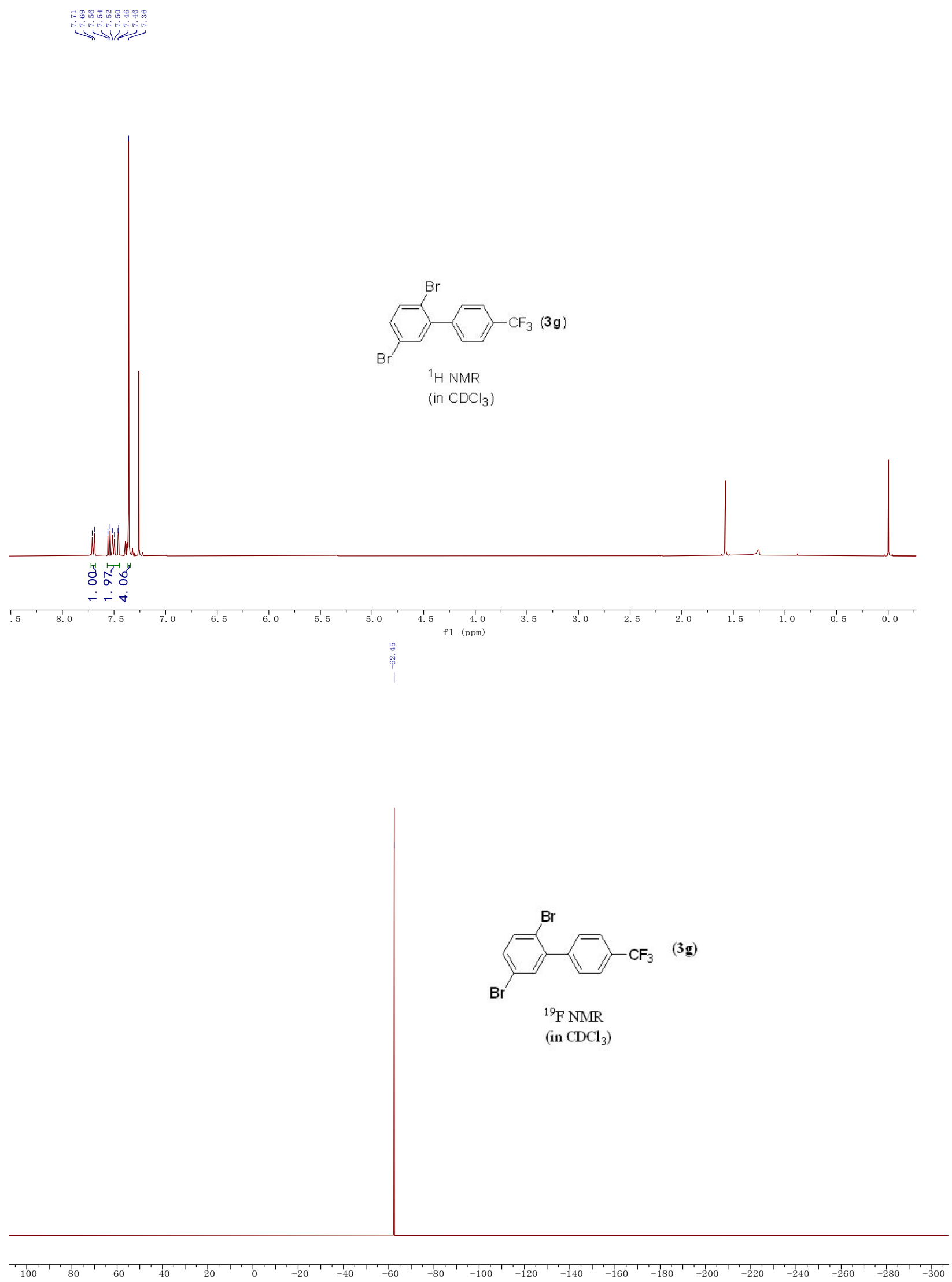


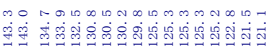

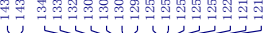

$V$ in
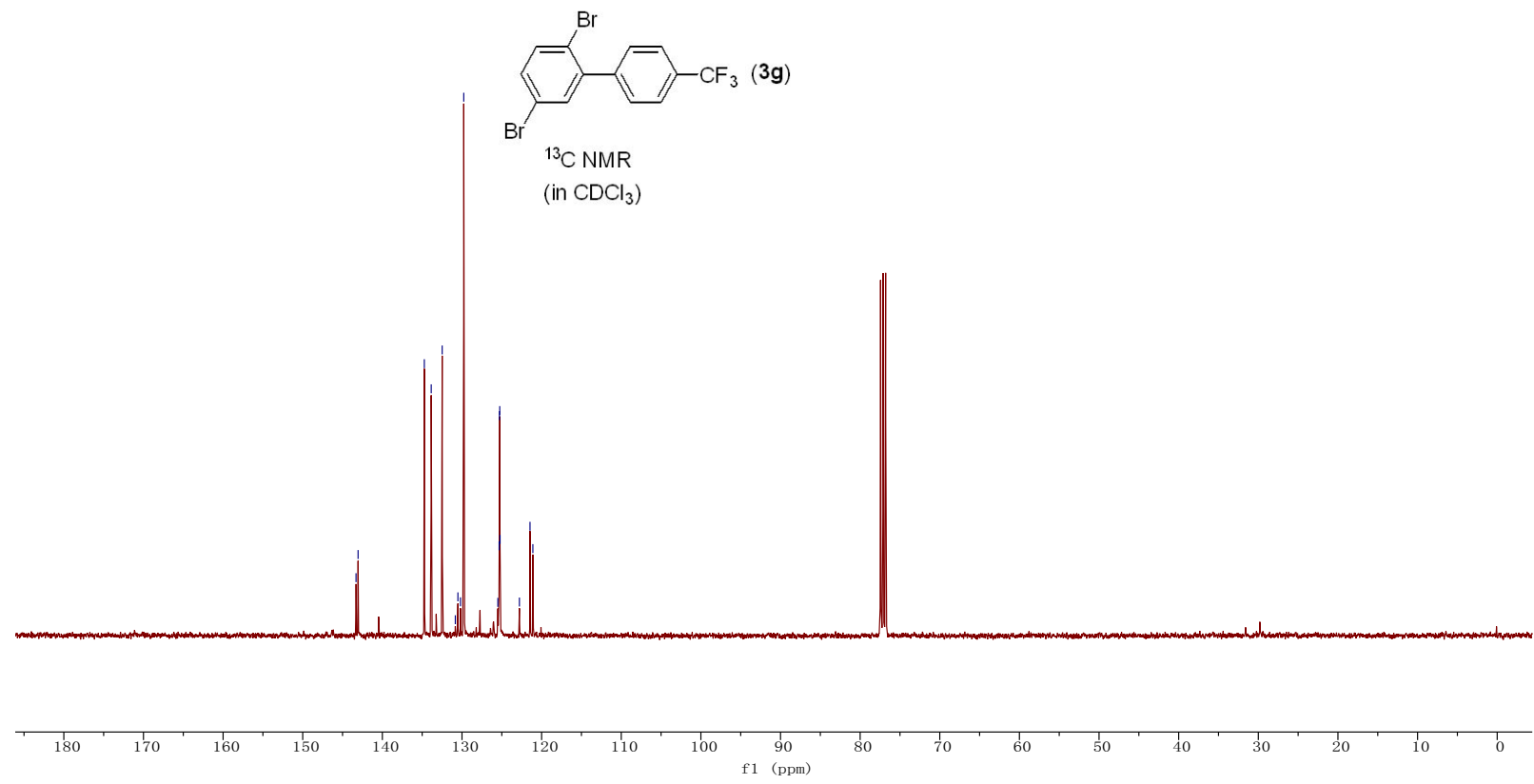

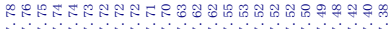

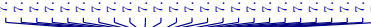

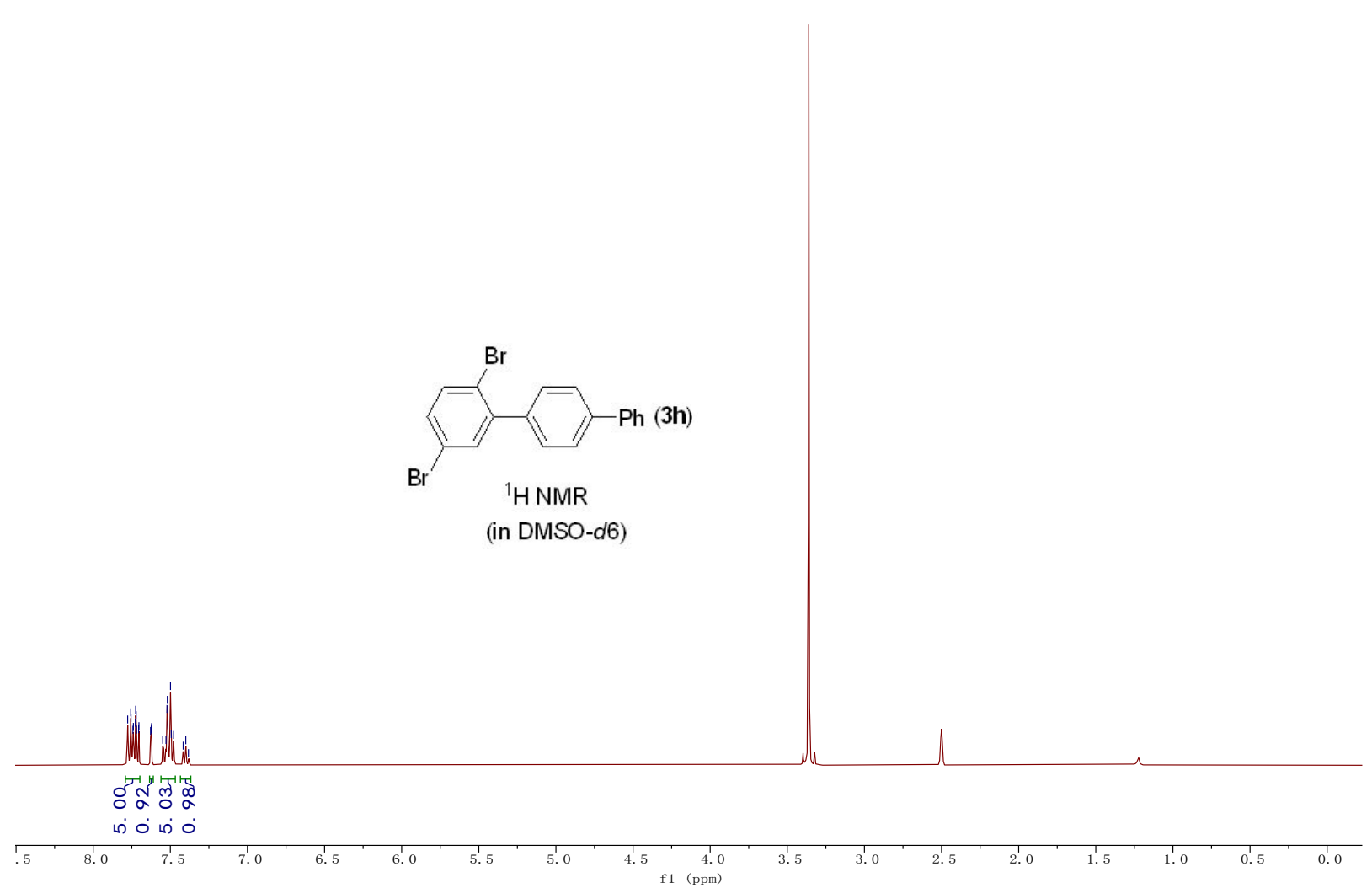



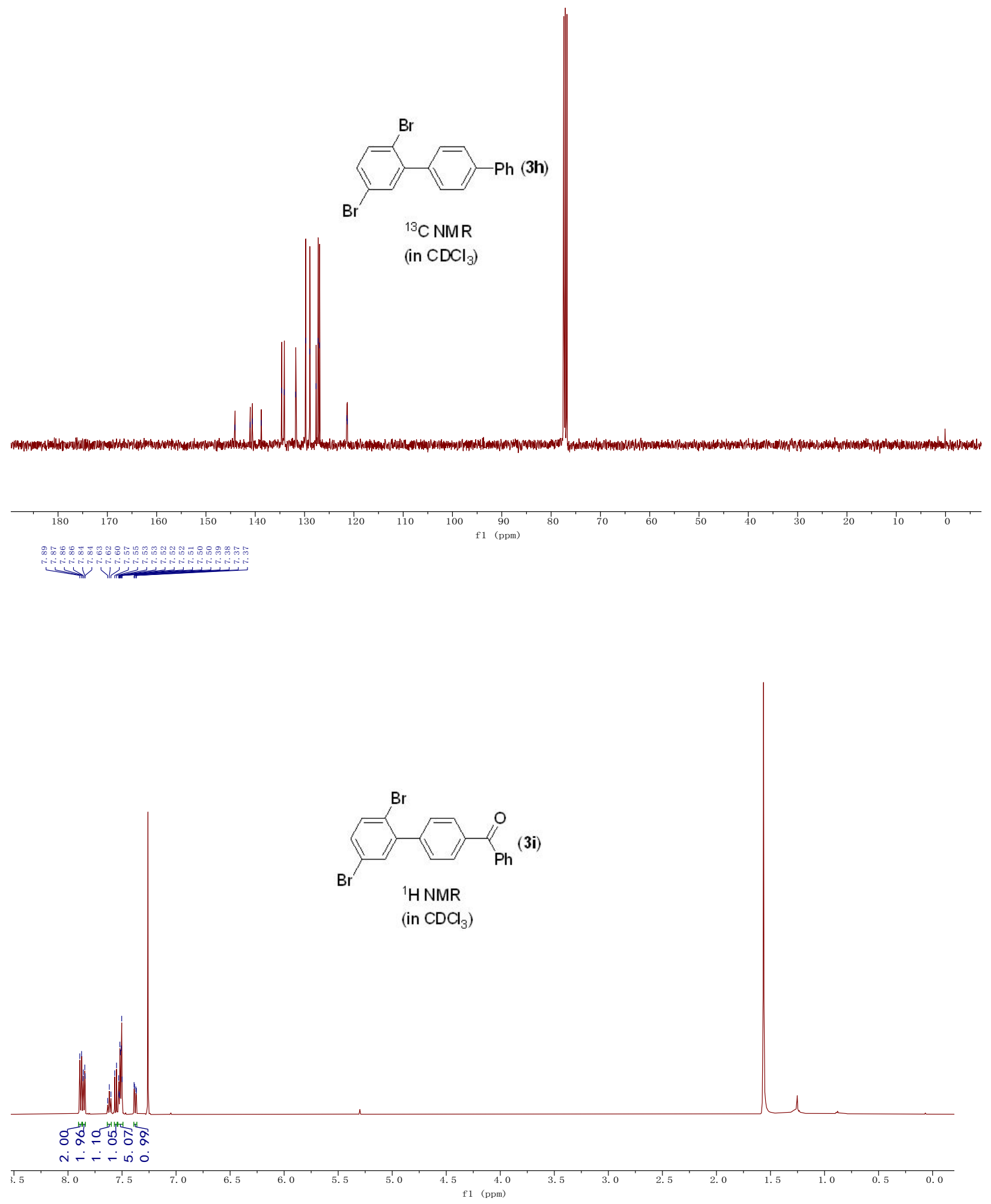

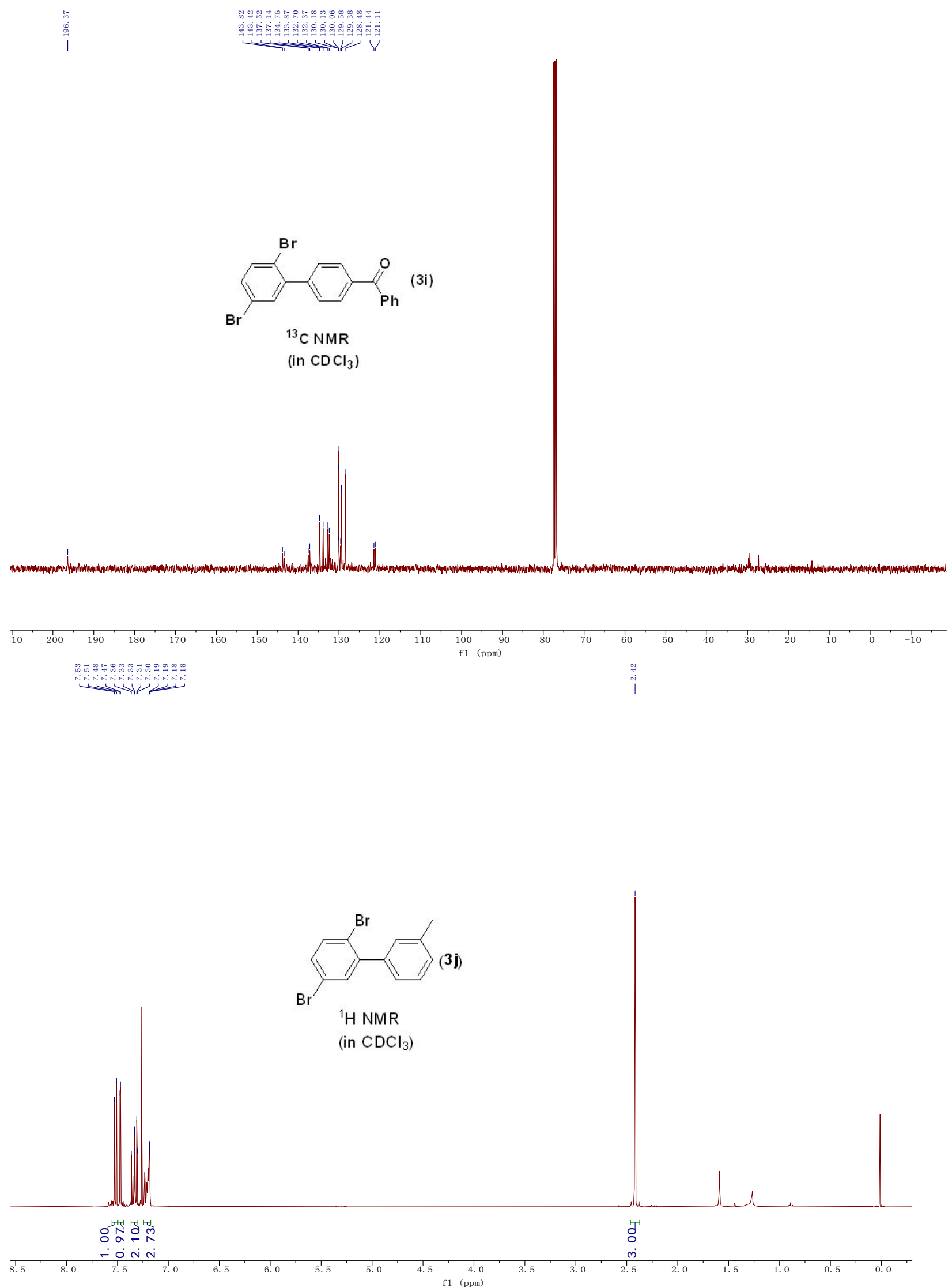

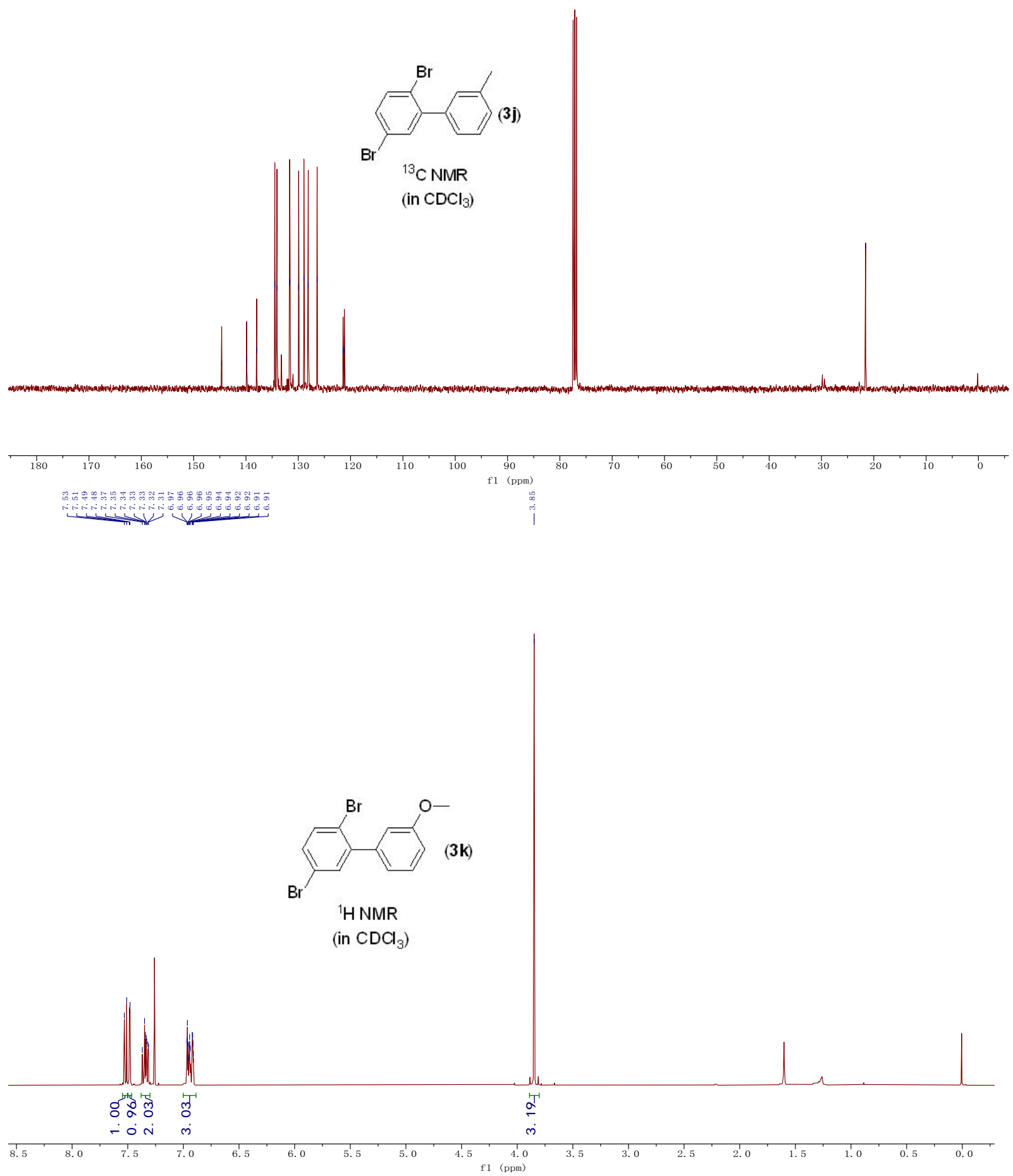

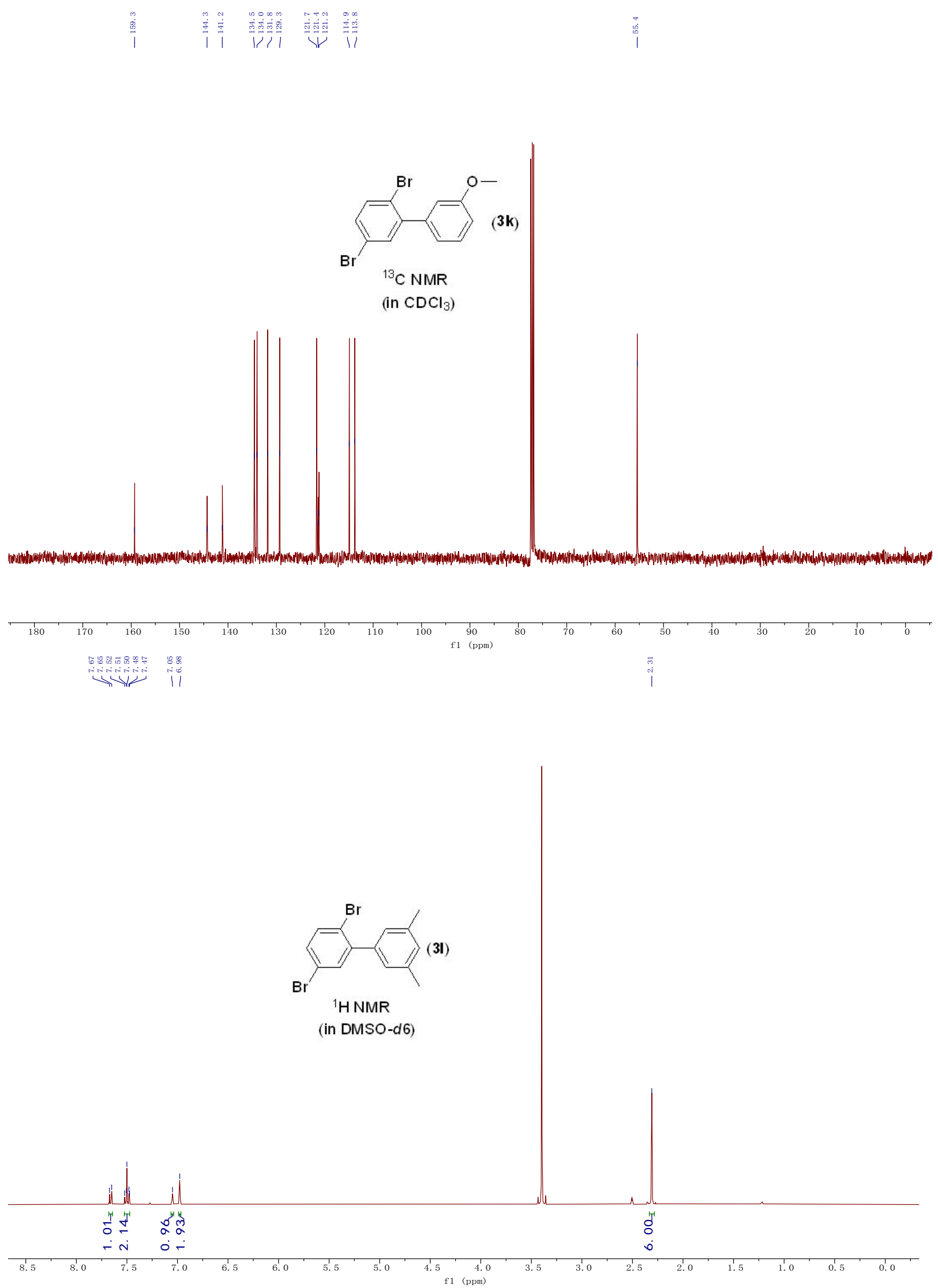


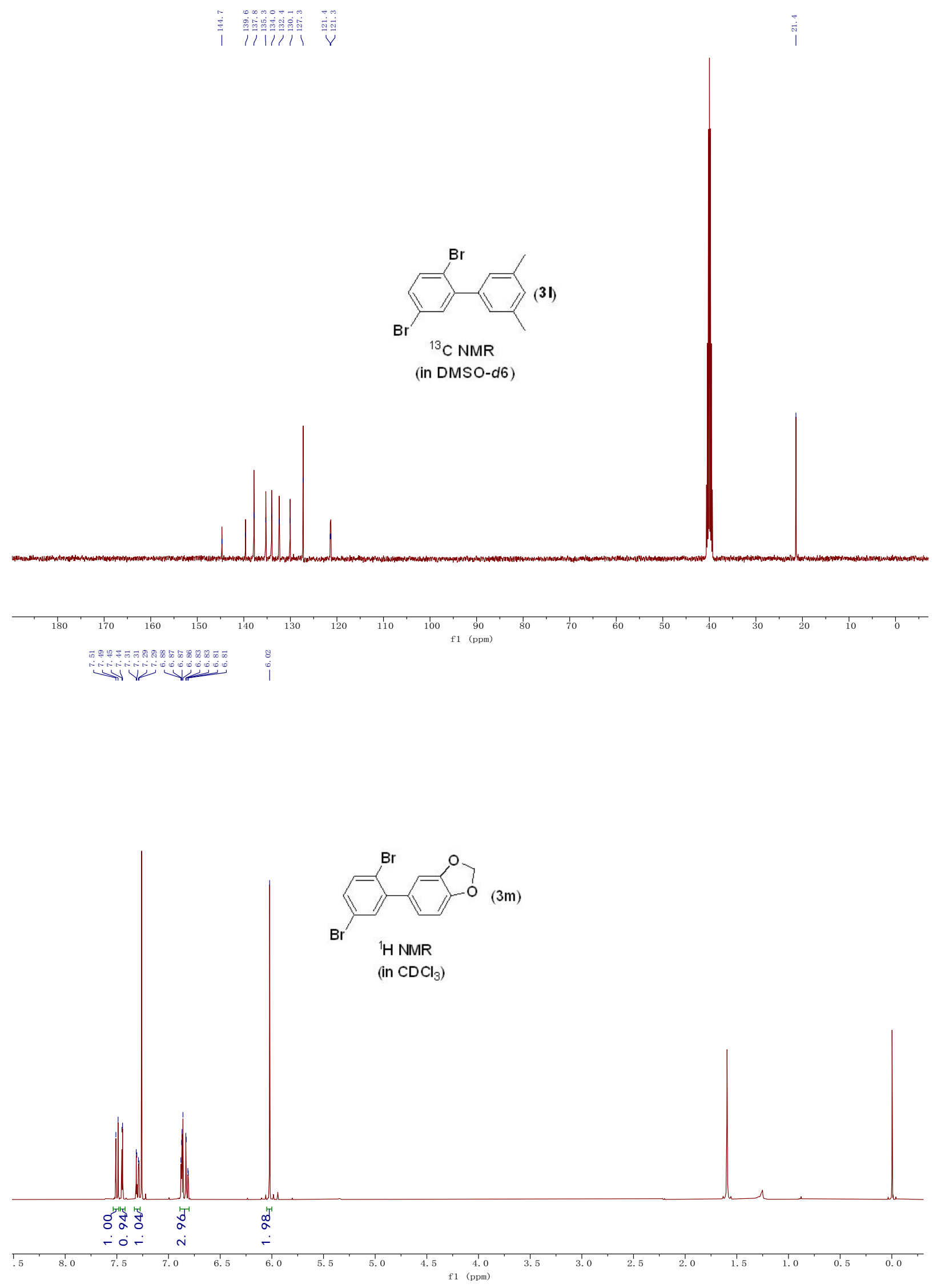




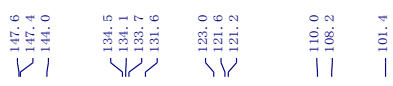
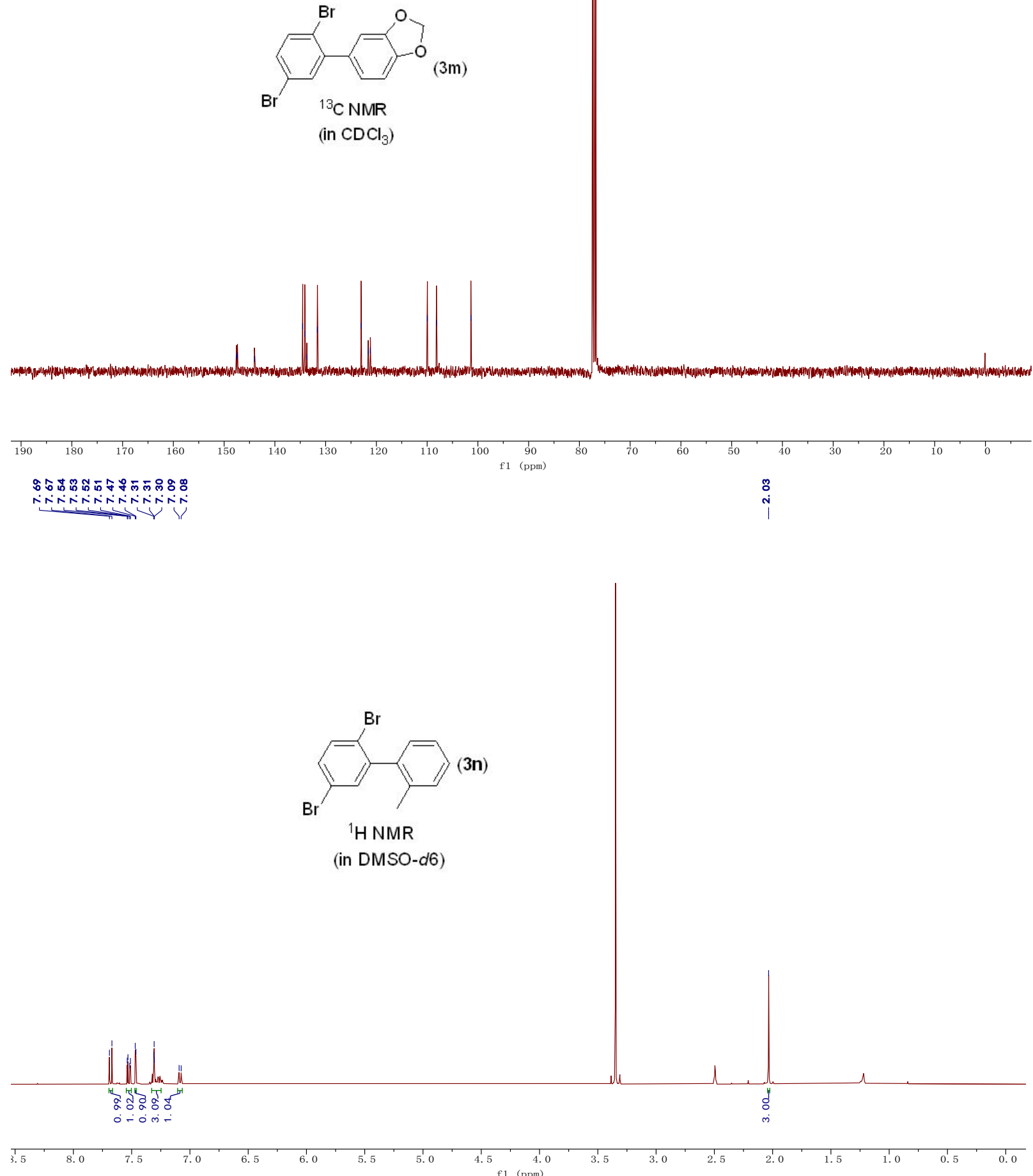

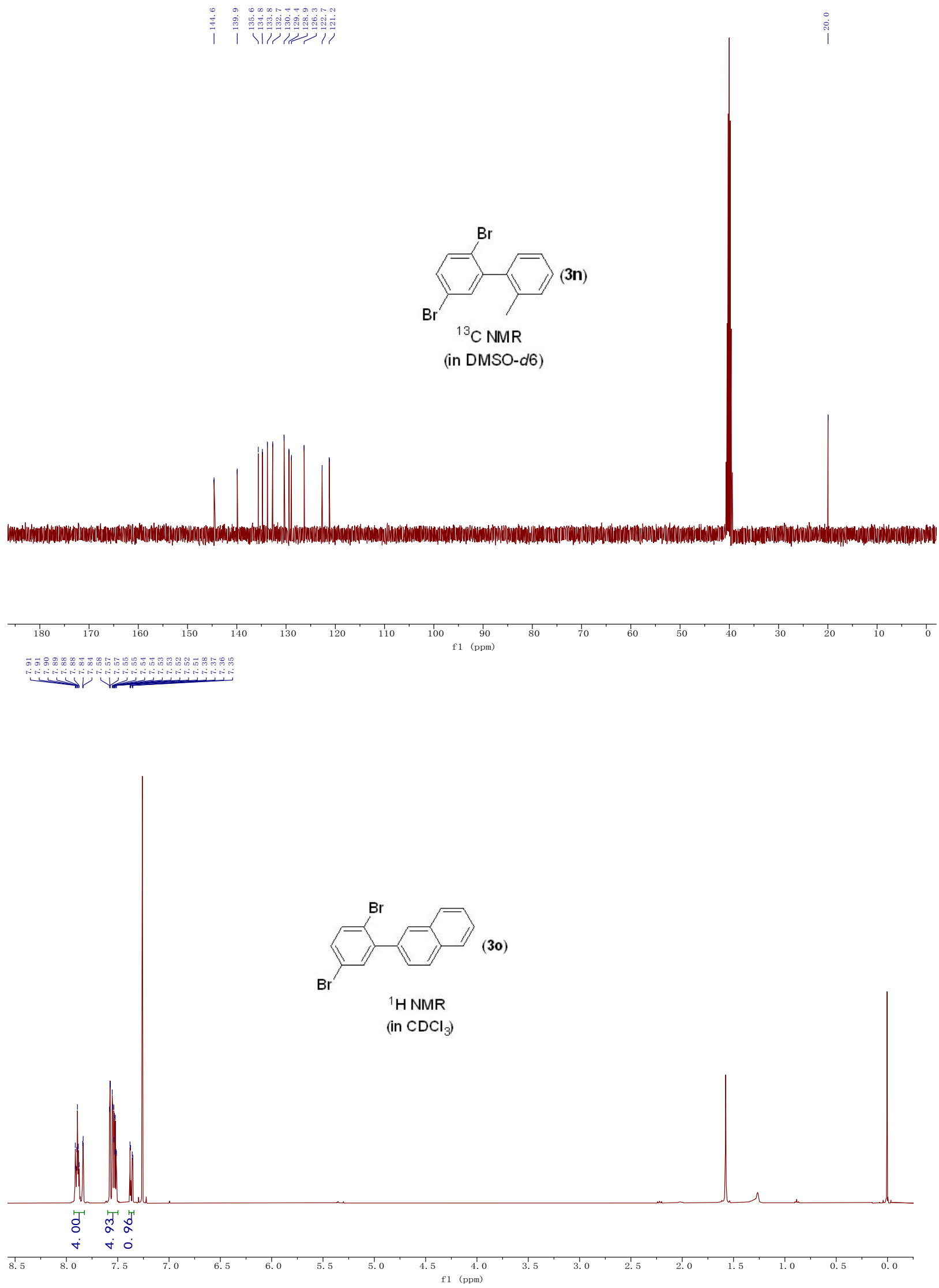

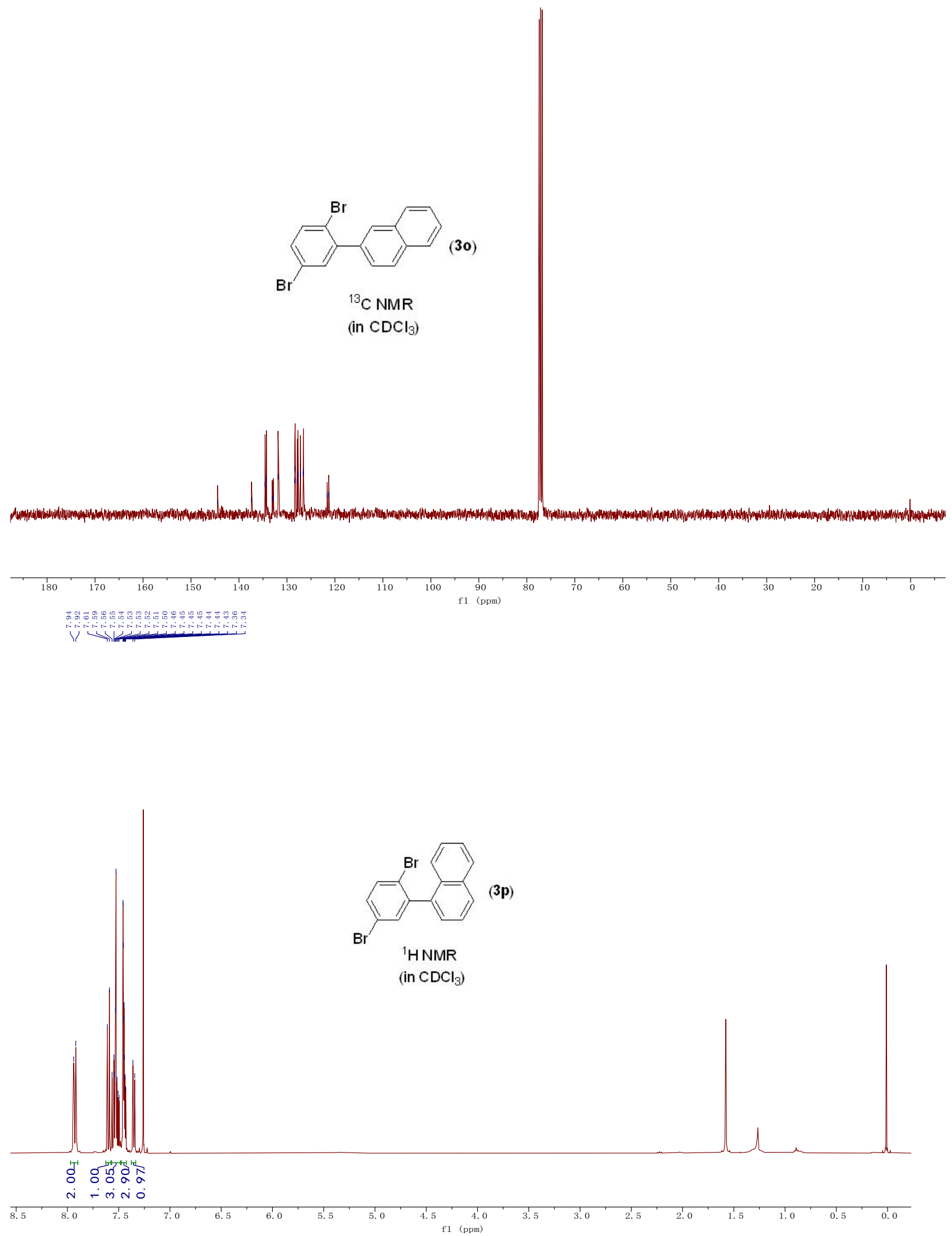

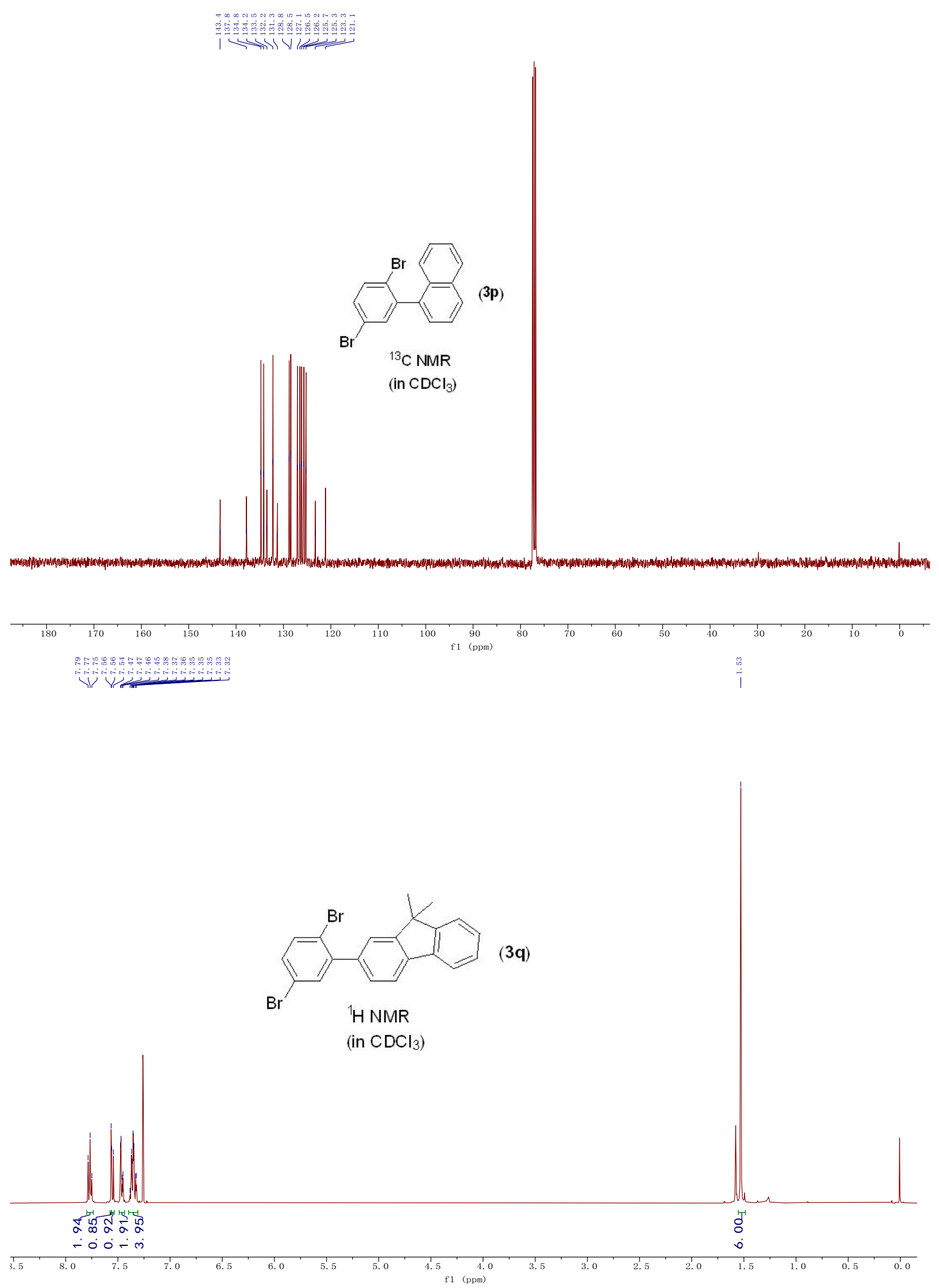


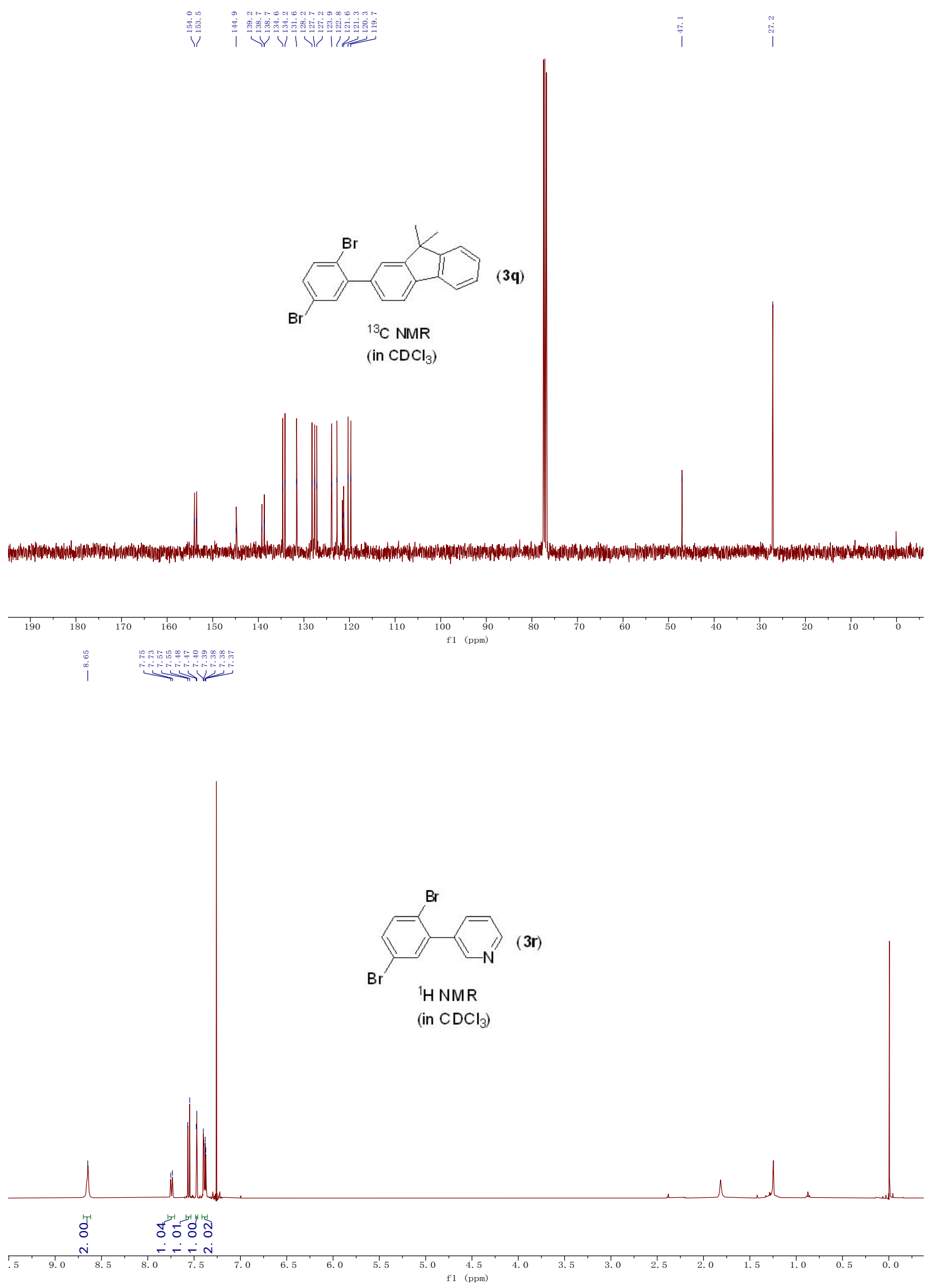




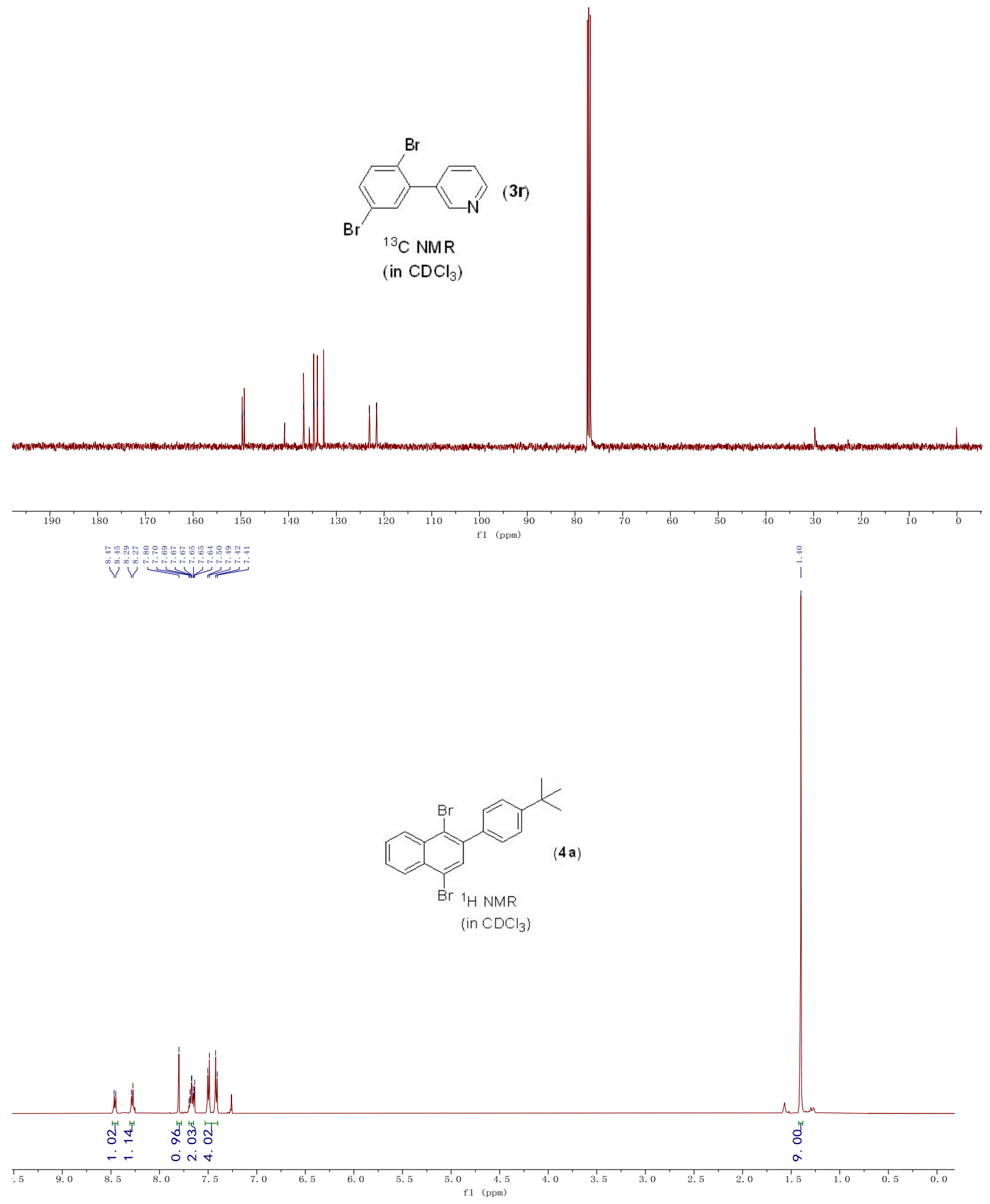



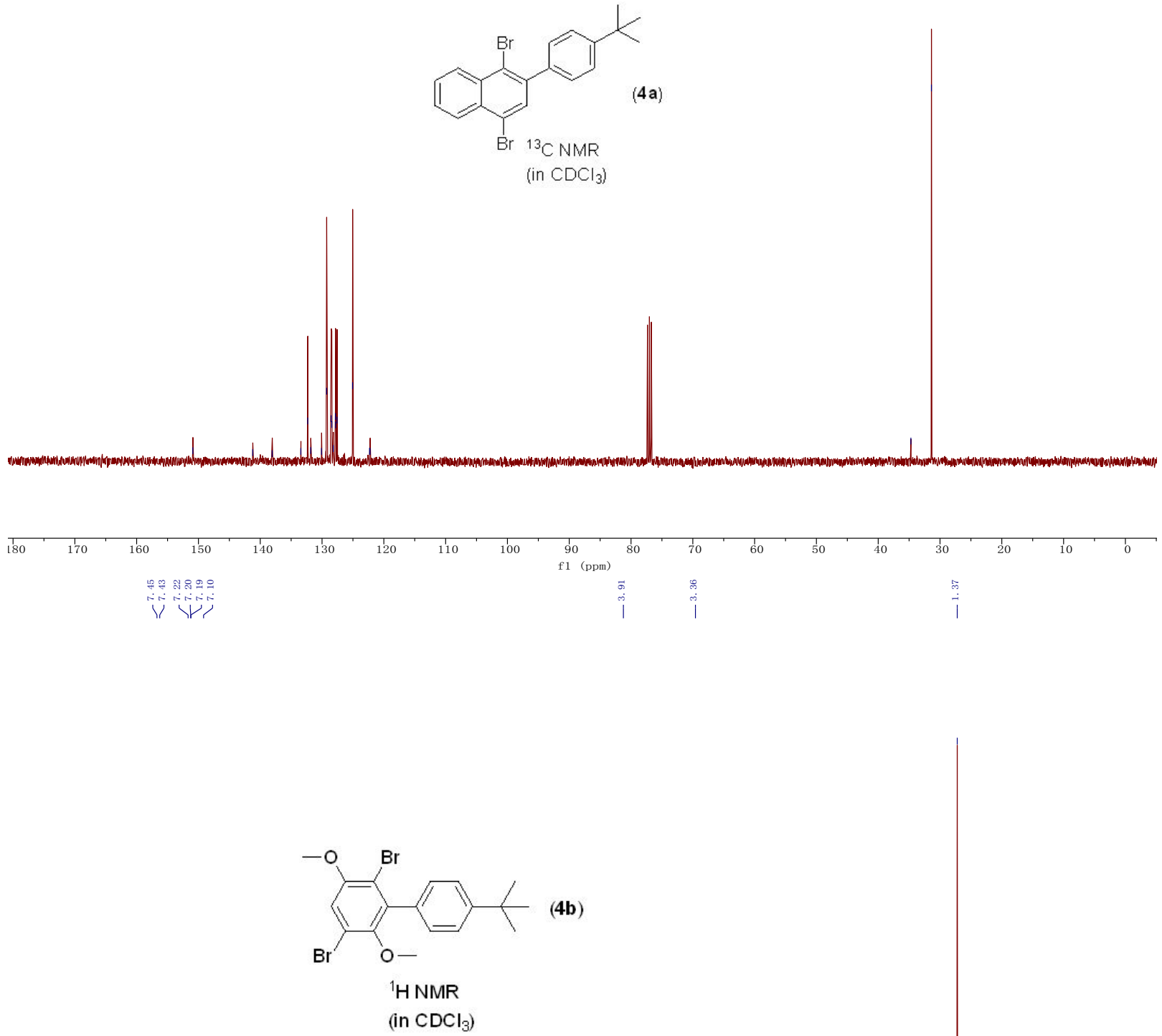

4b)

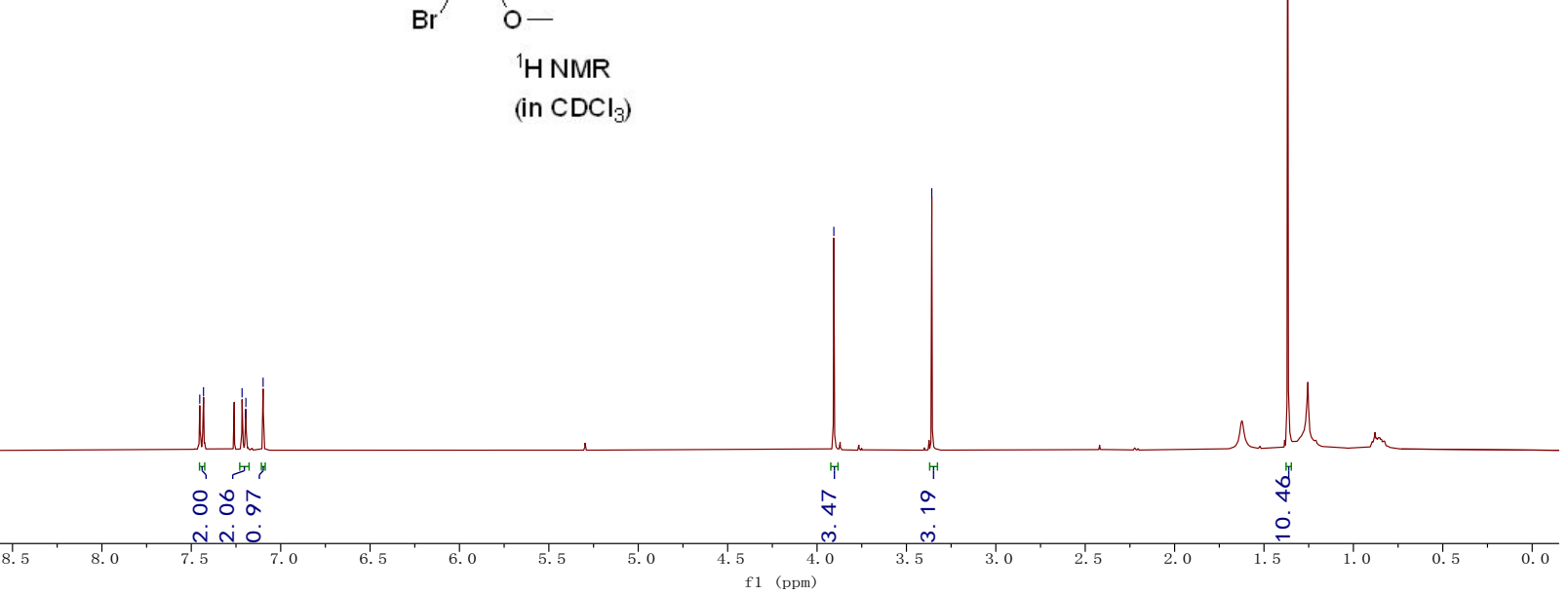



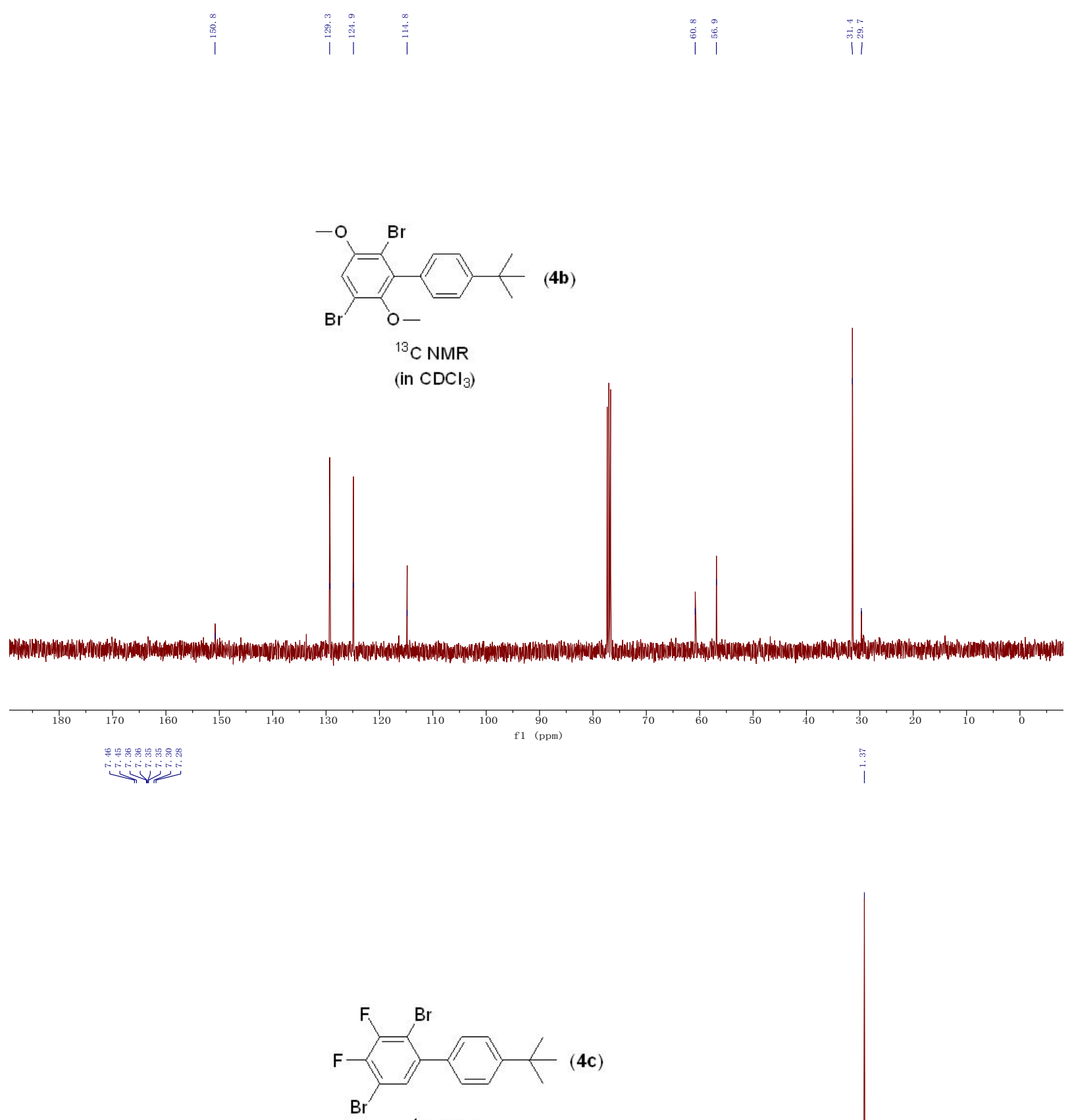

${ }^{1} \mathrm{H}$ NMR

(in $\mathrm{CDCl}_{3}$ )

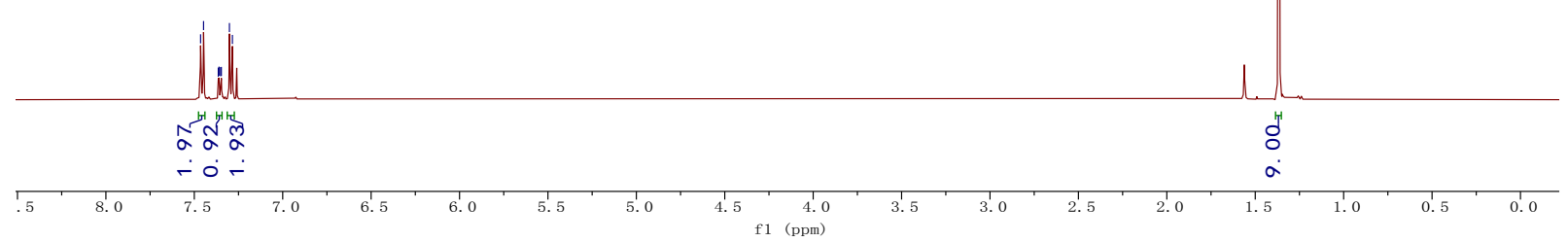




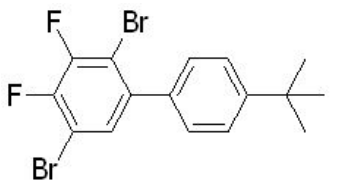

${ }^{19} \mathrm{FNMR}$

(in $\mathrm{CDCl}_{3}$ )
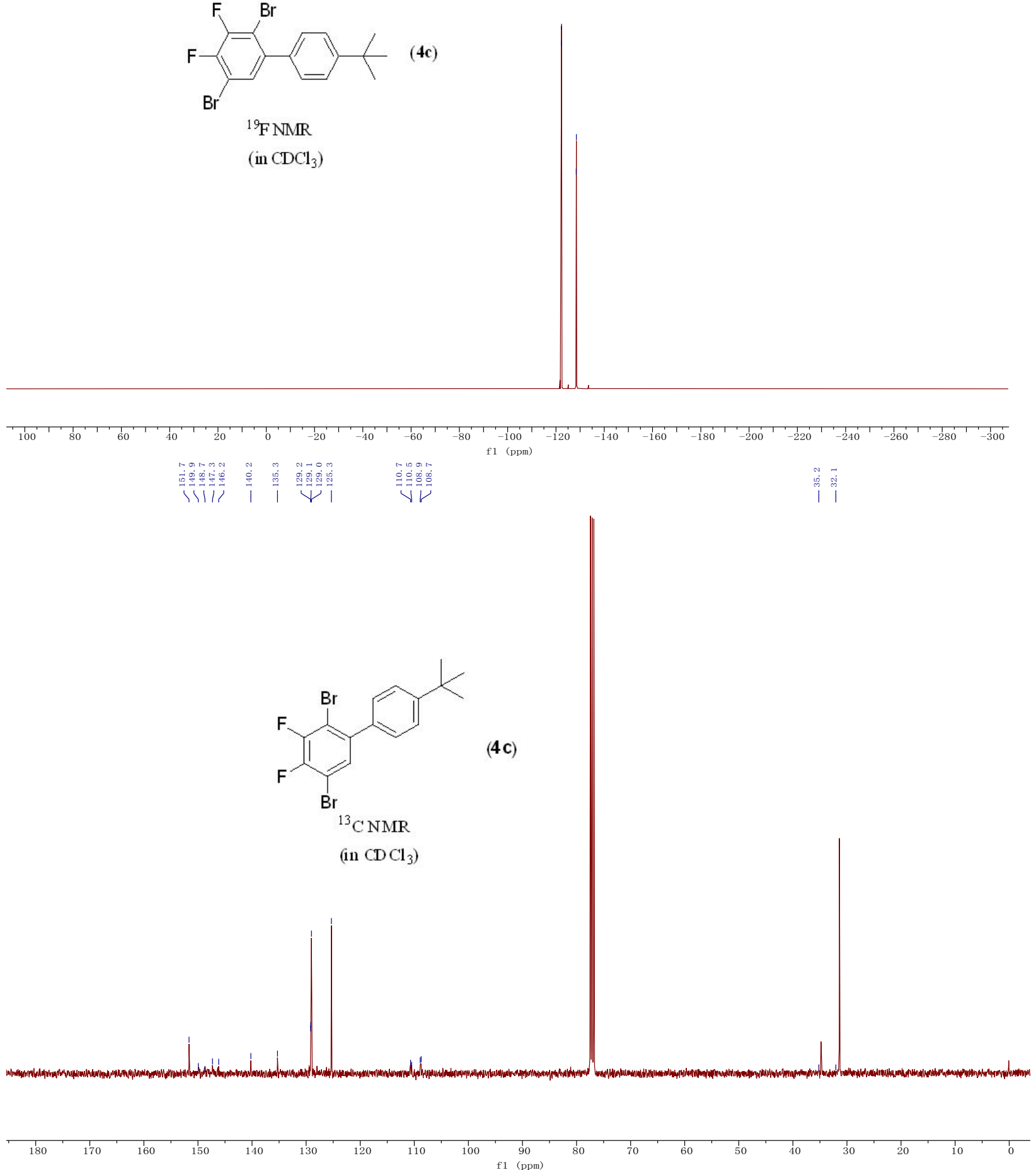

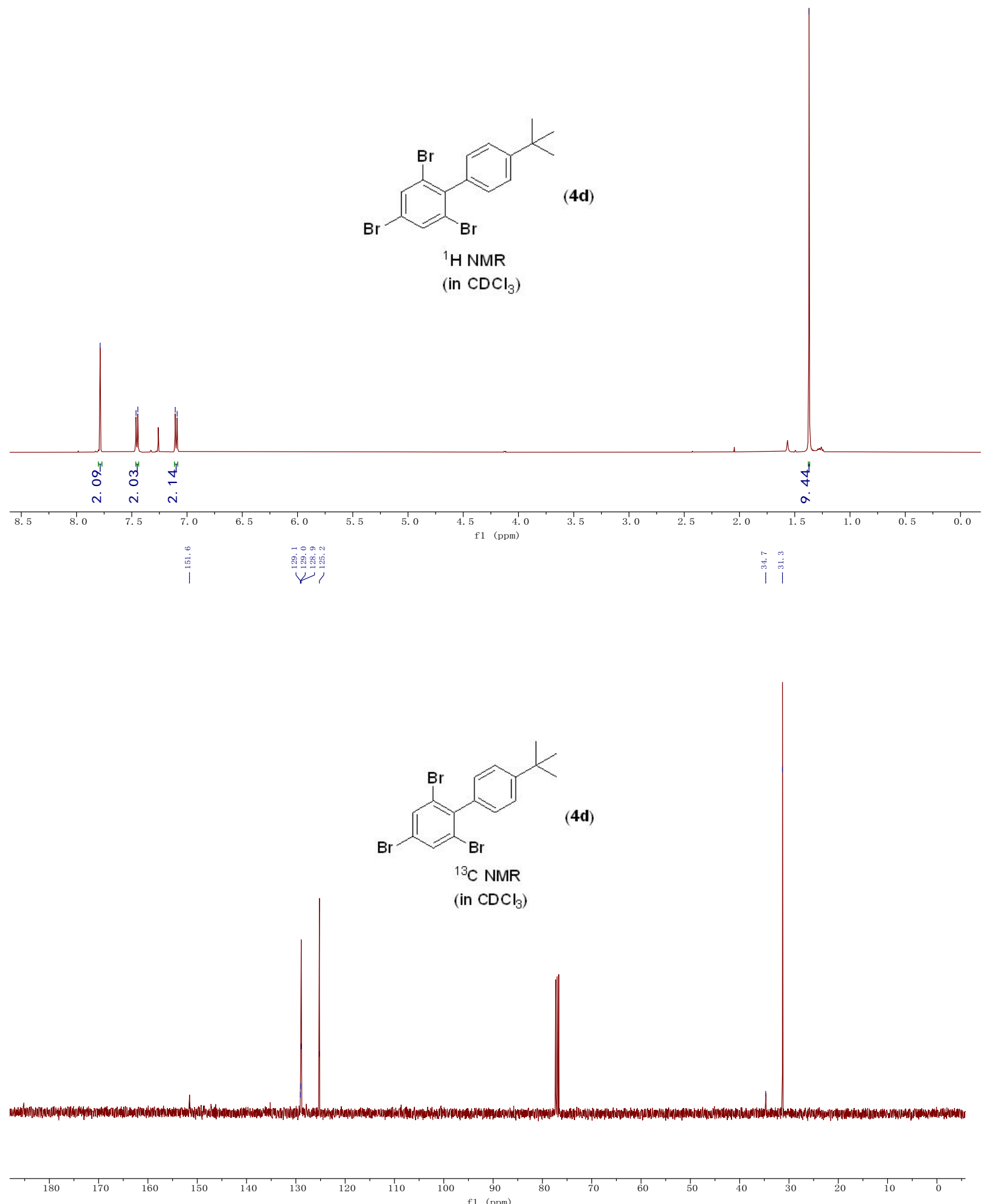


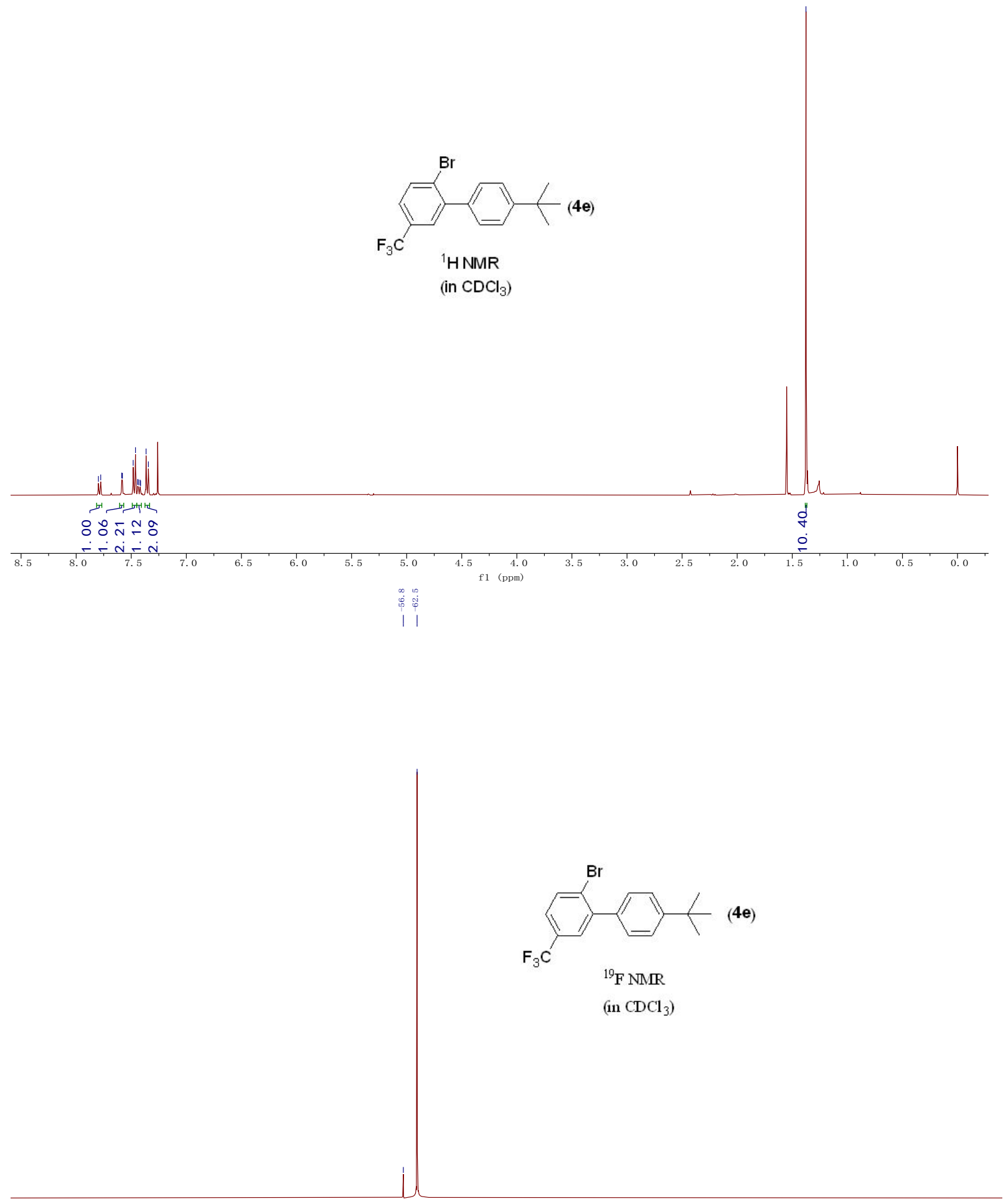



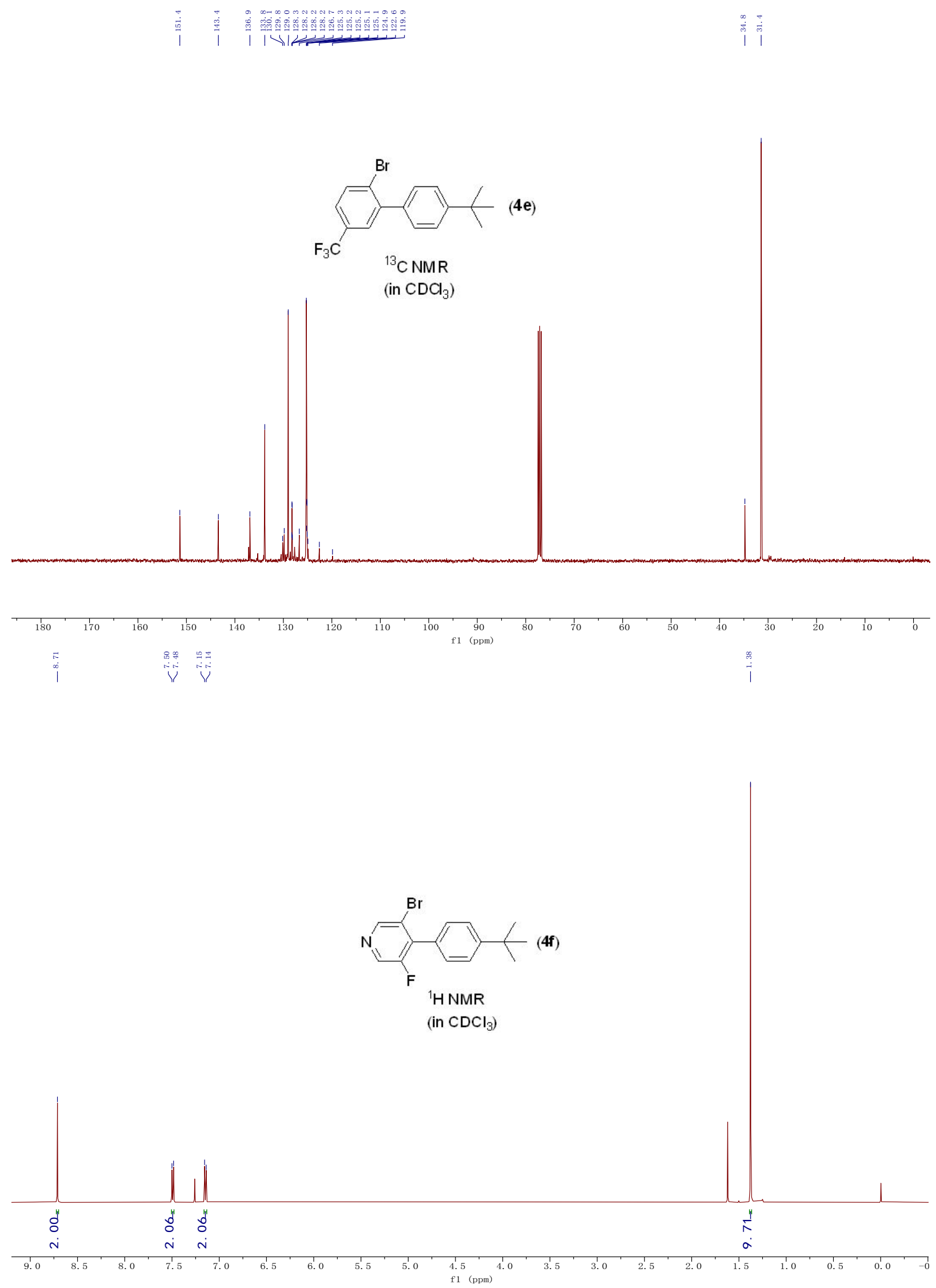

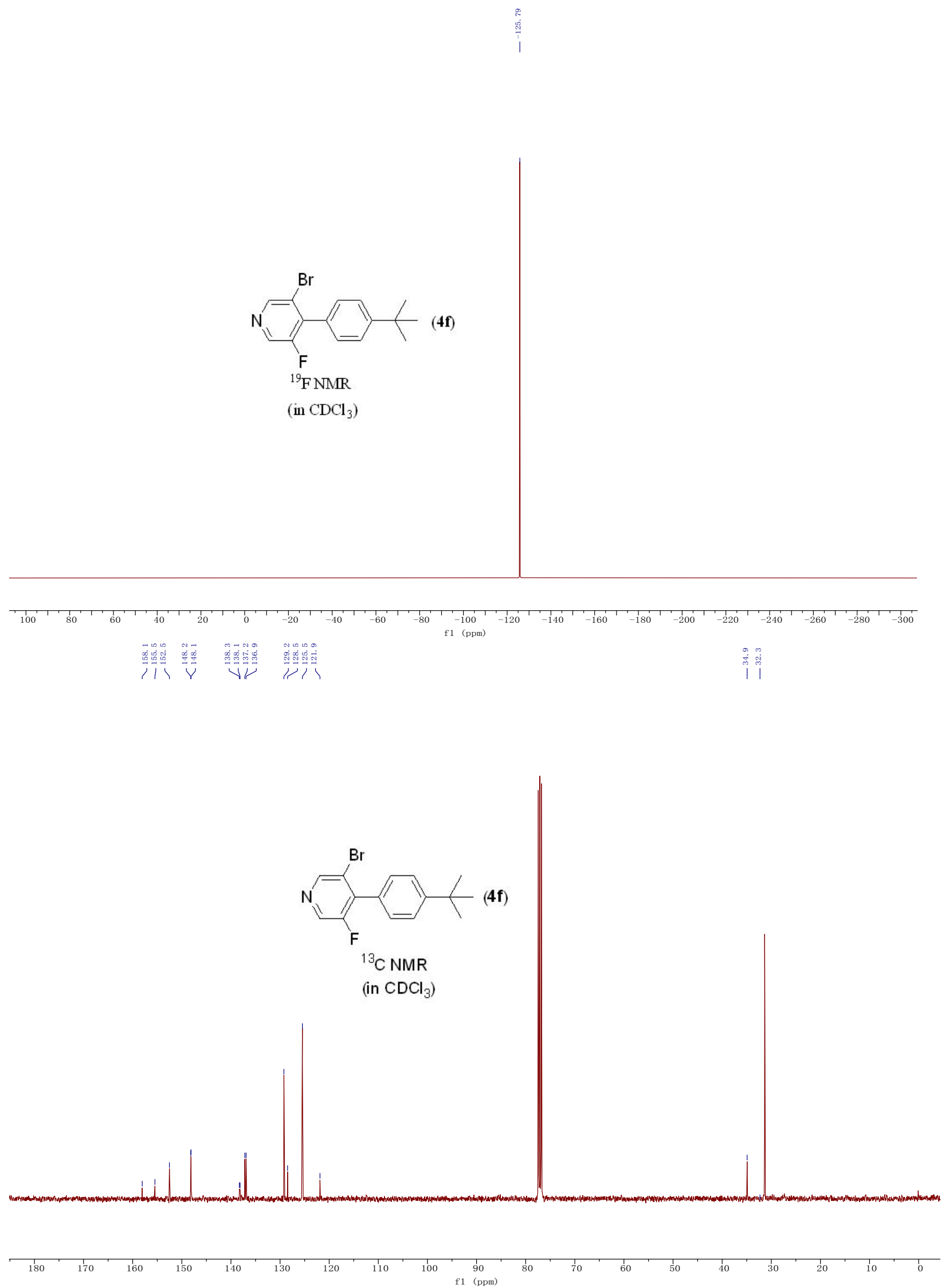


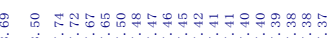

$1 \underbrace{1} \underbrace{\infty}$
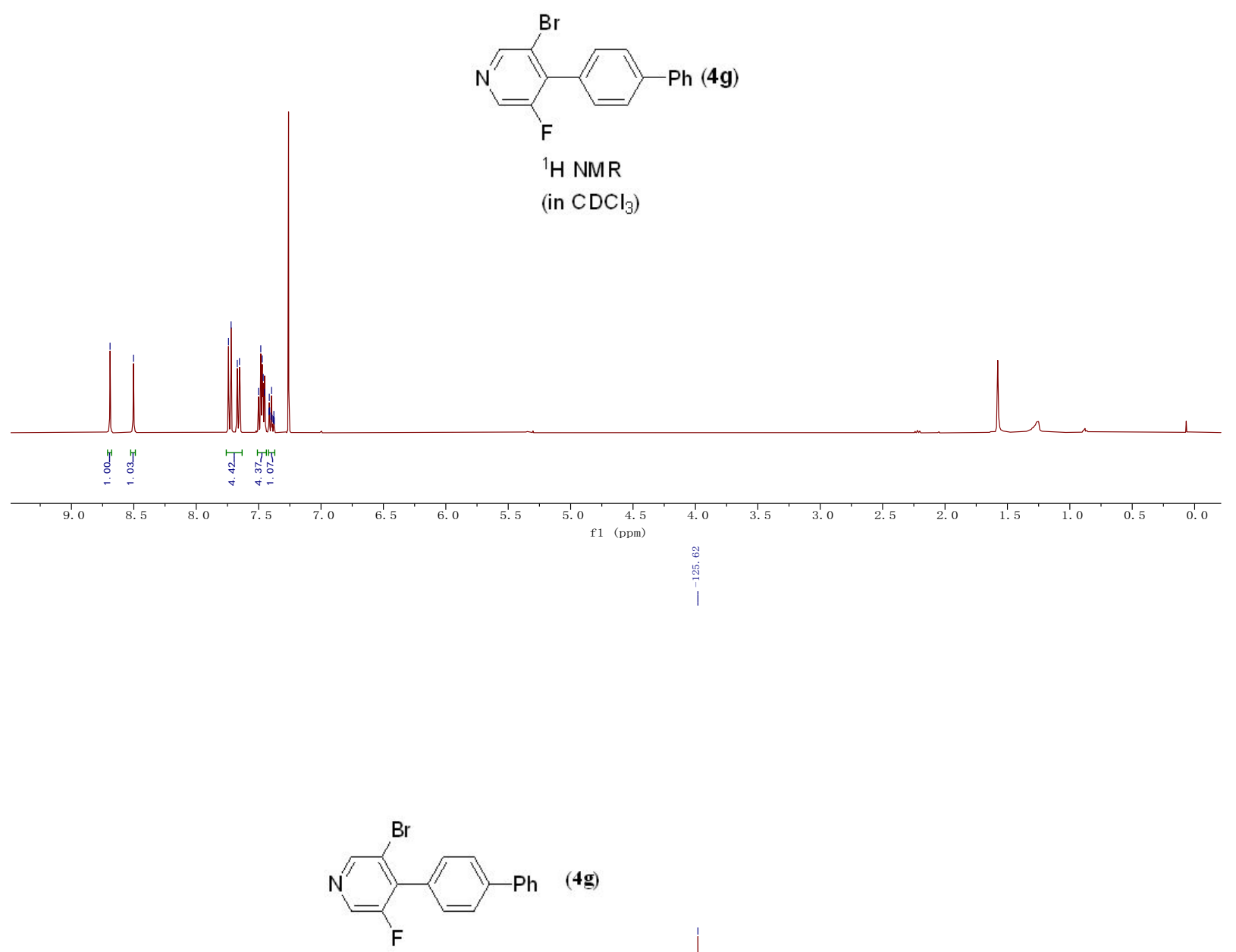

${ }^{19} \mathrm{~F} \mathrm{NMR}$

(in $\mathrm{CDCl}_{3}$ ) 

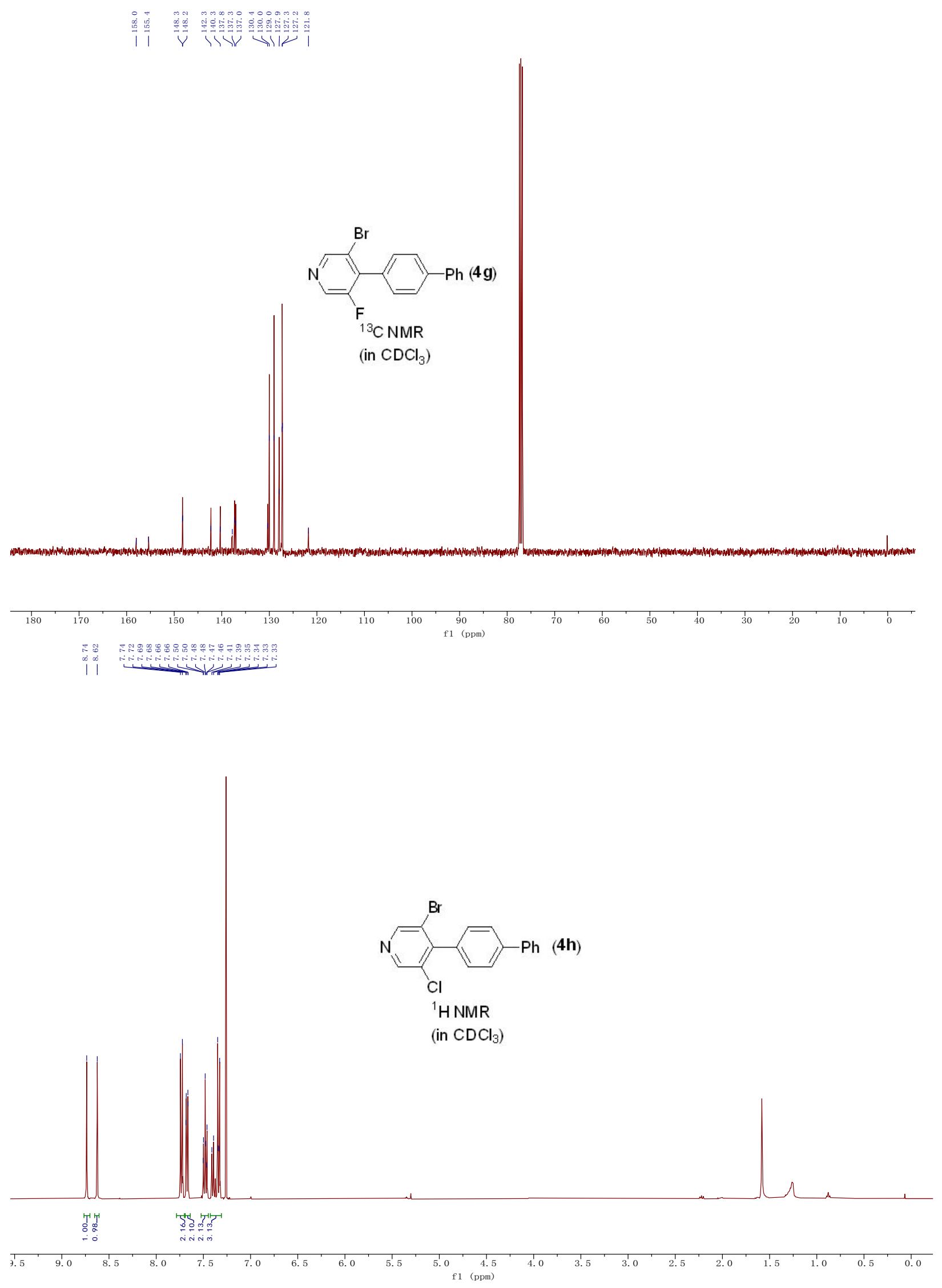


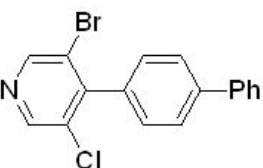

(4h)

${ }^{13} \mathrm{C}$ NMR

(in $\mathrm{CDCl}_{3}$ )
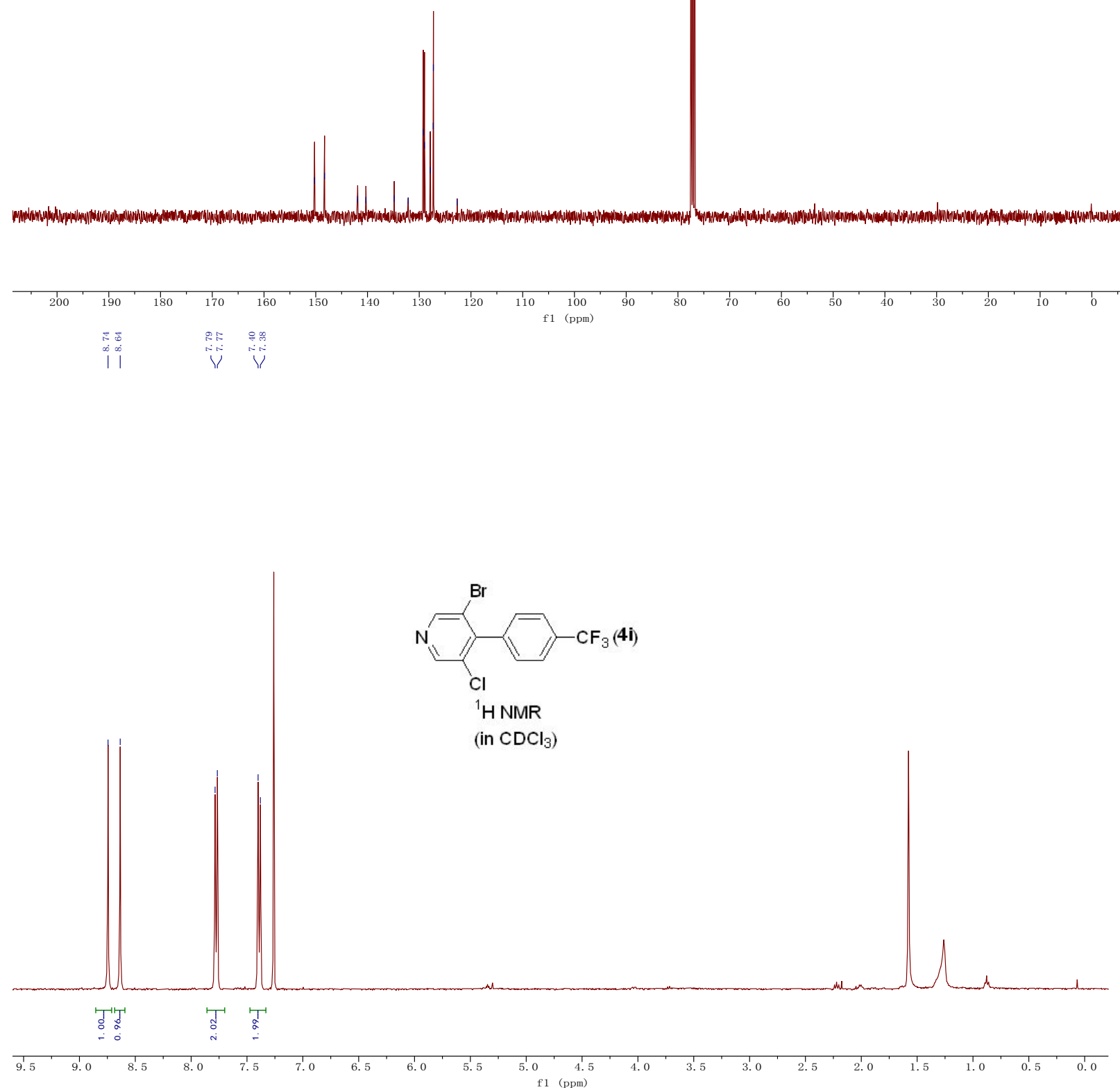

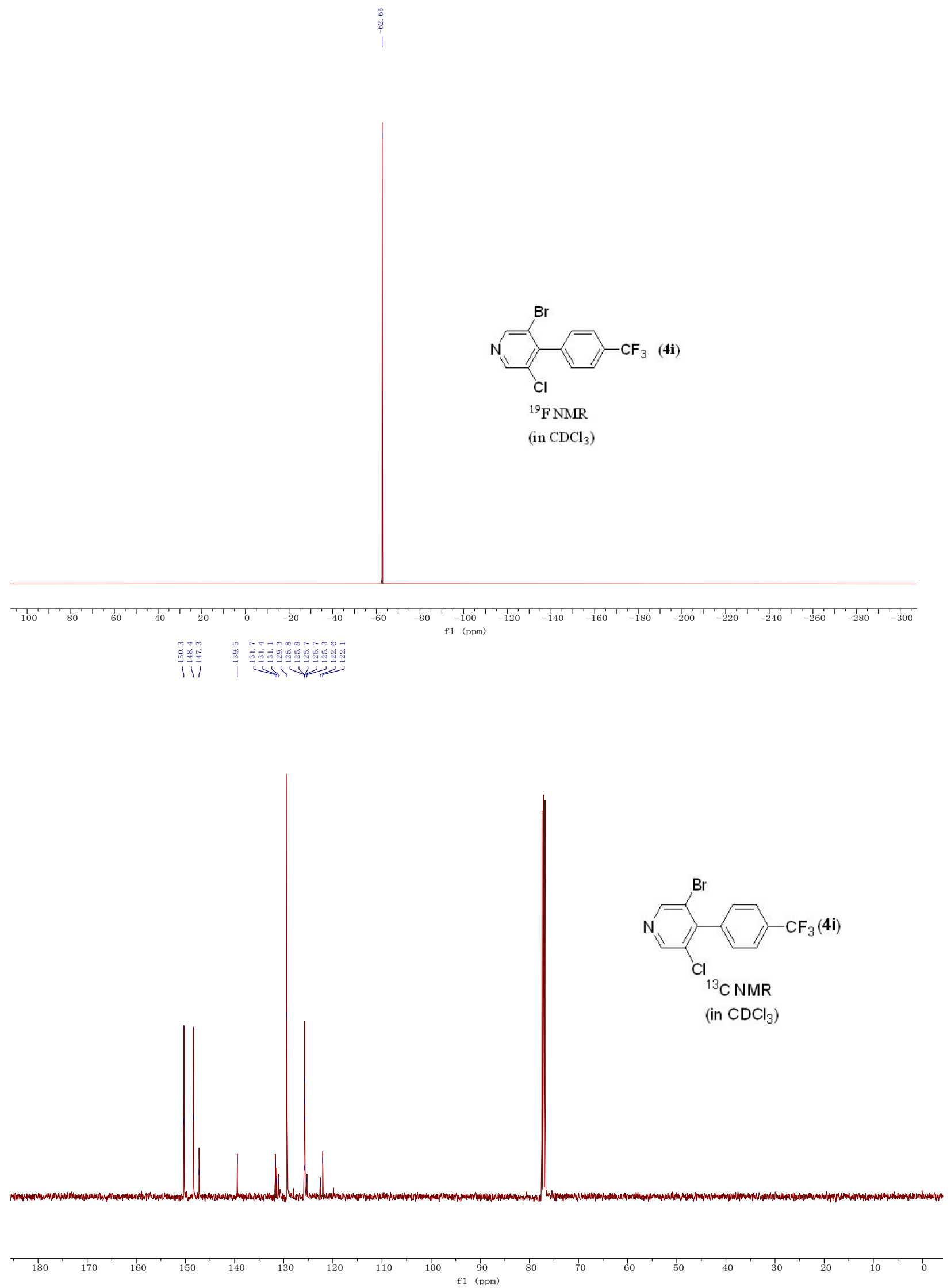

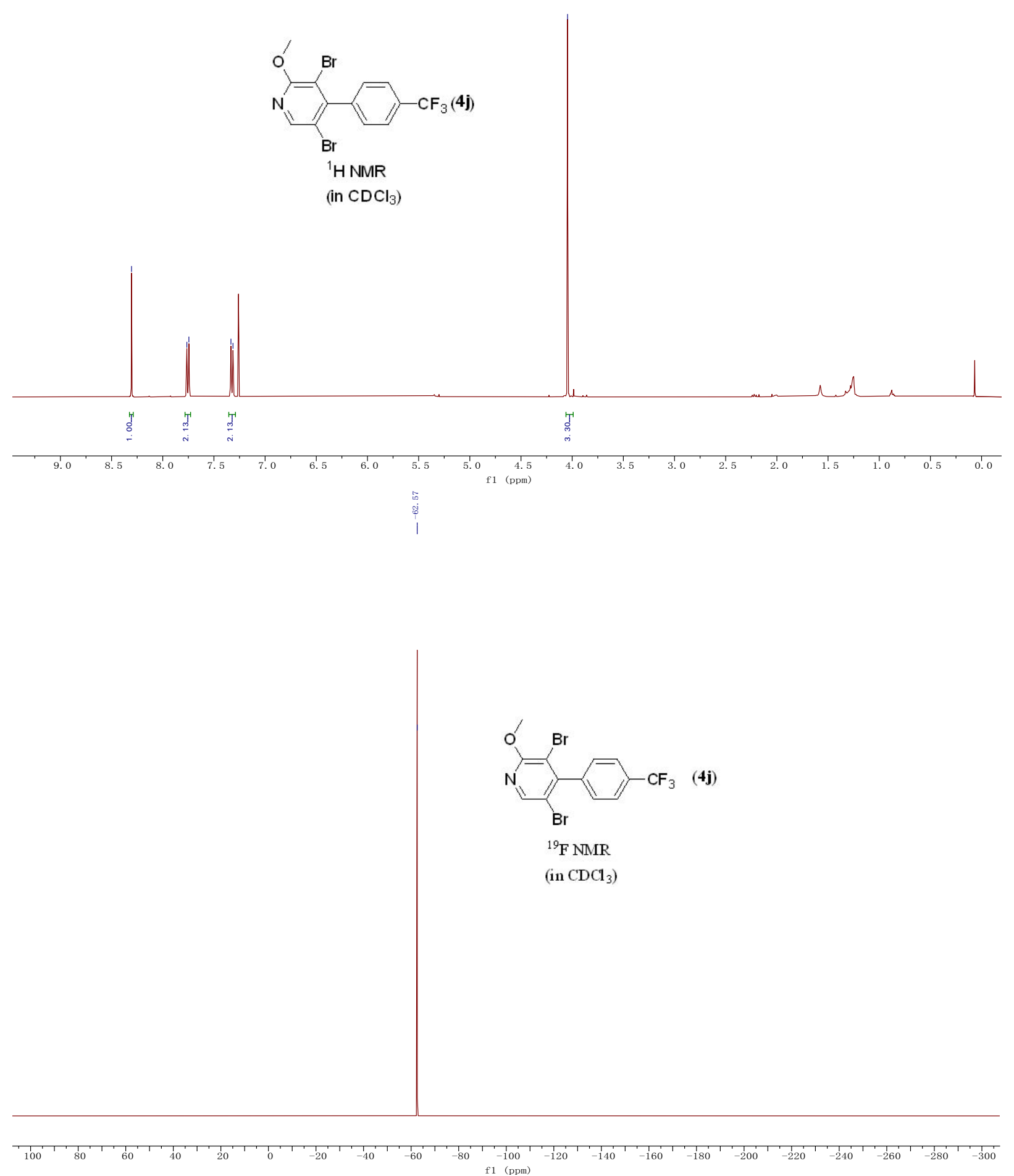

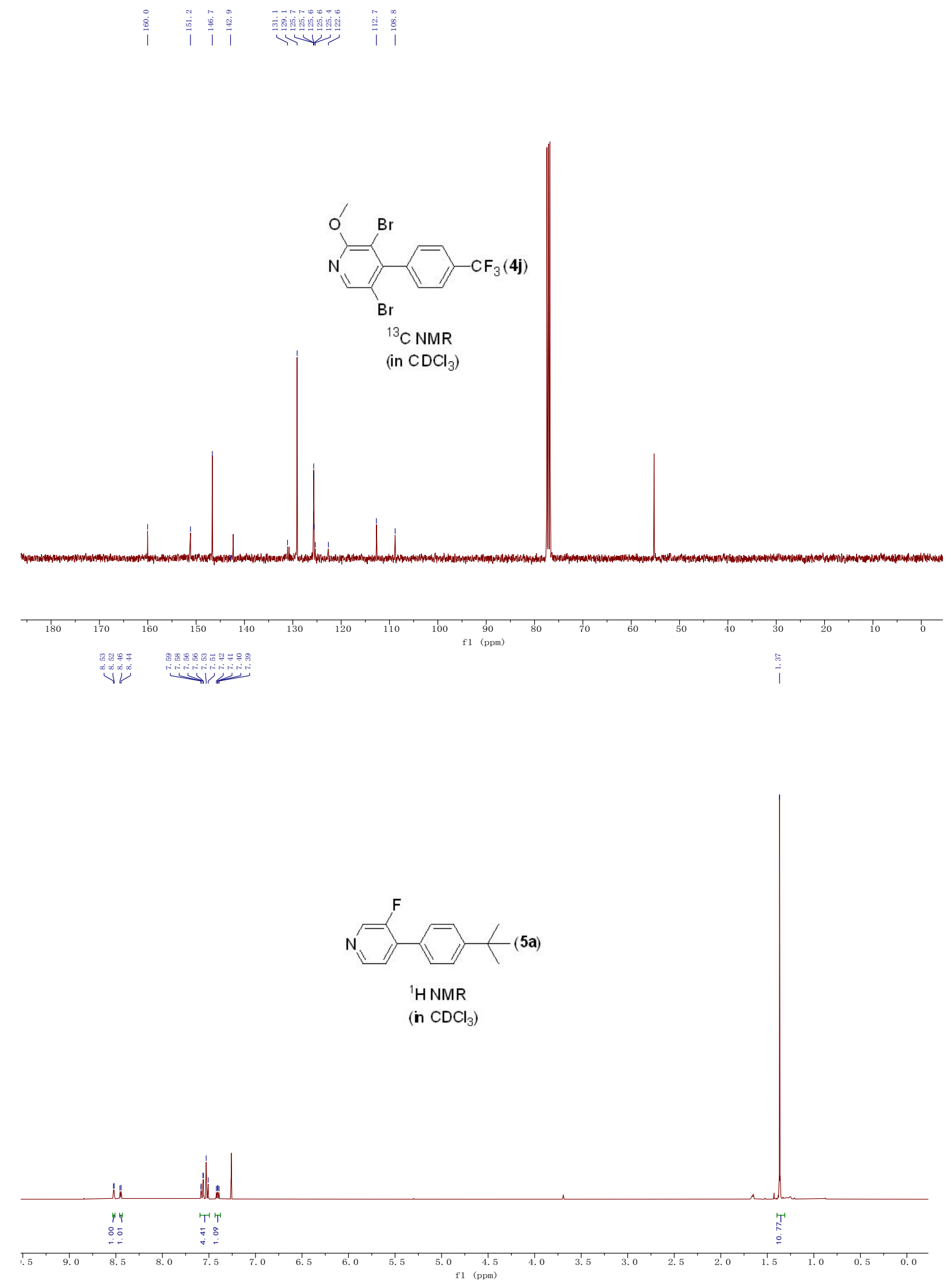


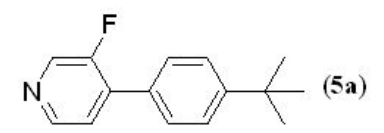

${ }^{19} \mathrm{~F} \mathrm{NMR}$

(in $\mathrm{CDCl}_{3}$ )
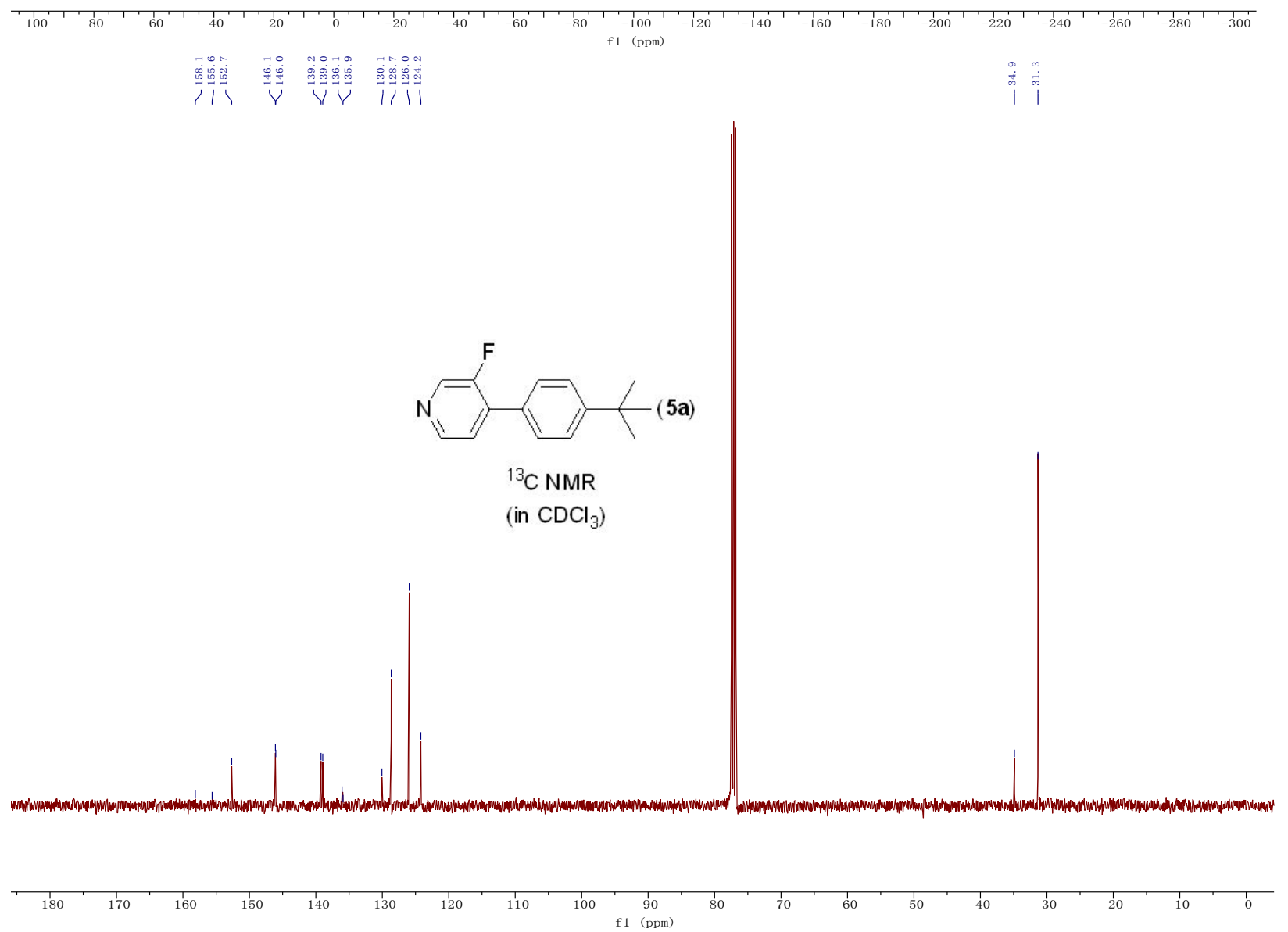

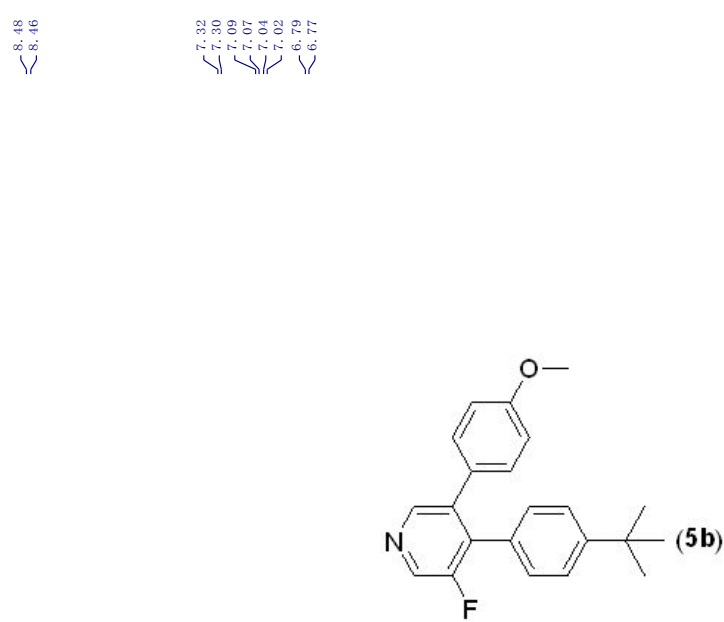

${ }^{1} \mathrm{H}$ NMR

(in $\mathrm{CDCl}_{3}$ )
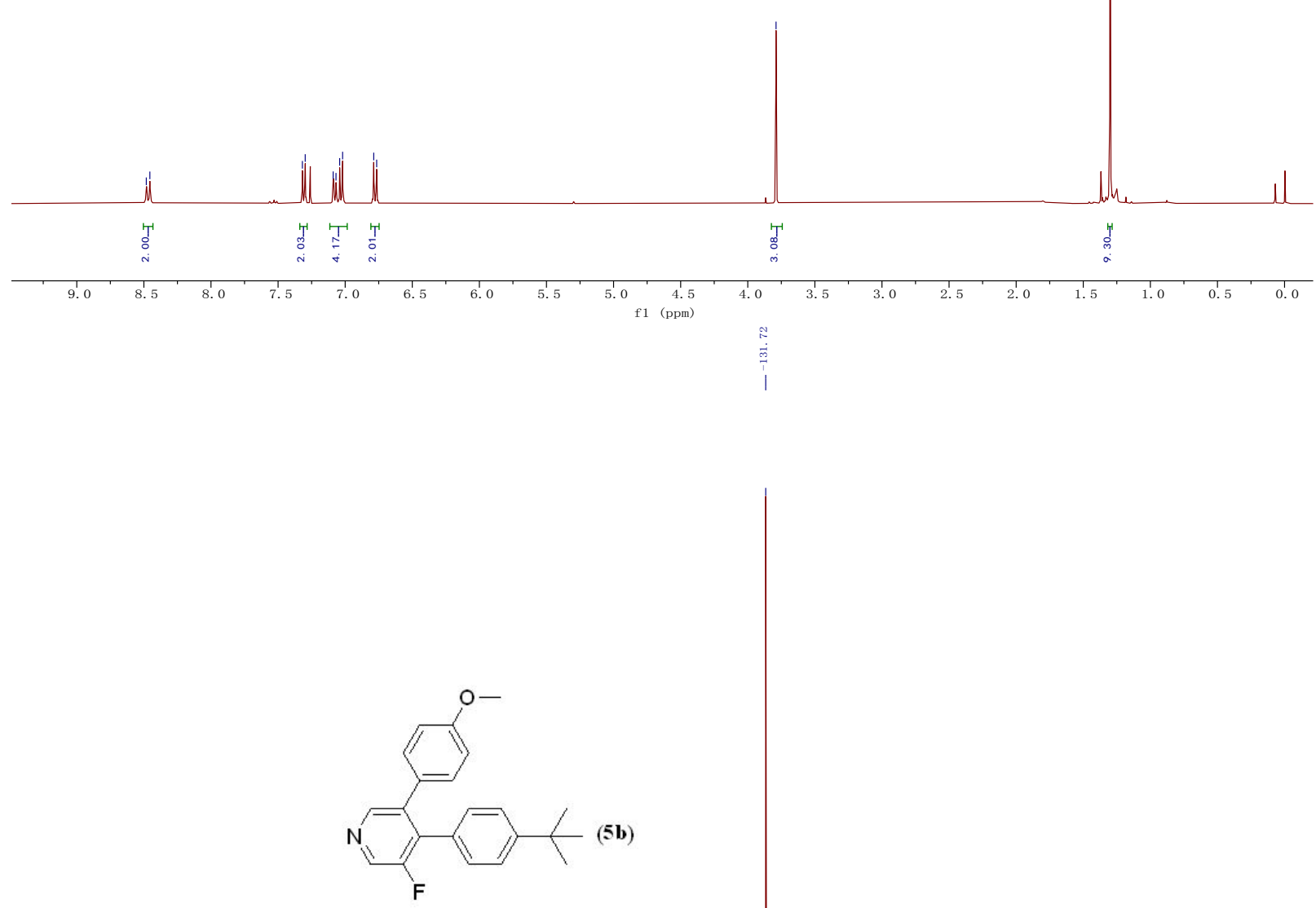

${ }^{19} \mathrm{~F} \mathrm{NMR}$

(in $\mathrm{CDCl}_{3}$ )

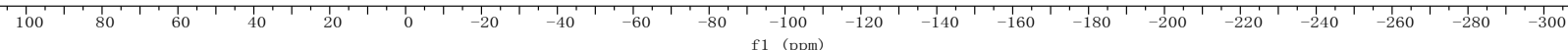



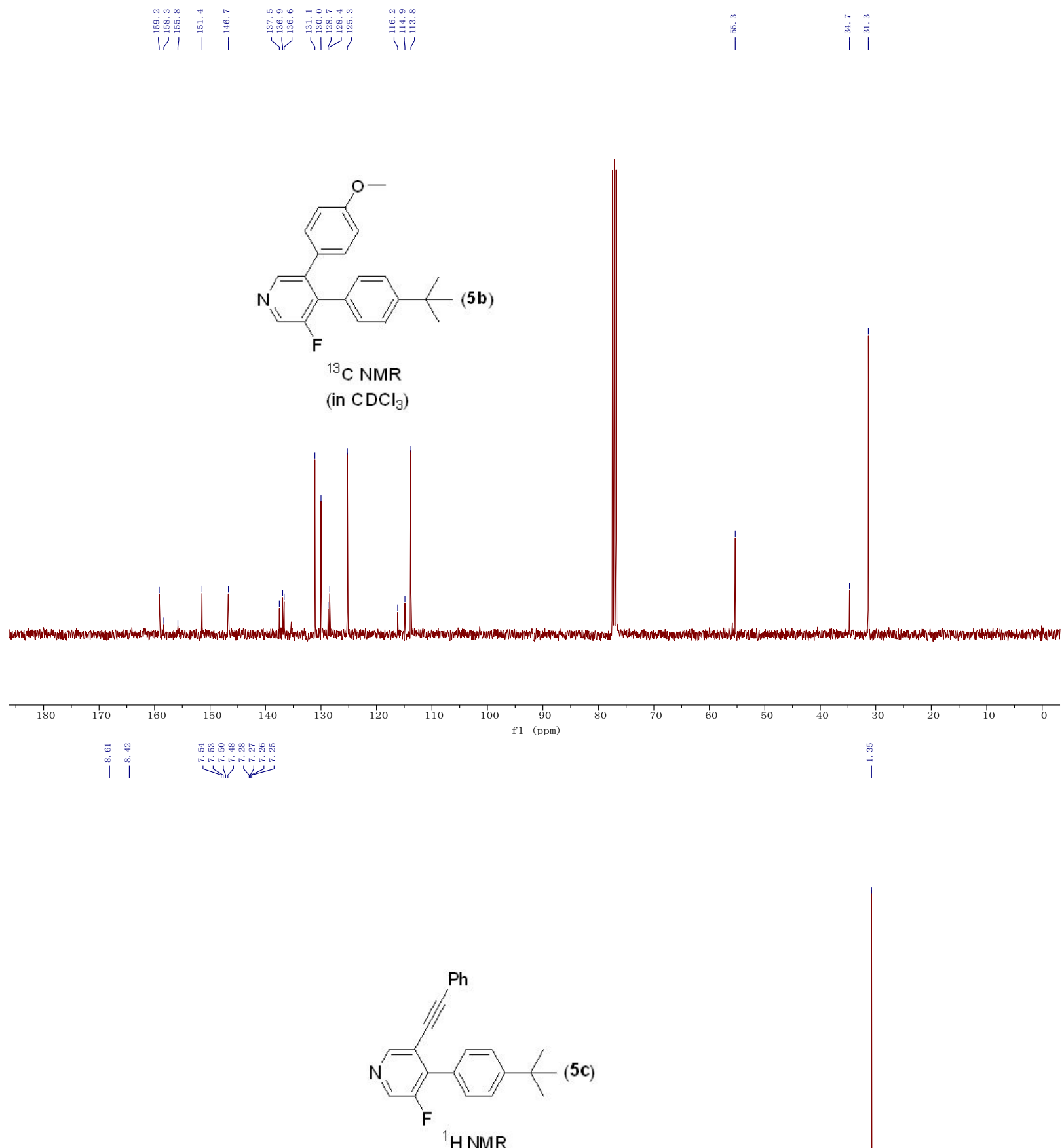

(in $\mathrm{CDCl}_{3}$ )

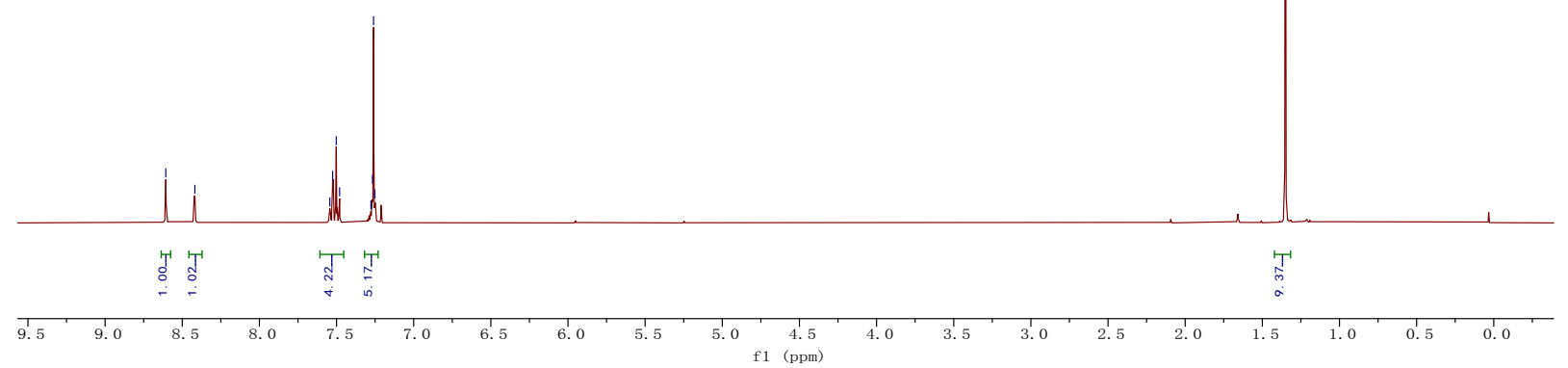



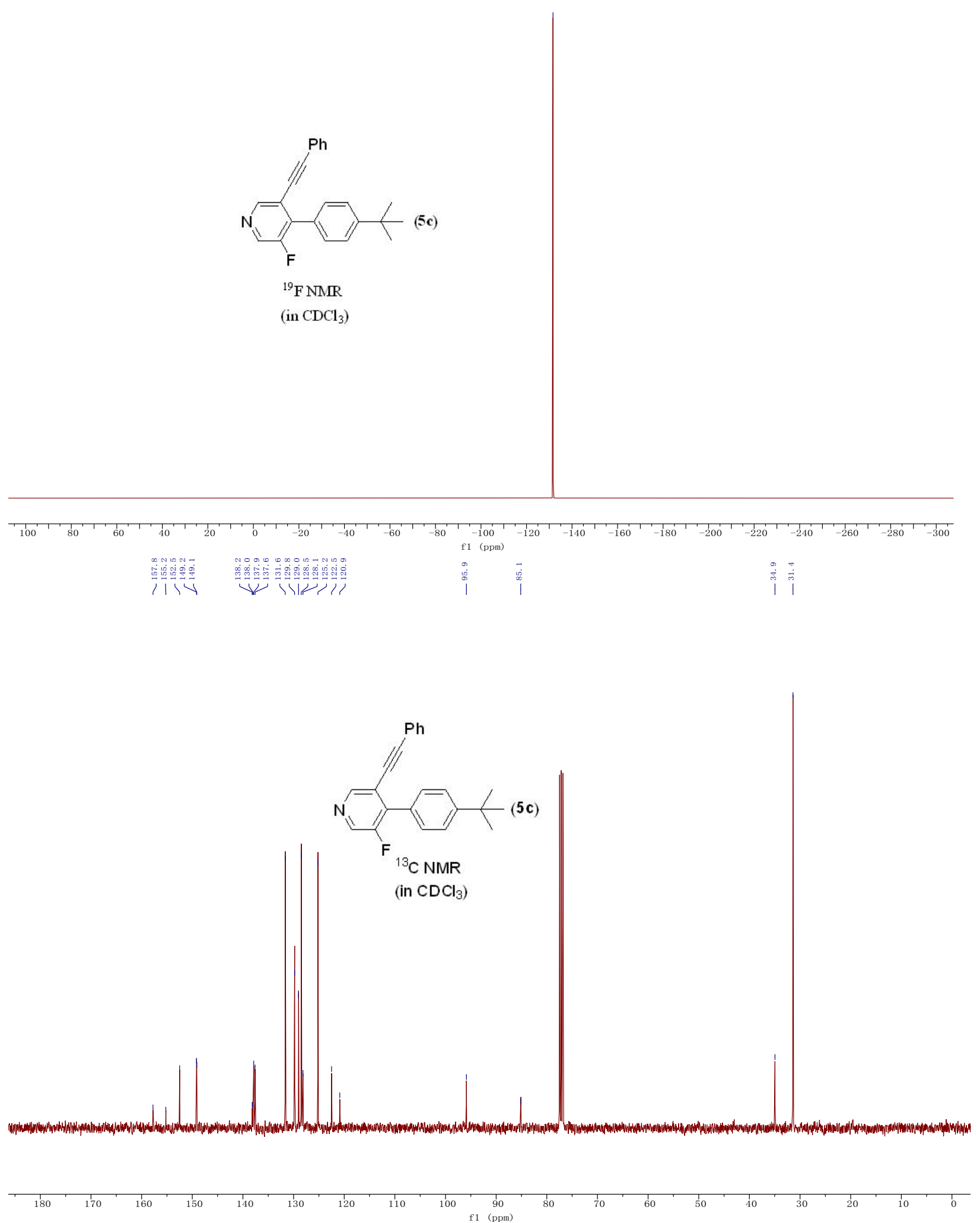


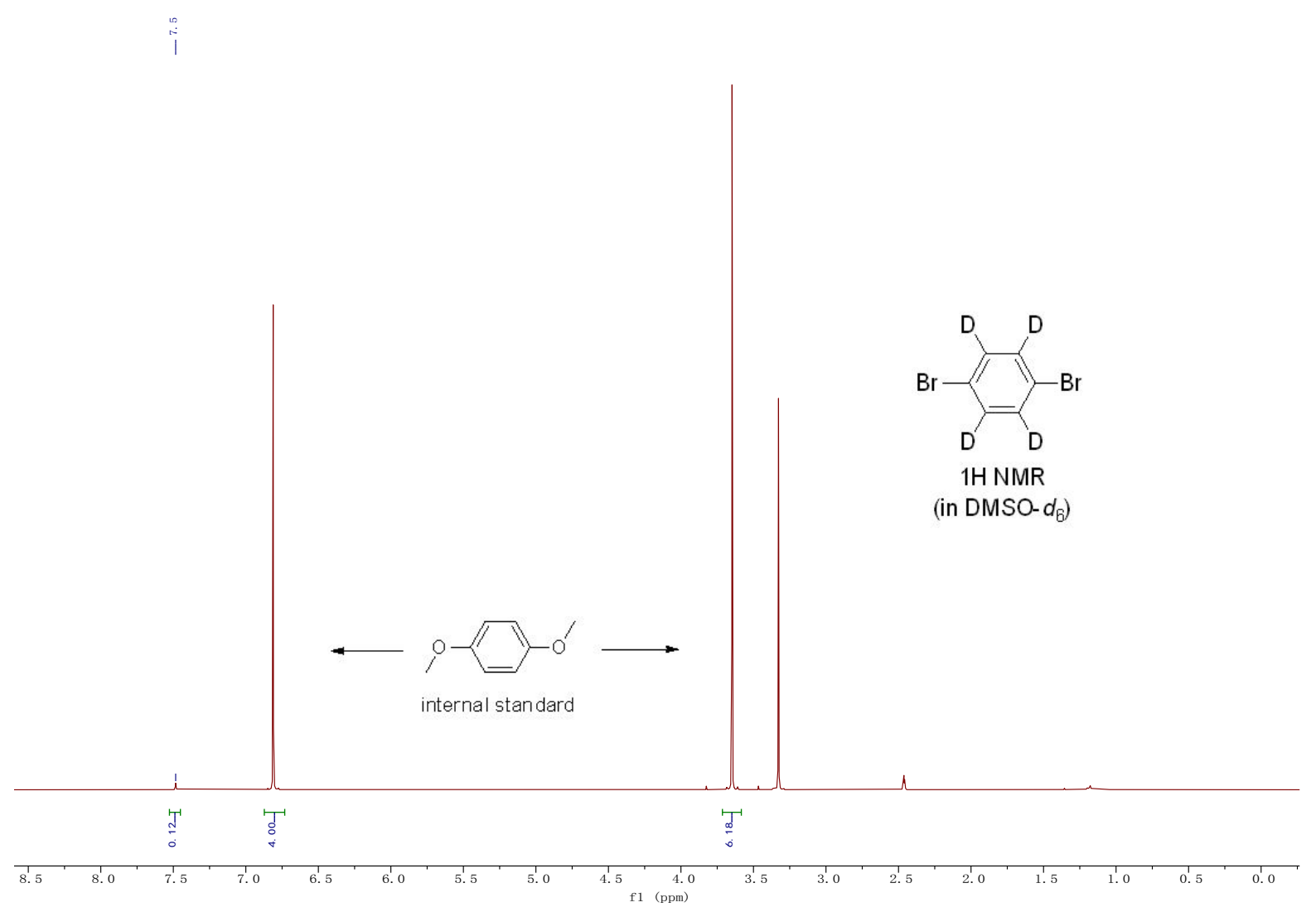

